\title{
Laser resurfacing in the treatment of potential malignant skin diseases. Just optical improvement?
}

Citation for published version (APA):

Ostertag, J. U. (2006). Laser resurfacing in the treatment of potential malignant skin diseases. Just optical improvement ? [Doctoral Thesis, Maastricht University]. Maastricht University. https://doi.org/10.26481/dis.20060615jo

Document status and date:

Published: 01/01/2006

DOI:

10.26481/dis.20060615jo

Document Version:

Publisher's PDF, also known as Version of record

\section{Please check the document version of this publication:}

- A submitted manuscript is the version of the article upon submission and before peer-review. There can be important differences between the submitted version and the official published version of record.

People interested in the research are advised to contact the author for the final version of the publication, or visit the DOI to the publisher's website.

- The final author version and the galley proof are versions of the publication after peer review.

- The final published version features the final layout of the paper including the volume, issue and page numbers.

Link to publication

\footnotetext{
General rights rights.

- You may freely distribute the URL identifying the publication in the public portal. please follow below link for the End User Agreement:

www.umlib.nl/taverne-license

Take down policy

If you believe that this document breaches copyright please contact us at:

repository@maastrichtuniversity.nl

providing details and we will investigate your claim.
}

Copyright and moral rights for the publications made accessible in the public portal are retained by the authors and/or other copyright owners and it is a condition of accessing publications that users recognise and abide by the legal requirements associated with these

- Users may download and print one copy of any publication from the public portal for the purpose of private study or research.

- You may not further distribute the material or use it for any profit-making activity or commercial gain

If the publication is distributed under the terms of Article $25 \mathrm{fa}$ of the Dutch Copyright Act, indicated by the "Taverne" license above, 
Laser resurfacing in the treatment of potential malignant skin diseases

Just optical improvement? 
ISBX-10: $90-52-8-534-1$

ISB $\div-13: 9-8-90-52-8-534-9$

(C) Copvright J.L. Ostertag. Maastricht. 2006

Layout \& Printing: Datawyse Maastricht

Financially support for this thesis was generously provided by LASERVISION INSTRUMENTS BV. 


\title{
Laser resurfacing in the treatment of potential malignant skin diseases Just optical improvement?
}

\author{
Proefschrift \\ ter verkrijging van de graad van doctor \\ aan de Universiteit Mastricht, \\ op gezag van de Rector Magnificus, \\ Prof.mr. G.P.M.F. Mols
}

volgens het besluit van het College van Decanen, in het openbaar te verdedigen op donderdag 15 juni 2006 om 16.00 uur

door

Judith Ulla Ostertag

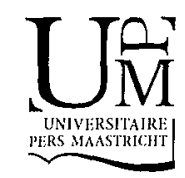




\section{Promotores}

Prot. dr. H.A.M. Neumann (Erasmus MC: Rotterdam)

Prof. dr. P.M. Steijlen

\section{Copromotor}

Dr. C.A.M. Krekels (Catharina ziekenhuis Eindhoven)

Beoordelingscomissie

Prof. dr. B. Kremer (voorzitter)

Prof. dr. W.D. Boeckx

Prof. dr. ir. M.J.C. van Gemert (Amsterdam Medisch Centrum)

Prof. dr. med. R. Kaufmann (J. W. Goethe Universität Frankfurt am Main) 
Für Mamma 


\section{Contents}

List of abbreviations 8

General introduction 9

Chapter 1 Ablative laser resurfacing 17

A new option for skin rejuvenation: $\mathrm{CO}_{2}$ laser resurfacing 19

Guidelines for ablative laser resurfacing $\quad 2.5$

Chapter 2 Laser resurfacing of actinic keratoses 37

Evidence based treatments of actinic keratoses 39

Recurrence rates and long-term follow-up after laser resurfacing as treatment for actinic keratoses

A comparison of topical 5 -fluorouracil versus laser resurfacing in the treatment of actinic keratoses

Chapter 3 Laser resurfacing of congenital melanocytic naevi 67

Giant congenital naevus: new treatment option with erbium:YAG laser 69

Congenital naevi treated with erbium:YAG laser resurfacing in neonates 73

Chapter 4 Complications of laser resurfacing 8.3

Hypertrophic scars after therapy with $\mathrm{CO}_{2}$ laser $\quad 8.5$

Delayed wound healing after treatment of actinic keratosis on the scalp 89

Chapter 5 General discussion and recommendations 95

$\begin{array}{lll}\text { Chapter } 6 & \text { Summary / Samenvatting } & 105\end{array}$

Dankwoord 111

Curriculum vitae $\quad 115$

$\begin{array}{ll}\text { List of publications } & 117\end{array}$ 


\section{List of abbreviations}

$\begin{array}{ll}\text { AK } & \text { actinic keratoses } \\ \text { CMN } & \text { congenital melanocytic nacvi } \\ \mathrm{CO}_{2} & \text { carbon dioxide } \\ \text { Er:YAG } & \text { erbium:yttrium-aluminium-garnet } \\ \text { 5-FU } & \text { 5-fluorouracil } \\ \text { GCMN } & \text { giant congenital melanocytic naevi } \\ \text { NMSC } & \text { non-melanoma skin cancer } \\ \text { PDT } & \text { photodynamic therapy } \\ \text { RCT } & \text { randomized controlled trial } \\ \text { SCC } & \text { squamous cell carcinoma } \\ \text { UV } & \text { ultraviolet }\end{array}$




\section{General introduction}

Controlled wounding to improve the appearance of the skin has been used since ancient times. Many treatment choices are currently available to rejuvenate the aging skin. Resurfacing involves mechanical, chemical or physical removal of the superficial layers of the (aged) skin.

The following wound healing response with re-epithelialization and collagen remodelling is accompanied by an improvement in the superficial dermal and epidermal architecture resulting in rejuvenation of the skin with clinical improvement of rhytides, dyschromia, and textural irregularities. Various techniques are available for resurfacing the skin which include chemical peels, dermabrasion and lasers. ${ }^{1-3}$

In 1983 Anderson and Parrish developed the theory of selective photothermolysis, which revolutionized the use of lasers in medicine. ${ }^{4}$ The word LASER is acronym for Light Amplification by Stimulated Emission of Radiation. Lasers react through chemical, thermal and photo acoustic reactions with one of the primary tissue chromophores: water, hemoglobin or melanin. The principle of laser treatment is that the chromophore absorbs coherent monochromatic light that is emitted by the laser, followed by physical-chemical reactions of the target, but not damaging the surrounding structures. Superficial removal of tissue with laser is possible if the emission spectrum of the laser is specifically directed at the most important component of the tissue. This component is water in the skin. Two laser systems are suitable for laser resurfacing of the skin. ${ }^{5}$

The $\mathrm{CO}_{2}$ (carbon dioxide) laser was first developed in 1964 to cut and vaporize tis- sue. The laser produces an electromagnetic energy with a wavclength of $10600 \mathrm{~nm}$. The water present in the tissue absorbs this specific wavelength and the following photothermal effect leads to direct tissue vaporization. In the late $1980 \mathrm{~s}^{\mathrm{CO}_{2}}$ laser skin resurfacing was first applied by a dermatologist. ${ }^{6}$ In the 1990 s, subsequent development of high energy, short-pulsed and scanned $\mathrm{CO}_{2}$ laser systems enabled a precise layer by layer ablation of the skin. Using an accurate setting, it became possible to remove superficial tissue in a reproducible manner without damaging the underlying structures, leading to precise and predictable results which opened the way to cosmetic purposes. ${ }^{7-16}$

The Er:YAG (Erbium:yttrium-alumimium-garnet) laser with a wavelength of $2940 \mathrm{~nm}$ was first introduced in 1987 for comeal surgery ${ }^{17}$ and in the late 1990 s for skin resurfacing. 18,19 Due to the high absorption coefficient of water, it is an highly effective tool for skin ablation with the ability to remove very narrow layers of tissue with minimal residual thermal damage. ${ }^{20-23}$

Today's Er:Yag devices offer great flexibility in performing skin ablation. They can produce pure ablation craters, rapid superficial laser abrasion of large surfaces, and if desirable, they can even add controlled coagulation. 24,25

In the same time it became obvious that other ablative treatments techniques (e.g. dermabrasia and chemical peels) were less precise, and therefore less predictable, than $\mathrm{CO}_{2}$ and Er:YAG laser ablation. Ablative laser resurfacing gradually replaced the 
other resurfacing techniques as the results where equal or even superior. ${ }^{26-32}$

Various noninvasive treatment modalities and topical applications have been used to treat the visible signs of photodamage and photoaging, which includes rhytids, teleangiectasias, lentigines, and dyspigmentation. ${ }^{33}$ Recently a variety of lasers and light sources have been studied as nonablative treatment for rejuvenation of the skin. It is based on the concept that various light devices, selectively cause thermal damage to the dermis, inducing collagen remodelling while sparring the epidermis. Various substances, such as water, haemoglobin, and melanin, can serve as targets. These targets can further dissipate the heat into the surrounding collagen, causing structural remodelling. There are two basic approaches to this nonablative photorejuvenation: the first is to target the hemoglobin and melanin in the dermis or dermalepidermal junction, the second is to use wavelengths to target the tissue water.

Topical preparations with retinol and retinoids are potential to improve the photodamaged skin. Tretinoin reduces the up-regulation of metalloproteinases, and protects against loss of procollagen, which results in increase of dermal collagen I formation. Vitamin $\mathrm{C}$, which plays a role in synthesis and maintenance of collagen, and acts as free radical scavenger in human tissue, has shown some effects of improvement on wrinkles, erythema and brown spots. Alpha-hydroxy acids and growth factors, such as TGF- $\beta$, may also stimulate repair mechanisms that result in improvements of skin texture, colour and wrinkling. However, these nonablative treatments do not produce the same degree of improvement as ablative resurfacing techniques. ${ }^{34-37}$

Laser resurfacing has been used primarily in the cosmetic treatment of the aging skin, rhytides and acne scars. However its appli- cation can be extended to any skin disorder in which superficial treatment would be successful. The technique is suitable for treating several benign and (pre)malignant skin diseases. ${ }^{24,38-40}$ Hereby the same principle is used of ablating the superficial skin layers, wherein the disorder is located. The newly formed, re-epitheliazed skin is supposed to show normal aspect or at least improving of the skin disorder, without scarring of the tissue. This principle showed to be especially effective in treatment of premalignant skin diseases. ${ }^{41,42}$ In dermatology there are numerous premalignant skin diseases, that are easy and practically treated by simple excision. There are however premalignant lesions that effect large parts of the skin such as widespread actinic keratoses and large congenital melanocytic nevi. In particular in these diseases, excision often would lead to unacceptable scar formation or is simply not applicable. In the past other less precise ablative treatments were used for treatment of these disorders: chemical peeling, dermabrasion and topical chemotherapy.

Actinic Keratosis (AK) was first identified as "keratoma senilis" by Freudenthal in $1926,{ }^{43}$ and later more fully described and renamed "actinic keratosis" by Pinkus in 1958. ${ }^{44}$ Actinic keratoses are very common skin lesions, affecting a great proportion of the elderly white population. These premalignant lesions usually are a consequence of long-term solar radiation, but may also be caused by UV light exposure from artificial sources or exposure to polycyclic aromatic hydrocarbons. ${ }^{4.5}$ Excessive UV exposure is known to overwhelm DNA repair mechanisms leading to induction of p53 mutations. Keratinocytes carrying p53 mutations acquire a growth advantage by virtue of their increased resistance to apoptosis. Thus, resistance to cell death is a key event in photocarcinogenesis and conversely, elimination of cells containing excessive UV-induced DNA damage is a $\mathrm{key}$ 
step in protecting against skin cancer development. Apoptosis-resistant keratinocytes undergo clonal expansion that eventually leads to formation of actinic keratoses and squamous cell carcinomas. ${ }^{46}$

Actinic keratoses are cutaneous neoplasms that occur on sun-exposed skin areas such as the face (especially the forehead), lower lip, bald scalp, neck, arms, and hands. They appear as rough, scaly papules and plaques that range from skin tone to reddish brown. They range in size from $1 \mathrm{~mm}$ to 2.5 $\mathrm{cm}$ or more in diameter. Persons with Fitzpatrick skin types I and II are more susceptible to developing actinic keratoses. 47 There is an increasing prevalence of actinic keratoses with increasing age. In the third decade of life the prevalence is less than $10 \%$. This rises more than $80 \%$ in fair complexioned persons at the ages of 60-69. Men are more affected than women. ${ }^{48} \mathrm{Sev}$ eral histologic variants, including pigmented, acantholytic, and hyperplastic types, have been described. The classic features show epidermal abnormal architecture, irregular acanthosis, atypical, pleomorphic kertinocytes, hyperkeratosis and parakeratosis, and dermal solar elastosis. ${ }^{49,50}$

Actinic keratoses are epithelial premalignant lesions, which are potent to progress to non-melanoma skin cancer (NMSC)..$^{51-55}$ The risk for developing NMSC inceases more than sixfold in patients with AK. ${ }^{56}$ In our opinion $\mathrm{AK}$ is to be considered as in-situ carcinoma of the skin, which may evolve in true invasive carcinoma and eventually even can metastasize and cause death. In several studies estimations are made about the risk of developing a squamous cell carcinoma (SCC) from an AK. Risks of 0.025-16\% are reported in literature. ${ }^{57}$ The risk is higher with increase of the number of AK lesions and with time. AK is nowadays increasingly recognized as SCC in situ, with proposal for new terminology such as "keratinocytic intraepidermal neoplasia" or "solar kerato- tic intracpidermal squamous cell carcinoma". 49,58,59

Since AK is the most important risk factor for SCC, AK should be treated to reduce their number and thereby the risk of developing a malignant lesion. There are many effective treatment modalities for AK: cryosurgery, curettage, electrosurgery, excision, topical 5-fluorouracil (5-FU), chemical peeling, dermabrasion, laser surgery, photodynamic therapy, systemic retinoids, topical tretinoin, intralesional interferon, diclofenac, and imiquimod. ${ }^{60-66}$ For decades 5-FU has been one of the standard treatments for AK. ${ }^{67}$ Overall the treatment choice is based on several factors, including location and number of lesions, growth and morphology, area of sun-damaged skin, age, lifestyle, and factors related to previous treatment or patient history. In paticnts with widespread $\mathrm{AK}$ with vague, ill defined borders in a setting of diffuse background photodamage, the ideal treatment would not only destroy clinically affected skin, but also remove the layer of photo-damaged skin in adjacent areas thereby acting as treatment and prophylaxis of $\mathrm{AK}$ and possibly of cutaneous malignancies. With this field-directed therapies longer remissions may be initiated. These ficld specific therapies can be divided into two categories: field destruction like laser resurfacing, dermabrasion and chemical peels and topical chemotherapy. ${ }^{68,69}$

Congenital melanocytic nevi (CMN) are often disfiguring and potentially malignant lesions that are present in $1 \%$ of all Caucasian newborns. ${ }^{70}$ They are, by definition present at birth. The prevalence is equal in males and females, and they have been described in all races.

They can be classified according to their largest diameter. Kopf proposed this oftenused subdivision: a small congenital melanocytic naevus is less than $1.5 \mathrm{~cm}$ at its greatest diameter, a medium-sized congeni- 
tal melanocytic nevus is between 1.5 and $19.9 \mathrm{~cm}$ at its greatest diameter, and a large or giant congenital melanocytic nevus is 20 $\mathrm{cm}$ or more at its greatest diameter, all irrespective of patient age or size. ${ }^{71}$ More recently, Bittencourt et al. offered this definition: a giant congenital melanocytic nevus is one expected to reach a size of at least 20 $\mathrm{cm}$ in adulthood. ${ }^{72}$ Giant congenital melanocytic nevi are much rarer than the smaller congenital melanocytic nevus, and affect approximately one in 20,000 newborns. (73). Another term for a giant congenital melanocytic nevus is "Tierfell nevus" or "bathing-trunk nevus."

The pathogenesis is not yet known, they are presumed to occur as the result of a developmental defect in neural-crestderived melanoblasts. Histologically CMN show nevomelanocytes in well ordered clusters in the epidermis and in sheets and nests in the dermis. However the naevus cells can extend deep into the dermis, adnexal structures, and underlying fat or even muscles. 74,75

Malignant transformation in patients with giant CMN can result in cutaneous or noncutaneous melanoma. One must be aware that malignant transformation can also occur in extra cutaneous melanocyte deposits. The latter areas include mucosal involvement in the gastrointestinal tract, retroperitoneal involvement, and in neurocutaneous melanosis with leptomeningeal involvement. Historically, the risk of melanoma quoted in the literature in patients with giant $\mathrm{CMN}$ has ranged from $1.8 \%$ to $45 \% .(76)$ The latest published results from large prospective and retrospective studies report estimated risks of malignant transformation of 0.05 to $2.8 \%$. Risk factors for the development of melanoma in a congenital melanocytic naevus include multiple lesions, size, and younger age. Although there is a lifetime risk for malignant transformation, the risk is greatest in early childhood. ${ }^{72,77-79}$ A recently per- formed retrospective study performed in the Netherlands showed that congenital melanocytic nevi, and especially the giant congenital melanocytic nevi, have a significantly higher risk of devcloping a malignant melanoma compared with the age-, sex-, calendar-period-specific reference data from the Netherlands Cancer Registry. ${ }^{80}$

Smaller lesions may be excised and closed primarily. However lesions that involve substantial surface arca or regions of aesthetic importance may require other treatment options. The treatment of these large or giant CMN lesions is based on two principles: limiting the risk of malignant change and obtaining an acceptable cosmetic results without scarring or recurrence. The most curative method is (staged) excision. However, even after complete excision, the malignancy risk is not completely eradicated as naevus cells can extend deep into the subcutaneous fat, fascia and underlying tissue and malignant melanoma can still occur at extracutancous sites. 81,82 Especially in the GCMN (Giant congenital melanocytic nevi) the cosmetic result is of importance to decrease the psychosocial inconvenience to the patient. Complete removal of CMN and especially GCMN by surgical excision is usually difficult and often impossible without functional or cosmetic mutilation. Various other therapeutic approaches such as tangential excision ${ }^{83}$, dermabrasion ${ }^{84-86}$, curettage ${ }^{87-91}$, chemical peeling ${ }^{92}$ and $\mathrm{CO}_{2}$-laser dermabrasion ${ }^{93-95}$ have been used in the past in treating $C M N$.

Laser resurfacing is a excellent refined method of ablating the skin performing precise resurfacing of the skin. In this thesis this treatment modality is evaluated for premalignant skin diseases and compared to already existing therapies. 


\section{Aims of this thesis}

What is the evidence of therapy results in the treatment of actinic keratosis in the literature?

Is laser resurfacing an effective treatment for actinic keratosis?

Is laser resurfacing comparable to standard treatment modality like 5 -fluorouracil regarding efficacy and adverse effects in the treatment of actinic keratosis?

Is there difference in efficacy between $\mathrm{CO}_{2}$ and Er:YAG laser in the treatment of actinic keratosis?

What are the complications in the treatment of actinic keratosis with laser resurfacing?

Is laser resurfacing a possible effective therapy for congenital melanocytic nevi?

\section{References}

1. Coleman WP, Lawrence N. Skin Resurfacing. 1998 Williams \& Wilkins.

2. Facial Rejuvenation. Lowe NJ. 2002 Martin Dunitz Ltd, member of the Taylor \& Francis group.

3. Roy D. Ablative facial resurfacing. Dermatol Clin. 2005 Jul;23(3):549-59.

4. Anderson R, Parrish J. Selective photothermolysis: precise microsurgery by selective absorbtion of pulsed radiation. Science 1983;220:524-7.

5. Golman MP, Fitzpatrick RE. Cutaneous Laser Surgery. 1999 Mosby Inc.

6. David LM, Lask GP, Glassberg E, et al. $\mathrm{CO}_{2}$ laser ablation for cosmetic and therapeutic treatment of facial actinic damage. Cutis 1989;43:583-7.

7. Fitzpatrick RE, Ruiz-Esparza J, Goldman MP. The depth of thermal necosis using the $\mathrm{CO} 2$ laser: a comparison of the superpulsed mode and the conventional mode. J Dermatol Surg Oncol 1991:17:340-4.

8. David LM, Sarne AJ, Unger WP. Rapid laser scanning for fascial resurfacing. Dermatol Surg 1995;21:1031-33.

9. Fitzpatrick RE, Tope WD, Goldman MP, et al. Pulsed carbon dioxide laser, trichloroacetic acid, Baker Gordon phenol, and dermabrasion: a comparative clinical and histologic study of cutaneous resurfacing in a porcine model. Arch Dermatol 1996;132:469-471.
10. Fitzpatrick RE, Goldman MP, Satur NM, et al. Pulsed carbon dioxide laser resurfacing of photoaged facial skin. Arch Dermatol 1996;132:395-402.

11. Waldorf HA, Kauvar A, Geronemus A. Skin resurfacing of fine to deep rhytides using a charfree carbon dioxide laser in 47 patients. Dermatol Surg 1995;21:940-946.

12. Lowe NJ, Lask GP, Griffin Me, et al. Skin resurfacing with the Ultra Pulse carbon dioxide laser: obsevations on 100 patients. Dermatol Surg 1995;21:1025-9.

13. Kauvar AN, Waldorf $H$, Geronemus RG. A histopathological comparison of char free carbon dioxide lasers. Dermatol Surg 1996;22:343-8.

14. Cotton J, Hood A, Gonin R, Beesom W, Hanke $W$. Histologic evaluation of preauricular and postauricular human skin after high-energy short-pulse carbon dioxide laser. Arch Dermatol 1996; 132:425-48.

15. Bernstein L, Kauvar A, Grossman $M$, Geronemus R. The short- and long-term side effects of carbon dioxide laser resurfacing. Dermatol Surg 1997;23:519-25.

16. Ross V, Grossman M, Duke D, Grevelink JM. Long term results after laser skin resurfacing: a comparison of scanned and pulsed systems. J Am Acad Dermatol 1997;37:709-18.

17. Peyman GA, Katoh N. Effects of an erbium:YAG laser on ocular structures. Int J Opthalmol 1987;10:245-53. 
18. Kaufmann $\mathrm{R} \&$ Hibst R. Pulsed $2.94 \mu \mathrm{m}$ Erbium-YAG laser skin ablation: experimental results and first clinical application. Clin Exp Dermatol 1990; 15:389-93

19. Kaufmann R, Hartmann A, Hibst R. Cutting and skin-ablative properties of pulsed midinfrared laser surgery. J Dermatol Surg Oncol 1994; 20: 112-8.

20. Kaufmann R \& Hibst R. Clinical evaluation of Er:YAG lasers in cutaneous surgery. Las Surg Med 1996; 19: 324-30.

21. Hohenleutner U, Hohenleutner S, Baumler W, landthaler $M$. Fast and effective skin ablation with Er:YAG laser: determination of ablation rates and thermal damage zones. Lasers Surg Med 1997; 20: 242-7.

22. Weinstein C. Computerised scanning with erbium:YAG laser for skin resurfacing. Dermatol Surg 1998; 24: 83-9.

23. Flemming $D$. Contoversies in skin resurfacing: the role of erbium. I Cutan Laser Ther 1999;1:15-21

24. Kaufman R. Role of erbium:YAG laser in the treatment of aged skin. Clinical and Experimental Dermatology 2001;26:631-636.

25. Kathri K, Ross V, Grevelink J, Magro C, Anderson R. Comparison of erbium:YAG and carbon dioxide lasers in resurfacing of facial rhytides. Arch Dermatol 1999; 135: 392-7.

26. Ross EV, Naseef GS, Mc Kinley JR, et al. Comparison of carbon dioxide laser, dermabrasion, and dermatome: a study of thermal damage, wound contraction, and wound healing in a live pig model: implications for skin resurfacing. J Am Acad Dermatol 2000;42:92-105.

27. Chew J, Gin I, Rau KA, Amos DB, Bridenstine JB. Treatment of upper lip wrinkles: a comparison of 950 pusec dwell time carbon dioxide laser with unoccluded baker's phenol chemical peel. Dermatologic Surgery 1999;25:262-6.

28. Gin I, Chew J, Rau KA, Amos DB, Bridenstine JB. Treatment of upper lip wrinkles: A comparison of the $950 \mu s e c$ dwell time carbon dioxide laser to manual tumescent dermabrasion. Dermatologic Surgery 1999;25:468-74.

29. Holmkvist KA, Rogers GS. Treatment of perioral rhytides: a comparison of dermabrasion and superpulsed carbon dioxide laser. Archives of Dermatology 2000;136:725-31.
30. Kitzmiller WJ, Visscher M, lage 1) A, Wicket RR, Kitzmiller $\mathrm{KW}$, Singer L,J. A controlled evaluation of demabrasion versus $(C)$ laser resurfacing for the treatment of perioral wrinkles. Plast Reconstr Surg. 2000 Nov: 106(6):1366-72; discussion 1373-4.

31. Reed JT, Joseph AK, Bridenstine JB. Treatment of periorbital wrinkles. A comparison of the SilkTouch carbon dioxide laser with a mediumdepth chemical peel. Dermatol Surg. 1997 Aug;23(8):643-8.

32. Kauvar AN, Dover JS. Facial skin rejuvenation: laser resurfacing or chemical peel: choose your weapon. Dermatol Surg. 2001 I cb;27(2):20912.

33. M Samuel, RCC Brooke, S Hollis, CEM Griffiths. Interventions for photodamaged skin. Cochrane Database Syst Rev. 2005 Jan 25;(1):CDO01782.

34. Orringer, J. Voorhees, T. Hamilton, C. Hammerberg, S. Kang, T. Johnson, D. Karimipour, G. Fisher. Dermal matrix remodeling after nonablative laser therapy. J Am Acad Dermatol. 2005 Nov;53(5):775-82.

35. Shah GM, Kilmer SL. Combined nonablative rejuvenation techniques. Dermatol Surg. 2005 Sep;31:1206-10.

36. Rokhsar CK, Lee S, Fitzpatrick RE. Review of photorejuvenation: devices, cosmeceuticals, of both? Dermatol Surg. 2005 Sep;31:1 166-78;

37. Kim KH, Geronemus RG. Nonablative laser and light therapies for skin rejuvenation.

Arch Facial Plast Surg. 2004 Nov-Dec;6(6):398409.

38. Dmovsek-Olup B, Vedlin B. Use of Er:YAG laser for benign skin disorders. Lasers Surg Med 1997; 21:13-9.

39. Greve B, Raulin C. Medical dermatologic laser therapy. A review Hautarzt. 2003 Jul;54(7):594-602.

40. Hruza GJ. Laser treatment of epidermal and dermal lesions. Dermatol Clin. 2002 Jan;20(1):147-64.

41. Laws RA, Wilde JL, Grabski WJ. Comparison of electrodessication with $\mathrm{CO}_{2}$ laser for the treatment of actinic cheilitis. Dermatol Surg. $2000 \mathrm{Apr} ; 26(4): 349-53$.

42. Trimas SJ, Ellis DA, Metz RD. The carbon dioxide laser. An alternative for the treatment of actinically damaged skin. Dermatol Surg 1997; 23: 885-9. 
43. Freudenthal W. Verruca senilis und keratoma senile. Arch Dermatol Syphilol (Berlin) 1926 : 158:539-44.

44. Pinkus H. Keratosis Senilis: a hiologic concept of its pathogenesis and diagnosis based on the study of normal epidermis and 1730 seborrheic and senile keratoses. Am J Clin Pathol 1958;29:193-2078.

45. FU W, Cockerell CJ. The Actinic (Solar) Keratosis. A 21-st Century Perspective. Arch Dermatol. 2003;139:66-70.

46. Melnikova VO, Ananthaswamy HN. Mutat Res 2005 Apr 1;571(1-2):91-106. Cellular and molecular events leading to the development of skin cancer.

47. Moy R.L. Clinical presentation of actinic keratoses and squamous cell carcinoma. J Am Acad Dermatol, 2000;42:s8-10.

48. Salasche S.J. Epidemiology of actinic keratoses and squamous cell carcinoma. J Am Acad Dermatol, 2000;42:s4-7.

49. Cockerell CJ. Histopathology of incipient intraepidermal squamuos cell carcinoma (actinic keratosis). J Am Acad 2000;42:s11-7

50. Cockerell C.J. Pathology and pathobiology of the actinic (solar) keratosis. Br J Dermatology, 2003;149(suppl.66): 34-36.

51. Anwar J, Wrone DA, Kinyai-Asadi A, Alam M. The development of actinic keratosis into invasive squamous cell carcinoma: evidence and evolving classification schemes. Clin Dermatol. 2004;22:189-196.

52. Crarnecki D, Meehan CJ, Bruce F, Culjak G. The majority of cutaneous squamous cell carcinomas arise in actinic keratoses. J Cutan Med Surg 2002;6(3):207-9.

53. Long CC, Turner RJ, Marks R. Actinic keratosis: the bald facts. Arch dermatol 1996;132:1132-33.

54. Lebwohl M. Actinic keratosis: epidemiology and progression to squamous cell carcinoma. $\mathrm{Br}$ J Dermatology 2003;149(suppl.66): 31-33.

55. Ortonne JP. From actinic keratosis to squamous cell carcinoma. Br J Dermatol. 2002 Apr;146 Suppl 61:20-3.

56. Chen GJ, Feldman SR, Williford PM, Hester EJ, Kiang SH, Gill I, Fleischer AB. Clinical diagnosis of actinic keratosis identifies an elderly population at high risk of developing skin cancer. Dermatol Surg. 2005 Jan;31(1):43-7.

57. Gogau RG The risk of progression to invasive disease. J Am Acad Dermatol. 2000 Jan;42:s234.
58. Cockerell (J, Wharton JR. Now histo pathological classification of actinic keratosis (incipient intraepidermal squamous cell carcinoma). J Drugs I)ermatol 2005;4(4):462-7.

59. Yantsos VA, Comad N, Tabawski F, Cockerell C. Incipient intracpidermal cutancuos squamous cell carcinoma: a proposal for reclassifying and grading solar (actinic) kertoses. Semin Cutan Med Surg. 1999 Mar;18(1):3-14.

60. Tutrone, W.ID., Saini R, Caglar S et all. Topical therapy for actinic keratoses, I: 5-Fluorouracil and imiquimod. Cutis 2003;71:365-70.

61. Drake L.A, Ceilley R.I, Cornelison R.I.. Guidelines of care for actinic keratoses. Committee on Guidelines of Care. I Am Acad Dermatol 1995;32(1):95-8.

62. Jorizzo JL. Current and novel treatment options for actinic keratosis. J Cutan Med Surg 2005;13-21.

63. Dinehart S.M. The treatment of actinic keratoses. J Am Acad Dermatol 2000;42 $\{1 \mathrm{Pt}$ 2): $25-8$

64. Marmur E.S., C.D. Schmults, and D.J. Goldberg. A review of laser and photodynamic therapy for the treatment of nonmelanoma skin cancer. Dermatol Surg 2004;30(2 Pt 2): 264-71.

65. Edwards L, Levine $N$, weidner $M$. Effect of intralesional alpha 2-interferon on actinic keratoses. Arch Dermatol 1986;122(7):779-82.

66. Tran H, Chen K, Shmack S. Summary of actinic keratosis studies with imiquimod $5 \%$ cream.

Br J Dermatol. 2003 Nov;149 Suppl 66:37-9. Review.

67. Goette D.K. Topical chemotherapy with 5fluorouracil. A review. J Am Acad Dermatol 1981;4(6):633-49.

68. Spencer JM, Hazan C, Hsiung SH, Robins P. Therapeutic decision making in the therapy of actinic keratoses. J Drugs Dermatol. 2005 MayJun;4(3):296-301.

69. Jorizzo JL, Carney PS, Ko WT, Robins P et al. Treatment options in the management of actinic keratosis. Cutis 2004;74(6 Suppl):9-17.

70. Walton RG, Jacobs AH, Cox AJ. Pigmented lesions in newborn infants. $\mathrm{Br} \mathrm{J}$ Dermatol $1976 ; 95: 389$.

71. Kopf, A. W., Bart, R. S., and Hennessey, P. Congenital nevocytic nevi and malignant melanomas. J Am Acad Dermatol 1979;1:123-130. 
72. Bittencourt, F. V., Marshoob, A. A., Kopt, A. W. Koenig, K. L., and Bart, R. S. Large comgenital melanocytic nevi and the risk for development of malignant melanoma and neurocutaneous melanosis. Pediatrics 2000;106:736-741

73. Castilla EE, Da Graca Dutra M, OrioloParreiras IM. Epidemiology of congenital pigmented nevi: incidence rates and relative frequencies. Br J Dermatol 1981; 104:307-15.

74. Zitelli JA, Grant G, Abel E, Boyd JB. Histologic pattern of congenital nevocytic nevi and implications for treatment. J Am Acad Dermatol 1984;11:402-9.

75. Tannous ZS, Mhim MC, Sober AJ, Duncan I,M. Congenital melanocytic nevi: clinical and histopathologic features, risk of melanoma, and clinical management.

J An Acad Dermatol. 2005 Feb;52(2):197-203.

76. Kaplan EN. The risk of malignancy in large congenital nevi. Plast Reconstr Surg 1974;53:421-428

77. Berg P, Lindelof B. Congenital melanocytic naevi and cutaneous melanoma. Melanom Res $2003 ; 13(5): 441-445$.

78. Watt AJ, Kotsis SV, Chung KC. Risk of melanoma arising in large congenital melanocytic nevi: a systematic review. Plast Reconstr Surg 2004; $113(7): 1968-73$.

79. Ka VSK, Dusza SW, Halpern AC, Marghoob AA. The association between large congenital melanocytic naevi and cutaneous melanoma: preliminary findings from an internet based registry of 379 patients. Melanoma Res 2005; 15(1):61-67.

80. Zaal LH, Wolter J, Mooi MD, Klip H, van der Horst CM. Risk of malignant transformation of congenital melanocytic nevi: a retrospective nationwide study from the Netherlands. Plast Reconstr Surg 2005;116:1902-9.

81. Ruiz-Maldonado R, Tamayo L, Laterza AM, Duran C. Giant pigmented nevi: Clinical, histopathologic and therapeutic considerations. J Pediatr 1992;120:906-11.

82. Rhodes AR. Congenital nevomelanocytic nevi: Histologic patterns in the first year of life and evolution during childhood. Arch Dermatol 1986;122:1257-62.

83. Lawrence CM. Treatment options for giant congenital naevi. Clin Exp Dermatol 2000;25:711.
84. Johnson IA. Permanent removal of pismentation from grant hary navevi by dermabrasom in carly life. Br J Plast Surg 1977:30:321-3.

85. Miller (J, Becker I)W. Removing pigmentation by dermabrading naevi in infancy. Br J Plast Surg 1979;32:124-6.

86. Rompel R, Möser M, Petres J. Dermabrasion of congental nevocellular nevi: experience in 215 patients. Dermatology 1997;194:261-7.

87. De Racve I.F, Rosecuw 1)I. Curettage of giant congenital melanocytic nevi in neonates: A decade later. Arch Dermatol 2002;138:943-8.

88. Michel JL, Laborde-Milaa Roux V, Chavrier Y et al. Neonatal curettage of giant congenital nevi. Ann Dermatol Venereol $2000 ; 127(1): 23-$ 8.

89. Casanova D, Bardot J, Andrac-Meyer I, Magalon (i. Farly curettage of giant congenital naevi in children. Br J Dematol 1998;138:3415.

90. De Raeve LE, De Coninck AI, Dicrickx PR, Rosecuw DI. Neonatal curettage of giant congenital melanocytic nevi. Arch Dermatol 1996;132:20-2.

91. Moss ALH. Congenital giant naevus: a preliminary report of a new surgical approach. Br J Plast Surg 1987;40:410-9.

92. Hopkins JD, Smith AW, Jackson IT. Adjunctive treatment of congenital pigmented nevi with phenol chemical peel. Plast Reconstr Surg 2000;105:1-11.

92. Reynolds N, Kenealy J, Mercer N. Carbon dioxide laser dermabrasion for giant congenital melanocytic nevi. Plast Reconstr Surg 2003;111:2209-14.

94. Kay AR, Kenealy J, Mercer NS. Successful treatment of giant congenital melanocytic nevus with the high energy pulsed $\mathrm{CO}_{2}$-laser. $\mathrm{Br}$ J Plast Surg 1998;51:22-4.

95. Michel JL, Caillet-Chomel L. Traitement par laser $\mathrm{CO}_{2}$ superpulsé des nevus congénitaux géants. Arch Pediatr. 2001;8:1185-94. 


\section{CHAPTER 1}

\section{Ablative laser resurfacing}

Berretty PJ. Ostertag JL. Leumann H.A.

A new option for skin rejuvenation: $\mathrm{CO}_{2}$-laser resurfacing.

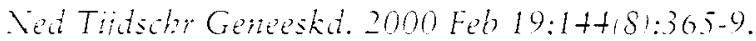

Ostertag JL: Berretry PJ.

Guidelines for ablative laser resurfacing

Richtim laserbehandelingen en flitshotherapie. $H 2: 35-+1$.

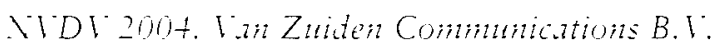


18 CHAPTER 1 


\title{
A new option for skin rejuvenation: $\mathrm{CO}_{2}$ laser resurfacing
}

\author{
PAUL J. BERRETTY, JUDITH U. OSTERTAG, H.A. MARTINO NEUMANN
}

The term 'resurfacing' involves mechanical, chemical or physical removal of the superficial layers of aged skin. This activates collagenesis, which is accompanied by an improvement in the epidermal architecture. $\mathrm{CO}_{2}$ laser resurfacing is a modern technique for treating manifestations of skin aging. $\mathrm{CO}_{2}$ laser resurfacing enables an accurate layer by layer ablation of the skin. This technique cannot only be used for cosmetic indications, but also for a wide variety of dermatological disorders.

Remaining vital and young is a much sought after ideal for many individuals in the present society. The strong demand from the population for the possibility of curbing the aging process has also led to an increase in research into ways of influencing the (patho-physiological) changes that accompany skin aging.

The individual skin aging is determined both by extrinsic and intrinsic factors. The intrinsic factors include the physiologic aging processes, such as the loss of elastin in the dermis whereby the skin loses its elasticity and wrinkles appear. In addition, pathologic factors such as progeria may also influence the intrinsic skin aging. The most important extrinsic factor, without any doubt, is the epidermal and dermal damage caused by ultraviolet (UV) light. Other factors such as smoking also play a role.'

Within our present society, this 'normal' skin aging forms an cosmetic, but not medical indication for treatment. However, there is a definite indication for medical intervention when premalignant skin abnormalities such as extensive forms of actinic keratosis have developed as a result of exposure to UV light.

The options to actively steer the aging processes have increased tremendously during the last decade. As such, at the moment, both in the dermatological practice as well as in the cosmetic industry, active substances that are able to influence disturbed collagenesis and keratinization are used. Examples of such substances include antioxidants, retinoids and á-hydroxy acids. In the last decade, considerable progress has also been made in the technical-surgical options for treating manifestations of skin aging. The term 'resurfacing' was introduced, which involves mechanical, chemical or physical removal of the superficial layers of aged skin. This activates collagenesis, which is accompanied by an improvement in the epidermal architecture (clinical rejuvenation). ${ }^{2}$

Dermabrasion and chemical peeling were commonly used to treat manifestations of skin aging such as actinic keratosis and wrinkles prior to the arrival of laser resurfacing. Although, excellent results can be achieved with these methods, there is an important disadvantage: one is unable to determine the end result during treatment. Radical treatment is accompanied by the risk of scar formation and pigment changes, whereas the desired effect remains unachieved if the treatment is too superficial. New developments in laser equipment for treating manifestations of skin aging have been available since the beginning of the 1990s. In particular, it was the American dermatologists who rendered this technique 
applicable in the clinical practice. ${ }^{3-5}$ Through technical adaptation of the already existing laser cquipment, using an accurate setting, it became possible to remove superficial tissue in a reproducible manner without damaging the underlying structures.

There is still room for dermabrasion and chemical peeling in the esthetic surgery, but it seems that these techniques, because of the already mentioned reasons, to have compete with the laser resurfacing.

\section{$\mathrm{CO}_{2}$ LASER RESURFACING}

The principle of laser treatment is that a specific part of the body (treatment target) absorbs coherent monochromatic light that is emitted by the laser (laser is abbreviation for "light amplification by stimulated emission of radiation'). Generally, the treatment would be optimum if the physical-chemical properties of the target are such that the emitted laser light is absorbed (by specific chromophores such as hemoglobin or water) only by the target, but not by the surrounding structures. It is also essential that the target of laser treatment does not directly damage (e.g. chemically or by developing warmth) the surrounding tissue. Superficial removal of tissue with laser is possible if the emission spectrum of the laser is specifically directed at the most important component of the tissue. This component is water in the skin.

\section{Operation of the $\mathrm{CO}_{2}$ lasers}

$\mathrm{CO}_{2}$ lasers that operated on the principle of absorption of the produced electromagnetic energy have been available for decades. The $\mathrm{CO}_{2}$ laser produces electromagnetic energy with a wavelength of $10,600 \mathrm{~nm}$. The water present in the tissue absorbs this specific wavelength (Fig. 1). Initially, $\mathrm{CO}_{2}$ lasers were only used in surgery for cutting or coagulation. The results that were achieved with these lasers were certainly no better

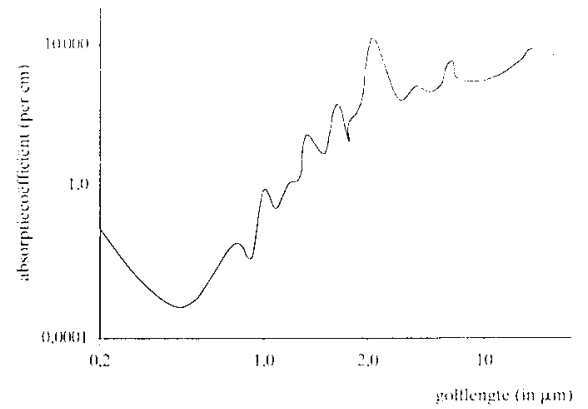

Figure 1: The absorption spectrum of water (the absorption coefficient is logarithmically depicted): there is a specific absorption peak at $10,600 \mathrm{~nm}(10.6$ $\mu \mathrm{m})$, the wavelength that is emitted by a $\mathrm{CO}_{2}$ laser. The optimum water absorption is at $2940 \mathrm{~nm}(2.94$ $\mu \mathrm{m})$, the wavelength of an erbium-yttrium-aluminumgarnet laser.

than those achieved with a scalpel, but an additional hemostatic effect and an accurate reach for difficult locations had unmistakable advantages. However, for an accurate ablation of the skin structures, technical developments were required for achieving the desired effect (removal of superficial tissue without damaging the underlying structures).

Absorption of the monochromatic laser light by the water component initially results in the so-called specific thermolysis. In addition there are non-specific thermal and evaporation effects. These non-specific effects will predominate over the specific effects leading to the damage in the underlying tissue when conventional equipment is used. Thereby scar formation and pigment disturbance may also easily occur. Therefore, limiting the specific thermal effects to a minimum was essential in the development of laser resurfacing equipment. One can achieve this limitation by improving the specific thermolytic effect with the so-called thermal relaxation time of the target (i.e. the time required by the tissue to cool down by $50 \%$ ). Theoretically, one is able to solve this problem by increasing the applied energy and simultaneously shortening the pulse 
duration considerably. A themolytic effect that is applied for a very short time results in less non-specific warming effects.

A warmth gradient develops upon radiation of the tissue. This gradient drops sharply and flattens out because of the warmth diffusion to the surrounding tissue directly after the pulse. The temperature at the treated site is more than $100^{\circ} \mathrm{C}$ resulting in vaporization of the tissue. The underlying tissue is heated up to no more than $50-60^{\circ} \mathrm{C}$. This heating has two important effects. On the one hand, a hemostatic effect is achieved and on the other hand, it appeared that slightly warmed (but not overheated) collagen showed a contraction effect, the socalled collagen shrinkage. Finally, more collagen with a better structure (with more thicker bundles) is demonstrably formed (Fig. 2). ${ }^{6-8}$ The consultant is thus able to remove the tissue layer by layer. Moreover, during the treatment, one is able to correctly assess the effectiveness of the treatment on the basis of dermal color changes. ${ }^{9}$

\section{Improvement of the treatment technique}

During the past 10 years, a revolutionary development has occurred for rejuvenating the face: The development of a high energy pulsed or scanning $\mathrm{CO}_{2}$ laser, which can selectively and accurately vaporize the superficial skin layers. An accurate ablation of the tissue occurs because the $10,600 \mathrm{~nm}$ light bundle that is emitted by the laser system is selectively absorbed by the water-containing tissue, such as the epidermis and the superficial papillary dermis (Fig.1). Moreover, the dermal denaturation of type- 1 collagen, which occurs during the treatment, leads to tightening of the skin because of collagen shrinkage. Supplementary to the ablation, this also contributes in remodeling and reduction of superficial irregularities. Tissue ablation caused by $\mathrm{CO}_{2}$ lasers is a controlled injury with residual $30-150 \mu \mathrm{m}$ deep dermal damage and initiation of new collagen depositions.

Often, several laser passages over the affected skin are required for optimum effect. Extensive dermal damage through exaggerated laser induced thermal damage will always lead to scar formation. This is occurs if too many passages are conducted. Therefore, accuracy in intervention is imperative even with such modern equipment. Two different groups of $\mathrm{CO}_{2}$ lasers have been developed for achieving the described effects. ${ }^{10,11}$ The first is a high peak pulsed $\mathrm{CO}_{2}$ laser with a high capacity (Ultra Pulse, Coherent, Palo Alto, Calif., USA), which can deliver up to $500 \mathrm{~mJ}$ energy in $600 \mu$ s to $1 \mathrm{~ms}$ pulse. The second type of laser is a conventional continuous beam laser with a microprocessor-controlled scanner enabling a focused laser beam on the skin (the Silk Touch and the Feather Touch; Sharplan, Allendale, N.J., USA). The time for which the laser beam remains on the skin at any given point is less than $1 \mathrm{~ms}$. Other continuous and pulsed $\mathrm{CO}_{2}$ laser systems have been introduced on the market for resurfacing: the Nova Pulse (Luxar, Bothell, Wash., USA) and the True Pulse (Tissue Technology, Lexington, Mass., USA) with a variation on the mentioned themes. However, much less scientific research has been conducted with these lasers because of lower capacity and imprecise tuning options. Therefore, the options for highly precise treatment are clearly less.

\section{Medical application of $\mathrm{CO}_{2}$ laser resurfacing}

The most important application of laser resurfacing is for treating aged skin (actinic skin damage and wrinkles) and scars. However, a controlled laser ablation may also be used for a wide variety of dermatologic disorders such as epidermal nevi, Bowen's disease, actinic cheilitis, syringoma, xanthelasma, verruca plana, verruca vulgaris, 

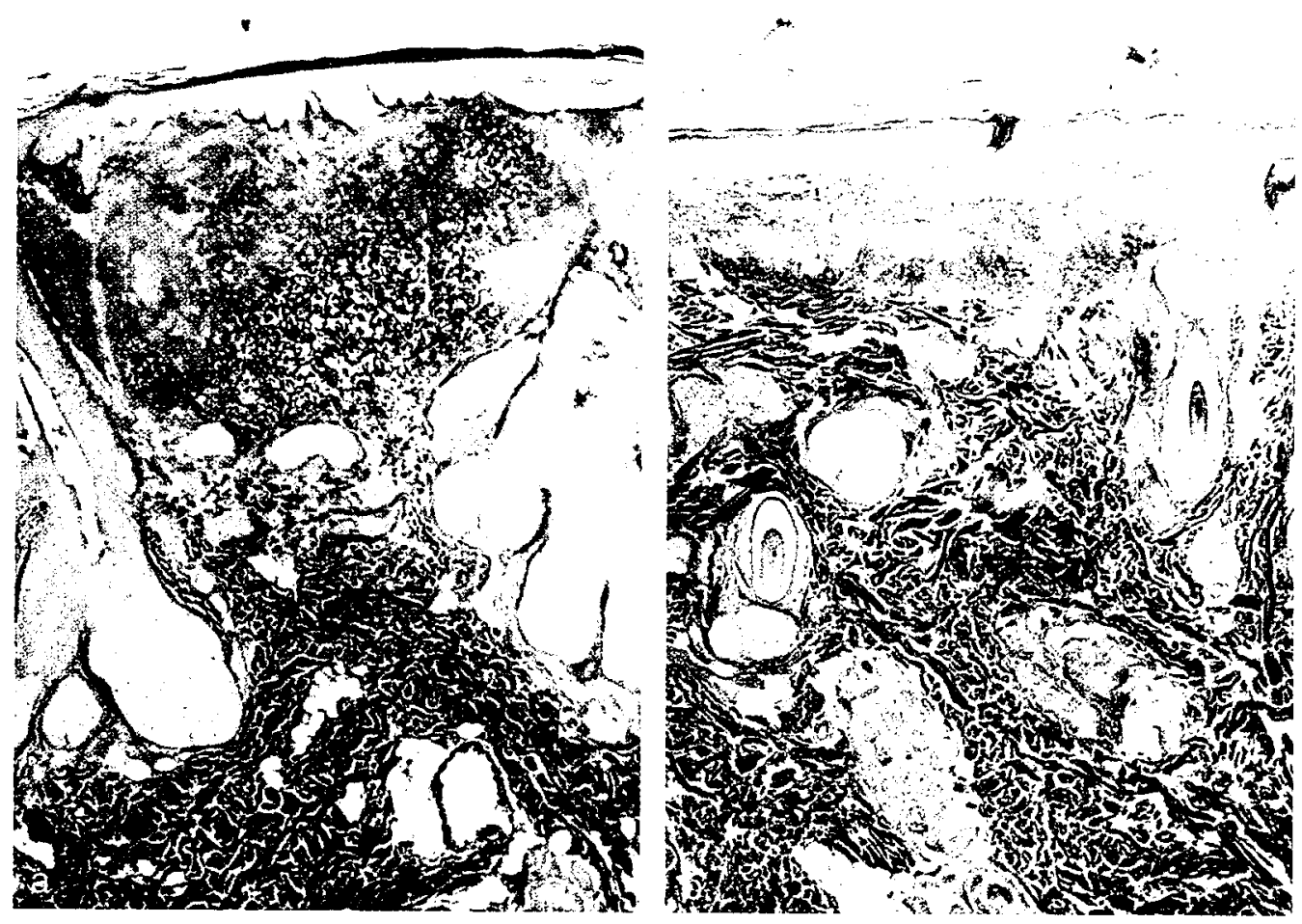

Figure 2: Histological characteristics of skin before and after treatment with $\mathrm{CO}_{2}$ laser resurfacing: the elastin fibers are stained black, whereas the collagen fibers are stained red with Van Gieson stain; (a) before the treatment there is degeneration of collagen and elastin in the gray area in the upper part of the dermis; (b) after treatment, a

rhinophyma, Zoon's erythroplasia, lichen sclerosus et atrophicus, Hailey-Hailey disease and actinic keratosis. ${ }^{12}$ Lesions on the face can be treated because the large number of skin adnexa facilitate good reepithelialization. Peri-oral and peri-ocular wrinkles are also excellent indications. Delayed wound healing and scar formation are easily occurring complications if other areas such as the neck and the hands are treated.

\section{Results and complications}

At present, there is no generally accepted classification, which would permit a differentiated discussion on the therapeutic effectiveness in actinic skin damage or wrinkles. Subjective as well as objective criteria (docu- mented by photographs or judged by a panel) are used to discuss the results of the therapy. However, practical experience has shown that limited damage and superficial wrinkles disappeared after well-conducted laser resurfacing. Deep wrinkles clearly faded (Fig. 3). Thus, excellent results may also be achieved. The outcome also depends on the personal experience of the therapist. There are no differences in the results that can be achieved with different $\mathrm{CO}_{2}$ laser systems. ${ }^{6,7,1,3}$ The most important complications are post-operative bacterial and viral infections. Adequate anti-viral and antibiotic prophylactics should be given until complete re-epthelialization. Other complications and side effects are post-laser erythema, persistent erythema, pruritus, contact dermatitis, irritation dermatitis, acne 


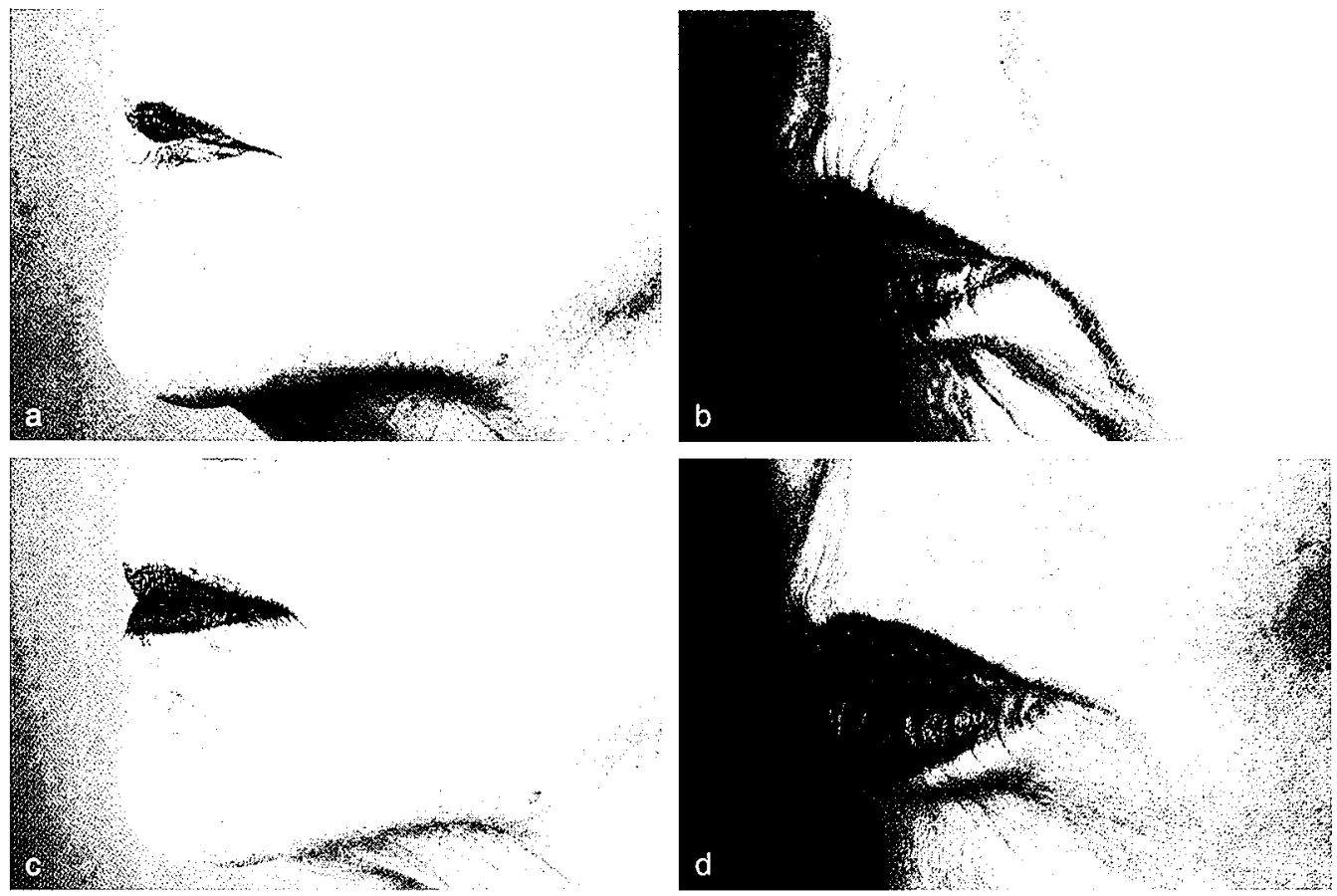

Figure 3: Peri-oral wrinkles in a woman $(a, b)$ before treatment with $\mathrm{CO}_{2}$ laser resurfacing; $(c, d)$ results of treatment after 1 year.

and milia, hyperpigmentations, hypopigmentations, hypertrophic scars and ectropion. $9,14,1.5$

\section{Discussion}

The possibility of conducting precise abla tion of the skin with $\mathrm{CO}_{2}$ lasers has meant a breakthrough for treating manifestations of skin aging. The precise effects are particularly an advantage compared with dermabrasion and chemical peeling. The therapist has the clear advantage of being able to directly evaluate the effects of the treatment. The additional hemostatic effect is also an important advantage compared with heavy bleeding in the skin during dermabrasion. Aerial dispersal of blood particles does not occur during $\mathrm{CO}_{2}$ laser treatment, but fumes and gases are released during laser peeling. An adequate smoke evacuation device fitted in the laser handle pre- vents the dispersal of unwanted particles. Scars and pigment disturbances can be prevented effectively because the treatment can be closely monitored. During $\mathrm{CO}_{2}$ laser resurfacing, besides ablation of the tissue, a thermal effect on the collagen whereby shortening of the interstitial matrix (shrinkage) also occurs. Controlled thermal damage is thus necessary for the re-modeling effect and for tight skin. In contrast, uncontrolled thermal damage would cause scars. ${ }^{2}$ The cosmetic effects of laser treatment are long-lasting; 5 years have been reported. ${ }^{9}$

Laser resurfacing is certainly not an easy treatment. In spite of the computer assistance, the therapist must be well-versed with the technique. Moreover, after every laser treatment an effective follow-up treatment should be implemented for accomplishing a satisfactory re-epithelialization and optimum repigmentation. Knowledge of skin type, wound healing and acknowledging 
and treating side effects and complications is absolutely imperative.

In practice, the $\mathrm{CO}_{2}$ laser treatments also result in, as yet not understood, persisting depigmentations. Depigmentations are not only observed directly post-operatively, but also later on. Additional investigations into the influence of heat on the melanocyte should provide clarification. Post-operative erythema occurs during weeks in every patient. The erythema depends on the depth of the treatment and on the rise in temperature in the tissue. New laser resurfacing equipment has been developed (the erbiumyttrium-aluminum-garnet laser) operating at a wavelength of $2940 \mathrm{~nm}$ (the optimum absorption for water-Fig. 1 ) in order to shorten, among others, the erythema phase. Results similar to those reported for $\mathrm{CO}_{2}$ laser have been reported. ${ }^{16}$ Even lesser nonspecific thermal effects occur because of the optimal absorption by water. However, less shrinkage and the elimination of the coagulation effect are negative aspects. Combinations of erbium-yttrium-aluminum-garnet laser and $\mathrm{CO}_{2}$ laser may possibly provide a solution for this.

\section{Conclusion}

It appears that with the currently available $\mathrm{CO}_{2}$ laser resurfacing equipment one is able to adequately treat manifestations of skin aging.

\section{References}

1. Smith IB, Fenske NA, Cutaneous manifestations and consequences of smoking. I Am Acad Dermatol 1996;34(5 Pt 1):717-32.

2. Fitzpatrick RE, Goldman MP, Satur NM, Tope WD. Pulsed carbon dioxide laser resurfacing of photo-aged skin. Arch Dermatol 1996; 1.32:395-402.

3. Fitzpatrick RE, Goldman MP. $\mathrm{CO}_{2}$ laser surgery. Cutancous laser surgery. St Louis: Mosby; 1994.
4. Circulink JM. Facial conteuring using at flashscamer-conbaned carbon dioxide laser. Facial Plastic Surgery Clinics of Vorth America $1996 ; 4: 241-6$.

5. Kauvar $A N$, Waldort HA, Ceronemus RG. A histopathological comparion of "char- frece carbon dioxide lasers. Dermatol Surg 1996; 22:34.3-8.

6. Ross EV, Grossman MC, Duke D), Cirevelink JM. Long-term results after $\mathrm{CO}_{2}$ laser skin resurfacing: a comparison of scanned and pulsed systems. I Am Acad Dermatol 1997;3715 Pt 1):709-18.

7. Trelles MA, Rigau J, Mellor TK, Garcia L. A clinical and histological comparison of flashscanning versus pulsed technology in carbon dioxide laser facial skin resurfacing. Dermatol Surg 1998;24:43-9.

8. Cotton J, Hood AF, Gonin R, Becsen WH, Hanke $C W$. Histologic cvaluation of preauricular and postauricular human skin after high-energy, short-pulse carbon dioxide laser. Arch Dermatol 1996;132: 425-8.

9. Weinstein C. Carbon dioxide laser resurfacing. I.ong-term follow-up in 2123 patients. Clin Plast Surg 1998;25:109-30.

10. Lowe NJ, Iask GP, Griffin ML, Maxwell A, Lowe P, Quilada F. Skin resurfacing with the Utrapulse carbon dioxide laser. Observations on 100 patients. Dermatol Surg 1995;21:102.5-9.

11. Lask GP, Keiler G, Lowe NJ, Gormley D. Laser skin resurfacing with the Silk Touch flashscanner for facial rhytides. Dermatol Surg 1995;21:1021-4.

12. Kelly KM, Nelson JS. Carbon dioxide laser resurfacing of rhytides and photodamaged skin. Lasers Med Sci 1998;13:232-41.

13. Gross EA, Rogers GS. A side-by-side comparison of carbon dioxide resurfacing lasers for the treatment of rhytides. J Am Acad Dermatol 1998;39(4 Pt 1):547-53.

14. Bemstein U, Kauvar AN. Grossman MC, Geronemus RG. The short- and long-term side effects of carbon dioxide laser resurfacing. Dcrmatol Surg 1997;23:519-25.

15. Namni CA, Alster TS. Complications of carbon dioxide lascr resurfacing. An evaluation of 500 patients. Dermatol Surg 1998;24:315-20.

16. Flenming D. Controversies in skin resurfacing: the role of erbium. J Cutan Laser Ther 1999:1:15-21. 


\title{
Guidelines for ablative Laser resurfacing
}

\author{
JUDITH U. OSTERTAG, PAUL J. BERRETTY
}

\section{Technical information}

The principle of an ablative vaporization laser is based on the fact that laser light that is absorbed by the water phase of the tissue shall not lead to boiling-, cutting- or coagulation-effects if the duration of the absorption is drastically shortened. Vaporization arises as a result of the shortening of this duration of absorption. There are 2 ablative vaporization laser systems: carbon dioxide $\left(\mathrm{CO}_{2}\right)$-lasers with a wavelength of $10,600 \mathrm{~nm}$ and erbium-yttrium-aluminumgarnet (Er:YAG)-lasers with a wavelength of $2,940 \mathrm{~nm}$.

Ablative lasers are lasers with which one can remove or reduce irregularities in the skin by vaporization via the principle of selective photothermolysis. The available laser systems are directed at the chromophor water, which makes up $70 \%$ of the epidermal tissue. The photothermolytic effects on the skin are: direct vaporization, collagen necrosis, thermal damage and collagen shrinkage. This technique is referred to as laser resurfacing and was initially developed to treat wrinkles and acne scars. Laser resurfacing in the peri-ocular area, combined with cutting with the pulsed $\mathrm{CO}_{2}$-laser is suitable for blepharoplasty.

\section{Wrinkles and acne scars}

\section{Equipment and performance}

Generally, the treatment is conducted under local or general anesthesia. The skin is ablated down in to the papillary or the reticular dermis depending on the disorder to be treated and the desired result.This can be accurately determined by the color and the structural changes in the tissue. The number of required passes depends on the type of laser and the settings that are used. The end-point of the treatment is determined visually. The skin area which has undergone ablation, is post-operatively covered with a semi-occlusive bandage during the first few days. Oral anti-viral drugs (e.g. valacyclovir $500 \mathrm{mg}$ twice a day during 2 weeks) and antibiotic prophylaxis (e.g. claritromycin $250 \mathrm{mg}$ twice a day during a week) are necessary to prevent wound infections and subsequent scar formation. The re-epithelialization of the treated area takes 7-14 days. Generally, edema and erythema are present for several weeks after reepithelialization. Sometimes, the erythema may persist for much longer (months). The newly formed skin is generally smoother and tighter because of remodeling of the newly formed collagen.

Risks and side effects that may occur are infections, scars, hyperpigmentation, hypopigmentation, (transient) acne and milia. Development of contact allergic and contact irritative reactions to topical agents (namely antibiotics) in the lasered area have also been reported.

\section{Evidence basis}

Literature listed in Medline and Cochrane electronic databases from 1993 until 2002 was reviewed. A total of 10 usable studies were found from which 8 were randomized, 1 was prospective non-comparable and 1 was a systematic review (Table 1 ). Nine articles were on facial cosmetic treatments because of wrinkles and/or acne scars. ${ }^{1-9}$ The number of patients in the studies was 7 to 35 , whereby a side-to-side comparison 


\section{Classification of literature according to the evidence}

A1 Systematic review concerning at least few studies with an A2 level.

A2 Randomized double-blind controlled trials with sufficient number and quality.

B Randomized controlled clinical trials of moderate quality or insufficient number, or non randomized comparative studies.

C Non comparative studies

D Expert opinion

\section{Level of evidence}

11 Systematic review (A1), or 2 independent $A 1$ or $A 2$ studies

2 At least 2 independent $B$ studies

3 One $\mathrm{A} 2$ or B study, or $\mathrm{C}$ studies

4 Expert opinion

\section{Conclusions}

Laser resurfacing with $\mathrm{CO}_{2}$-laser and Er:YAG-laser is effective in treating wrinkles. The estimated clinical improvement is between 40 and $70 \%$.

B McDaniel ${ }^{3}$; Duke

Level 2

The clinical improvement in wrinkles after laser resurfacing with the $\mathrm{CO}_{2}$-laser is better than that obtained with the Er:YAG-laser, but has more side effects such as erythema and hypopigmentation.

$B$ Newman ${ }^{1}$; Katri ${ }^{2}$

Level 2

There are no differences in the affectivity and side effects between different $\mathrm{CO}_{2}$-laser systems such as Ultra Pulse, Silk Touch/Feather. Touch, Tru Pulse and Nova Pulse for treating wrinkles and acne scars.

$B$ Alster ${ }^{4} ;$ Gross $^{5} ;$ Duke $^{6} ;$ Ross $^{7}$

Level 2

The most important side effects of laser resurfacing in wrinkles and acne scars are hyperand hypopigmentation and infections.

B Khatri ${ }^{2} ;$ Duke $^{6} ;$ Ross $^{7}$

Level 2

The are no large differences in the efficacy (25-80\% improvement) and side effects (transient pigment disturbances, acne and milia) between $\mathrm{CO}_{2}-$ and Er:YAG-laser for treating acne scars.

C Jordan ${ }^{20}$

Level 3 
was generally made. The number of included treatment sites in the studies varied from 20 to 70.

The results of the intervention were generally evaluated by non-blinded clinical examination. A blinded evaluation of the clinical effect was generally done by examining the photographs. In addition, profilometry, a chromometer and histological evaluation were used in some studies. The duration of the follow-up varied from 2 to 12 months.

The application of $\mathrm{CO}_{2-}$ and Er:YAGlaser systems for the cosmetic improvement of acne scars was reported in 1 systematically well-conducted review comprising an evaluation of 16 studies (case-series) of poor quality. ${ }^{10}$ Laser blepharoplasty whereby excision was conducted using pulsed $\mathrm{CO}_{2}-$ laser light in combination with or without peri-ocular resurfacing appeared to be safe and effective. Shorter duration of operation and fewer complications compared with the conventional cutting blepharoplasty have been reported. ${ }^{11-16}$

\section{Other considerations}

- For the time being, great caution should be exercised when performing laser resurfacing on the neck and on the extremities. Delayed wound healing and none to minimal cosmetic improvement have been reported. 8

- The differences in side effects between Er:YAG- and $\mathrm{CO}_{2}$-laser resurfacing possibly depend on the depth of the treatment and the difference in thermal damage.

- A treatment test spot on wrinkles and acne scars provides little information on the final result and eventual side effects.

- The current trend is to be more restraint in performing laser resurfacing treatment on wrinkles and acne scars considering the relatively prolonged recovery time and the chance of side effects. Nonetheless, there is a group of pationts in whom laser resur. facing, eventually in combination with other techniques is suitable.

- This form of laser treatment is unsuitable for non-physicians and in such hands may lead to unwanted complications.

\section{Recommendations}

- $\mathrm{CO}_{2}$ - and Er-YAG-laser resurfacing are suitable for treating wrinkles and acne scars. $\mathrm{CO}_{2}$-laser is preferred for treating deep wrinkles and extensive acne scars. Er:YAG-laser is more suitable for fine wrinkles and less prominent acne scars.

- Photographs before and after treatment, exact documentation of the complete procedure and the course are important in cosmetic laser resurfacing. Discussion of cosmetic results and eventual medico-legal aspects necessitate reporting. 
28 CHAPTFR 1

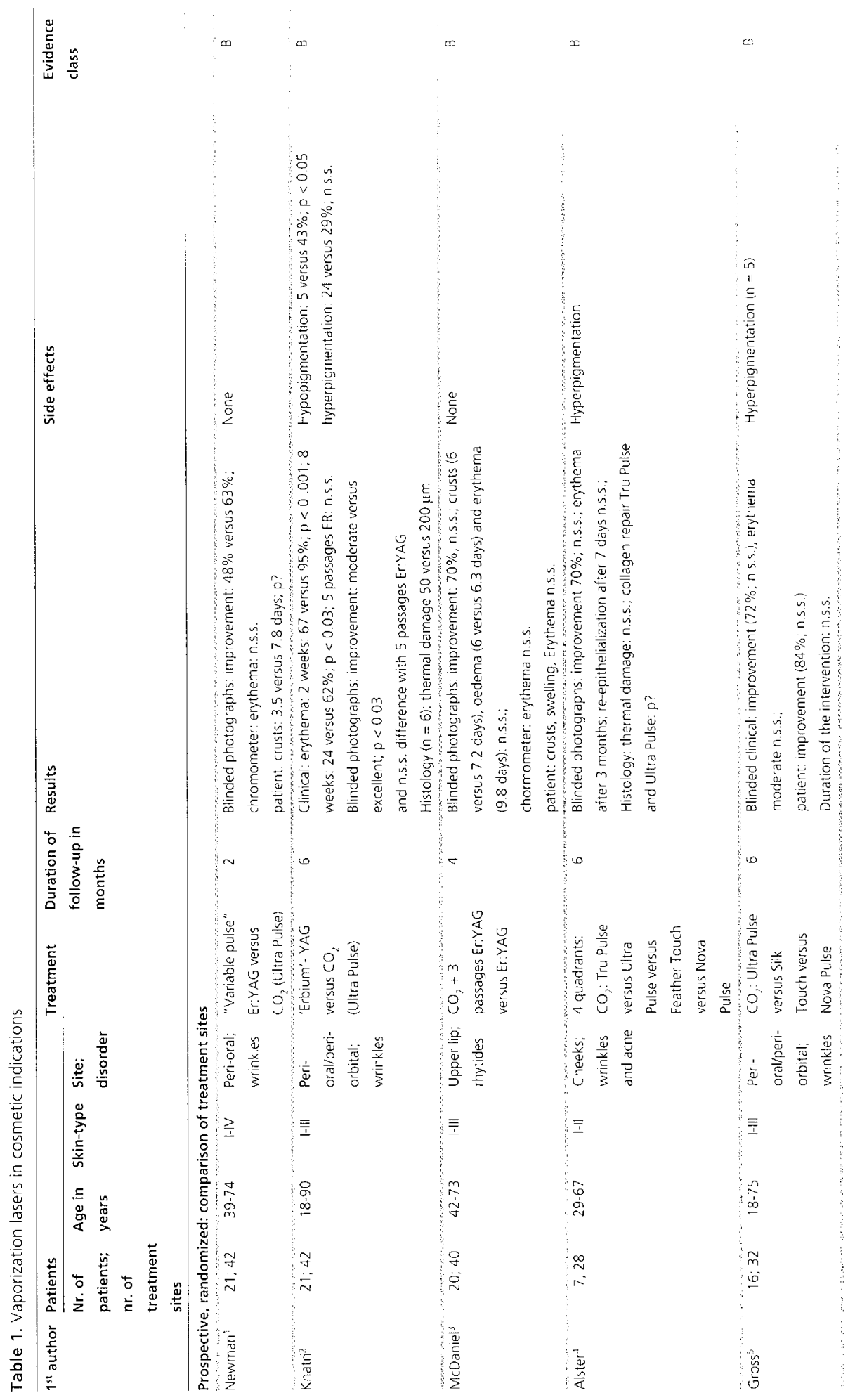




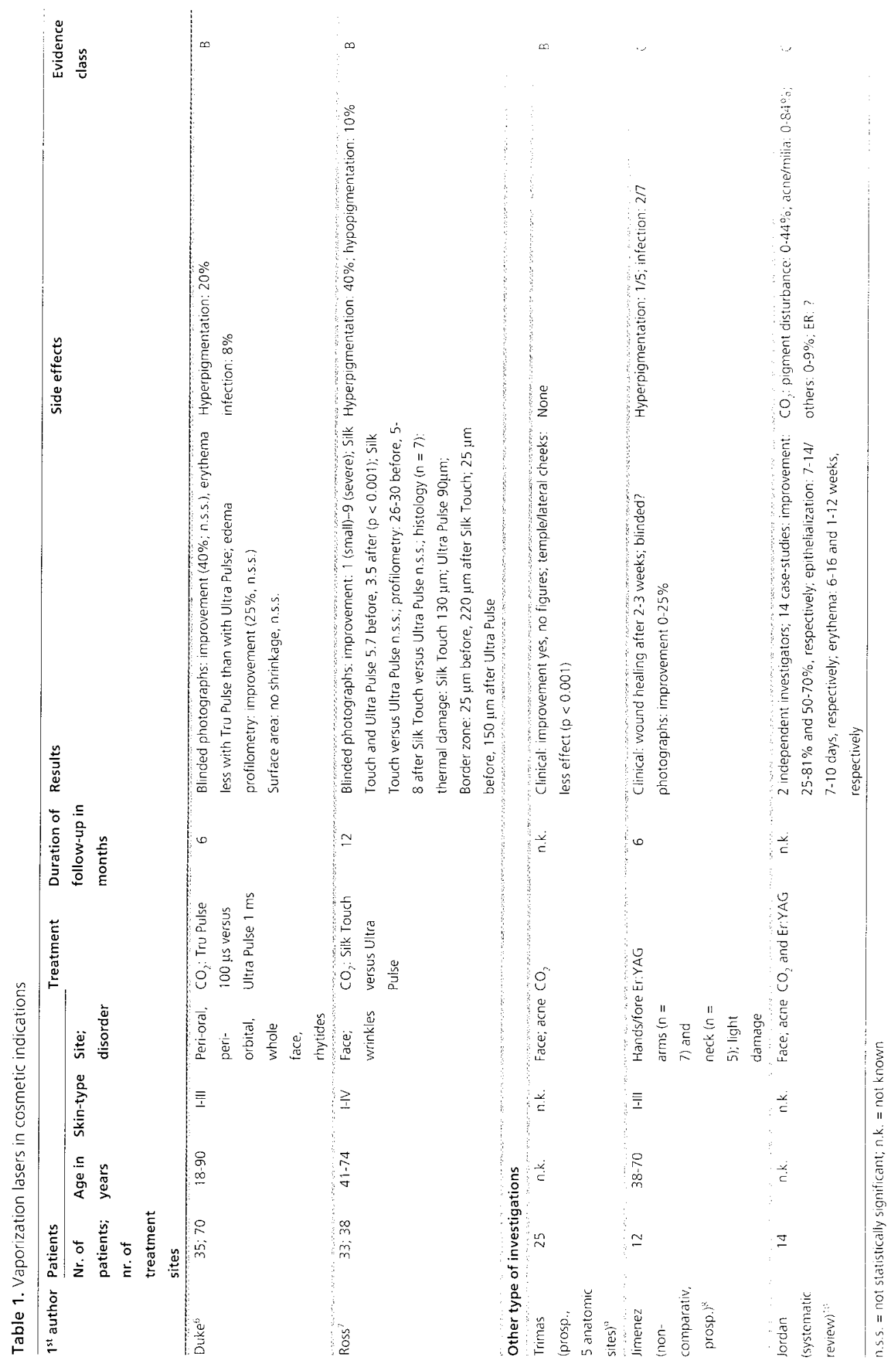




\section{References}

I. Newman JB, Lord JL, Ash K, Mc Daniel DH. Variable pulse erbium:YAG laser skin resurfacing of perioral rhytides and side-by-side comparison with carbon dioxide laser. lasers in surgery and medicine 2000; 26: 208-14.

2. Khatri KA, Ross V, Grevelink JM Magro CM, Anderson RR. Comparison of erbium:YAG and carbon dioxide lasers in resurfacing of facial thytides. Archives of Dermatology 1999; 1.3.5: $391-7$.

3. Mc Daniel DH, loard J, Ash K, Newman J. Combined $\mathrm{CO}_{2}$ / erbium: $\mathrm{YAC}$ laser resurfacing of peri-oral rhitides and side-by-side comparison with carbon dioxide laser alone. Dermatologic Surgey 1999; 25:285-93.

4. Alster TS, Nami CA, Williams C.M. Comparison of four carbon dioxide resurfacing lasers. $A$ clinical and histopathologic evaluation. Dermatologic Surgery 1999; 25: 153-8.

5. Gross EA, Rogers GS. A side-by-side comparison of carbon dioxide resurfacing lasers for the treatment of rhytides. I Am Acad Dermatol 1998; 39: 547-53.

6. Duke D, Khatri K, Grevelink JM, Anderson RR. Comparative clinical trial of 2 carbon dioxide resurfacing lasers with varying pulse durations. 100 microseconds vs 1 millisecond. Archives of Dermatology 1998; 134: 1240-6.

7. Ross EV, Grossman MC, Duke D, Grevelink JM. Long term results after $\mathrm{CO}_{2}$ laser skin resurfacing: a comparison of scanned and pulsed systems. J Am Acad Dermatol 1997; 37: $709-18$.

8. Jimenez $G$, Spencer JM. Erbium-Yag laser resurfacing of the hands, arms and neck. Dermatologic Surgery 1999; 25:831-4.

9. Trimas SJ, Boudreaux CF, Metz RD. Carbon dioxide laser abrasion. Is it appropriate for all regions of the face? Archives of Facial Plastic Surgery $2000 ; 2: 137-40$.

10. Jordan R, Cummins C, Burls A. Laser resurfacing of the skin for improvement of facial acne scarring: a systematic review of the evidence. $\mathrm{Br}$ J Dermatol 2000; 142: 413-23.

11. Carter S, Seiff S, Choo P, Vallabhanath P. Lower eyelid $\mathrm{CO}_{2}$ laser rejuvenation: a randomized, prospective clinical study. Ophthalmology $2001 ; 108: 437-41$.
12. Brychta l', Jrancu M. Koupil J, Ludikofkik. Our experience with transconjunctival laser assisted lower hepharoplasty. Acta Chir Plast 2000; 42: $118-2.3$.

13. Mele JA, Kulick MI, Lece I). I.aser blepharoplastr: is it sife? Aesthetic Plast Surg 1998; 22: 9-11.

14. Trelles MA, Baker SS, Ting J, Toregard BM. Carbon dioxide laser transconjunctival lower lid blepharoplasty complications. Ann Plast Surg $1996 ; 37: 465-8$.

15. Classberg E, Babapour R, lask (i. Current trends in laser blepharoplasty. Resules of a survey. Dermatol Surg 1995; 21: 1060-3.

16. Morrow D, Morrow I. $\mathrm{CO}_{2}$ laser blepharoplasty. A comparison with cold steel surgery. J Dermatol Surg Oncol 1992; 18:307-13. 


\section{Other medical indications}

\section{Equipment and performance}

Several dermatological disorders are considerable for laser resurfacing. Laser ablation removes the skin abnormality via vaporization. One or more treatment sessions may be required depending on the skin disorder. Local anesthesia is necessary for extensive and deeper skin abnormalities. Smaller areas may be generally treated without anesthesia with the Er:YAG-laser.

\section{Evidence basis}

With some exception, the literature involves case reports or patient series with small numbers. Prospective, randomized comparative investigations are lacking. Treatment with ablative vaporization lasers is generally effective in various disorders (Table 2). ${ }^{1-83}$ The list of other indications is undoubtedly incomplete. It is expected that this list of indications will grow in the future. In principle every hyperplastic, non-inflammatory benign dermatosis may be treated with an ablative laser. The $\mathrm{CO}_{2}$ - and $\mathrm{Er}$ :YAG-lasers are also suitable for hair transplantation and transplantations in vitiligo, where they are used to prepare acceptor sites. ${ }^{84-87}$

\section{Other considerations}

- Caution should be taken when $\mathrm{CO}_{2}$-laser is used for treating sites other then the face. The chances of scar formation of both hyper- or the atrophic type are considerable. If non-facial areas are treated with an ablative laser, then the Er:YAG-laser is preferred because this laser causes less thermal damage. ${ }^{3}$ However, a disadvantage of this laser is a less good hemostasis, especially in well vascularizised skin disorders.

- One should consider the same risks and side effects such as infections, scars and pigment disturbances that may oxeur in cosmetic treatment. Antibiotic prophylaxis (e.g. 250 mg claritromycin twice a day during 1 week) is recommend after treatment of large areas and an antiherpetic drug (valacyclovir 500 mg twice a day during 2 weeks) should be additionally prescribed after treatment in the face.

- The result of the treatment is directly related to the skill and the experience of the consultant. The consultant should be educated and familiar with the histopathology of the skin disorder to be treated and should be competent to deal effectively with the complications that may occur.

- Performing a treatment test spot is desirable for evaluating the results of the treatment (evaluation of the results 2-3 months after a test treatment).

- This form of laser treatment is unsuitable for non-physicians and in such hands may lead to unwanted complications.

\section{Conclusion}

The data in the literature are too summarily to allow any well-founded judgment. Comparative studies are lacking for all other indications. Therefore, a comparison between the $\mathrm{CO}_{2}$-laser or Er:YAG-laser is also not possible. Effective treatment of almost every hyperplastic non-inflammatory disorder has been reported in the limited amount of available literature.

C Literature list ${ }^{1-8.3}$

Level 3 

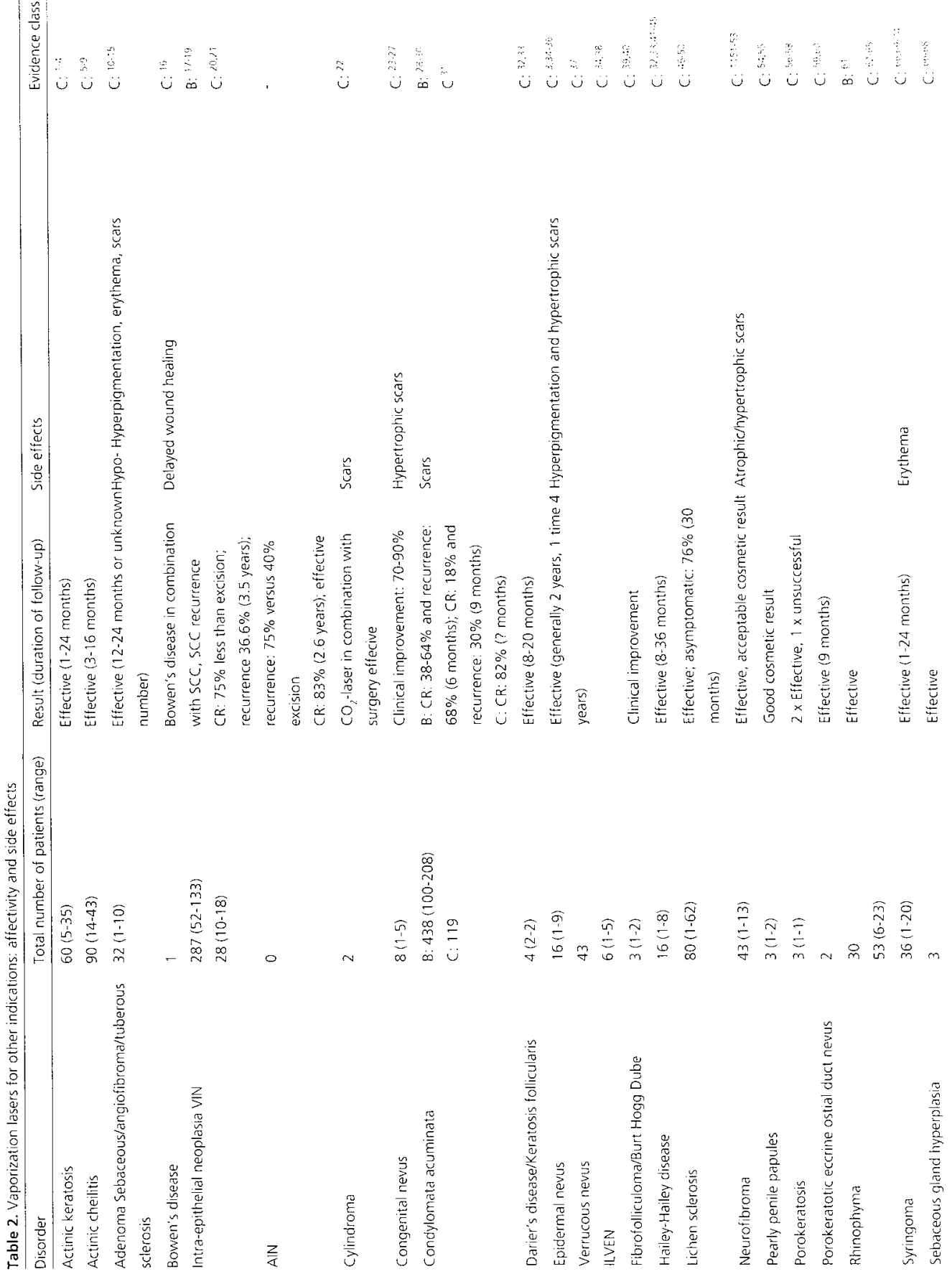

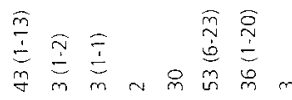

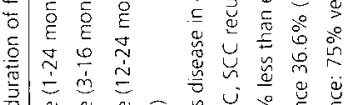

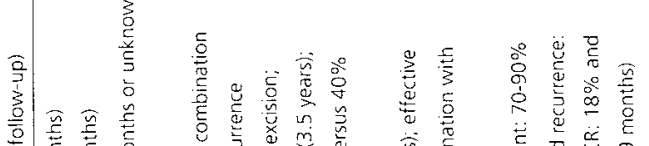

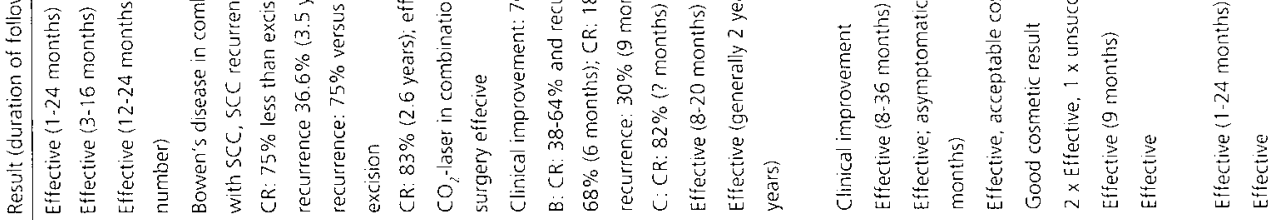



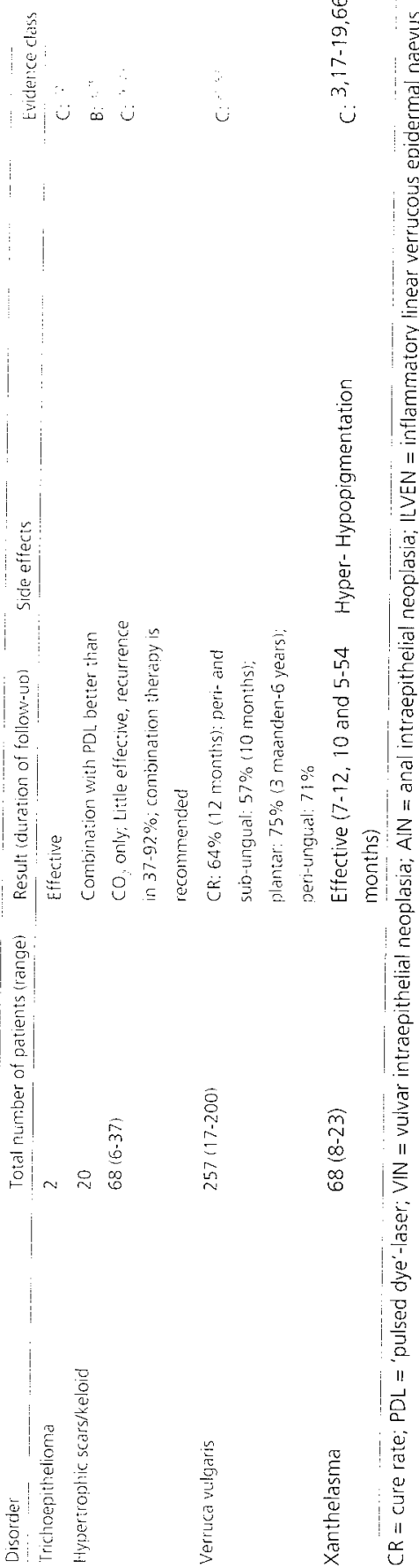

\section{Recommendation}

In principle every hyperplastic, nem-inflammatory benign dermatosis may be treated with an ablative vaporization laser. A treatment test spot is strongly recommended for evaluating the effectivity and the results of the actual treatment. Accurate photographic documentation is very important for an objective evaluation of the treatment results.

\section{References}

1. Jiang $S B$, I.evine VJ, Nehal KS, Baldassano $M$, Kamino H, Ashinoff RA. IEr:YAG laser for the treatment of actinic keratoses. Dermatol Surg 2000; 26: 437-40.

2. Fulton JE, Rahimi AD, Helton P, Dahlberg K, Kelly AG. Disappointing results following resurfacing of facial skin with $\mathrm{CO}_{2}$ lasers for prophylaxis of keratoses and cancers. Dermatol Surg $1999 ; 25: 729-32$.

3. Dmovsek-Olup B, Vedlin B. Usc of Er:YAG laser for benign skin disorders. Lasers Surg Med 1997; 21: 13-9.

4. Trimas SJ, Ellis DA, Metz RD. The carbon dioxide laser. An alternative for the treatment of actinically damaged skin. Dermatol Surg 1997; 23: 88.5-9.

5. Laws RA, Wilde JL, Grabski WJ. Comparison of electrodessication with $\mathrm{CO}_{2}$ laser for the treatment of actinic cheilitis. Dermatol Surg 2000; 26: 349-53.

6. Hohenleutner S, Landthaler M, Hohenleutner U. CO(2)-Laservaporisation der Cheilitis actinica. Hautarzt 1999; 50:562-5.

7. Dufresne RG, Curlin MU. Actinic cheilitis. A treatment review. Dermatol Surg 1997; 23: 1521.

8. Johnson TM, Sebastien TS, Lowe L, Nelson BR. Carbon dioxide laser treatment of actinic cheilitis. Clinicohistopathologic correlation to determine the optimal depth of destruction. J Am Acad Dermatol 1992; 27: 737-40.

9. Zclickson B1), Rocnigk RK. Actinic cheilitis. Treament with the carbon doxide laser. Cancer 1990; 65: 1307-11.

10. Bittencourt RC, Huilgol SC, Seed PT, Calonje I: Markey AC, Barlow RJ. Treatment of angiofibromas with a scanning carbon dioxide laser: a clinicopathologic study with long-term follow-up. J Am Acad Dermatol 200 1; 45: 731 1-5. 
11. Qucrings K, Fuchs D, Kung FE, Hafner J. $\mathrm{CO}_{2}$ Laser-Therapie stigmatisierender Hautveranderungen bei tuberoser Sklerose (BournevillePringle) und bei Neurofibromatose Typ I (von Recklinghausen). Schweiz Med Wochenschr 2000; 130: 1738-43.

12. Song M-G, Park KB, Lee ES. Resurfacing of facial angiofibromas in tuberous sclerosis patients using $\mathrm{CO}_{2}$ laser with flashscanner. Dermatol Surg 1999; 25: 970-3.

13. Ratnam KV. Cutaneous angiofibromas: treatment with the carbon dioxide laser. Ann Acad Med Singapore 1994; 23: 67-8.

14. Boixeda P, SanchezMiralles E, Azana JM, Arrazola JM, Moreno R, Ledo A. CO2, argon, and pulsed dye laser treatment of angiofibromas. J Dermatol Surg Oncol 1994; 20: 808-12.

15. Janniger CK, Goldberg DJ. Angiofibromas in tuberous sclcrosis: comparison of treatment by carbon dioxide and argon laser. J Dermatol Surg Oncol 1990; 16: 317-20.

16. Doberauer C, Voigtmann R. Bowenoide Papulose, Morbus Bowen und Plattenepithelkarzinom von Anus und Vulva bei kongenitaler intestimaler Lymphangiektasie. Dtsch Med Wochenschr 1995; 120: 130-3.

17. Sideri M, Spinaci L, Spolti N, Schettino F. Evaluation of $\mathrm{CO}(2)$ laser excision or vaporization for the treatment of vulvar intraepithelial neoplasia. Gynecol Oncol 1999; 75: 277-81.

18. Kuppers V, Stiller M, Somville T, Bender HG. Risk factors for recurrent VIN. Role of multifocality and grade of disease. J Reprod Med 1997; 42: 140-4.

19. Herod JJ, Shafi MI, Rollason TP, Jordan JA, Luesley DM. Vulvar intraepithelial neoplasia: long term follow up of treated and untreated women. Br J Obstet Gynaecol 1996; 103: 44652.

20. Hoffman MS, Pinelli DM, Finan M, Roberts WS, Fiorica JV, Cavanagh D. Laser vaporization for vulvar intraepithelial neoplasia III. J Reprod Med 1992; 37: 135-7.

21. Helmerhorst TJ, Vaart $\mathrm{CH}$ van der, Dijkhuizen GH, Calame JJ, Kenemans P, Stolk JG. $\mathrm{CO}_{2}-$ laser therapy in patients with vulvar intraepithelial neoplasia. Eur J Obstet Gynecol Reprod Biol 1990; 34: 149-55.

22. Martins C, Bartolo E. Brooke-Spiegler syndrome: treatment of cylindromas with $\mathrm{CO}_{2}$ laser. Dermatol Surg 2000; 26: 877-80.
23. Michel Jl., Cailfetchomel 1. Traitement par

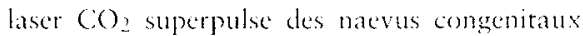
geants. Arch Pediatr 2001; 8: 1185-94.

24. Lawrence CM. Treatment options for giant congenital nacvi. Clin Exp Dermatol 2000); 25: 7-11.

25. Michel JL, Chalencon F, Mazzocchi C, Roux V, Metafiot H, Cambazard F. "Traitement par laser $\mathrm{CO}_{2}$ resurfacing des nacvus congenitaux geants. Ann Dermatol Venereol 2000; 127:661.

26. Kay AR, Kenealy J, Mercer NS. Successful treatment of a giant congenital melanocytic naevus with the high energy pulsed $\mathrm{CO}_{2}$ laser. Br.J Plast Surg 1998; 51: 22-4.

27. Arons MS. Successful treatment of a giant congenital melanocytic naevus with high-energy pulsed $\mathrm{CO}_{2}$ laser. Br J Plast Surg 1998; 51: 570-1.

28. Ferenczy A, Behelak Y, Haber G, Wright TC, Richart RM. Treating vaginal and external anogenital condylomas with electrosurgery vs $\mathrm{CO}_{2}$ laser ablation. J Gynecol Surg 1995; 11: 41-50.

29. Nieminen P, Aho M, Lehtinen M, Vesterinen $E$, Vaheri A, Paavonen J. Treatment of genital HPV infection with carbon dioxide laser and systemic interferon alpha-2b. Sex Transm Dis 1994; 21: 65-9.

30. Randomized placebo-controlled double-blind combined therapy with laser surgery and systemic interferon-alpha $2 \mathrm{a}$ in the treatment of anogenital condylomata acuminatum. The Condylomata International Collaborative Study Group. J Infect Dis 1993; 167: 824-9.

31. Bar-An A, Shilon M, Peyser MR, Ophir J, Brenners. Treatment of male genital condylomatous lesions by carbon dioxide laser after failure of previous nonlaser methods. J Am Acad Dermatol 1991; 24:87-9.

32. Beier C, Kaufmann R. Efficacy of erbium:YAG laser ablation in Darier disease and Hailey-Hailey disease. Arch Dermatol 1999; 135: 423-7.

33. McElroy JA, Melhregan DA, Roenigk RK. Carbon dioxide laser vaporization of recalcitrant symptomatic plaques of Itailey-Hailey disease and Darier's disease. J Am Acad Dermatol 1990; 23: 893-7.

34. Michel JI, Has C, Has V. Resurfacing $\mathrm{CO}_{2}$ laser treatment of linear verrucous epidermal nevus. Fur J Dermatol 2001; 11: 436-9.

35. Losee JE, Serletti JM, Pennino RP. Fpidermal nevus syndrome: a review and case report. Ann Plast Surg 1999; 43: 211-4. 
36. Hohenleutner U, Wlotske U, Kont B, Landthaler M. Carbon dioxide laser therapy of a widespread epidermal nevus. Lasers Surg Med $1995 ; 16: 288-91$.

37. Hohenleutner U, Landthaler M. I.aser therapy of verrucous epidermal nacvi. Clin Exp Dermatol 1993; 18: 124-7.

38. Molin L, Sarhammer G. Perivulvar inflammatory linear verrucous epidermal nevus (II.VEN) treated with $\mathrm{CO}_{2}$ laser. J Cutan Laser Ther $1999 ; 1: 53-6$.

39. Kahle B, Hellwig S, Schul\% T. Multipele Mantekione bei Birt-Hogg-1)ube-Syndrom. Erfolyreiche Therapie mit dem $\mathrm{CO}_{2}$ laser. Hautarzt 2001; 52: 43-6.

40. Giroux JM, Cadotte M, Barolet D, Provost N. Le fibrofolliculome. Traitement par laser a vapeur de cuivre. Ann Dermatol Venereol 1994; 121: 130-3.

41. Kruppa A, Korge B, Lasch J, ScharffetterKochanek K, Hunzelmann N. Successful treatment of Hailey-Hailey disease with a scanned carbon dioxide laser. Acta Derm Venereol 2000; 80: 53-4.

42. Rivollier C, Martin L, Gironet N, Lorctte C. Efficacite du laser $\mathrm{CO}_{2}$ dans la maladie de Hailey-Hailey. A propos d'un cas. Ann Chir Plast Fsthet 1999; 44: 549-51.

43. Christian MM, Moy RL. Treatment of HaileyHailey disease (or benign familial pemphigus) using short pulsed and short dwell time carbon dioxide lasers. Dermatol Surg 1999; 25: 661-3.

44. Touma DJ, Krauss M, Feingold DS, Kaminer MS. Benign familial pemphigus (Hailcy-Hailey disease). Treatment with the pulsed carbon dioxide laser. Dermatol Surg 1998; 24: 1411-4.

45. Kartamaa $M$, Reitamo S. Familial benign chronic pemphigus (Hailey-Hailey disease). Treatment with carbon dioxide laser vaporization. Arch Dermatol 1992; 128: 646-8.

46. Hackenjos K, Schroder W, Schopf E, Vanscheidt W. Therapie des Lichen sclerosus et atrophicus vulvac mit dem $\mathrm{CO}_{2}$-Silk-touch-L aser. Hautarzt 2000; 51: 502-4.

47. Kartamaa M, Reitamo S. Treatment of lichen sclerosus with carbon dioxide laser vaporization. Br J Dermatol 1997; 136: 356-9.

48. Abramov Y, Elchalal U, Abramov D, Coldfarb A, Schenker JG. Surgical treatment of vulvar lichen sclerosus: a review. Obstet Gynecol Surv 1996; 51: 193-9.
49. Windaly T, Ifellsten S. Carben dioxide laser tratment of lichen sclerosits at atrophicus. I Urol 1993; 150: 868-70.

50. Stuart CiC, Nation JC, Malliah VS, Robertson DI. Laser therapy of vulvar lichen sclerosus et atrophicus. (an J Surg 1991; 34: 469-70).

51. Katalinic D). Laser surgery of Neurofibromatosis 1 (NI: 1). J Clin Laser Med Surg 1992; 10: 18.592.

52. Becker IDW. Use of the carbon disxide laser in treating multiple cutaneous neurofibromas. Ann Plast Surg 1991; 26: 582-6.

53. Moreno JC, Mathoret C, I.antieri L, Zeller J, Revuz. J, Wolkenstein P. Carbon dioxide laser for removal of multiple cutaneous neurofibromas. Br J Dermatol 2001; 144: 10968.

54. McKinlay JR, Graham B-S, Ross E-V. The clinical superiority of continuous cxposure versus short-pulsed carbon dioxide laser exposures for the treatment of pearly penile papules. Dermatol Surg 1999; 25: 124-6.

55. Sonnex C, Dockerty WG. Pearly penilc papules: a common cause of concern. Int J STD AIISS 1999; 10: 727-7.

56. McCullough TL, I.esher JL. Porokeratosis of Mibelli: rapid recurrence of a large lesion after carbon dioxide laser treatment. Pediatr Dermatol 1994; 11:267-70.

57. Rabbin PE, Baldwin HE. Treatment of porokeratosis of Mibelli with $\mathrm{CO}_{2}$ laser vaporization versus surgical excision with split-thickness skin graft. A comparison. J Dermatol Surg Oncol 1993; 19: 199-202.

58. Merkle T, Hohenleutner U, Braun-Falco O, Landthaler M. Reticulate porokeratosissuccessful treatment with $\mathrm{CO}_{2}$-laser vaporization. Clin Exp Dermatol 1992; 17: 178-81.

59. Del-Pozo J, Martinez W, Verea MM, YebraPimentel MT, Garcia-Silva J, Fonseca E. Porokeratotic eccrine ostial and dermal duct nacvus: treatment with carbon dioxide laser. $\mathrm{Br}$ J Dermatol 1999; 141: 1144-5.

60. Leung CS, Tang WY, Lam WY, Fung WK, Lo KK. Porokeratotic eccrine ostial and dermal duct naevus with dermatomal trunk involvement: literature revicw and rcport on the efficacy of laser treatment. Br J Dermatol 1998; 138: 684-8.

61. Har-FI G, Shapshay SM, Bohigian RK, Krespi YP, Lucente FE. The treatment of rhinophyma. 'Cold' vs laser techniques. Arch Otolaryngol Head Neck Surg 1993; 119: 628-31. 
62. Orenstein A, Haik J, Tamir J, Winkler E, liand J, Zilinsky $I$, et al. Treatment of rhinophyma with Fr:YAG laser. I asers Surg Med 2001; 29: 230-5.

63. Karim-Ali M, Streitmann MJ. Excision of rhinophyma with the carbon dioxide laser: a ten-year experience. Ann Otol Rhinol Laryngol 1997: 106: 952-5.

64. Gjuric M, Rettinger G. Comparison of carbon dioxide laser and electrosurgery in the treatment of rhinophyma. Rhinology. 1993; 31:37-9.

65. el-Azhary R-A, Roenigk RK, Wang TD. Spectrum of results after treatment of rhinophyma with the carbon dioxide laser. Clin Proc 1991; 66: 899-905

66. Riedel F, Bergler W, Baker Schrcyer A, Stein E, Hormann $k$. Kontrollierte Feinstdermablation im gesichtshereich mit dem Erbiun:YAG-laser. HNO 1999; 47: 101-6.

67. Walther $T$, Holenleutner $U$, Landthaler $M$. Talgdrusenhyperplasien als Nebenwirkung von Cyclosporin A. Behandlung nit dem $\mathrm{CO}_{2}$-laser. Dtsch Med Wochenschr 1998; 123: 798-800.

68. Ashinoff R. Linear nevus sebaceus of Jadassohn treated with the carbon dioxide laser. Pediatr Dermatol 1993; 10: 189-91.

69. Metze D, Wigbels B, Hildebrand A. Familiare Syringome. Eine seltene klinische Variante. Hautarzt 2001; 52: 1045-8.

70. Frazier CC, Camacho AP, Cockerell CJ. The treatment of eruptive syringomas in an African American patient with a combination of trichloroacetic acid and $\mathrm{CO}_{2}$ laser destruction. Dermatol Surg 2001; 27: 489-92.

71. Riedel F, Windberger J, Stein E, Hormann K. Behandlung periokularer Hautveranderungen mit dem Erbium:YAG-Laser. Ophthalmologe 1998; 95: 771-5.

72. Sajben FP, Ross EV. The use of the $1.0 \mathrm{~mm}$ handpiece in high energy, pulsed $\mathrm{CO}_{2}$ laser destruction of facial adnexal tumors. Dermatol Surg 1999; 25: 41-4.

73. Wang JI, Roenigk HH. Treatment of multiple facial syringomas with the carbon dioxide (CO2) laser. Dermatol Surg 1999; 25: 136-9.

74. Kang WH, Kim NS, Kim YB, Shim WC. A new treatment for syringoma. Combination of carbon dioxide laser and trichloroacetic acid. Dermatol Surg 1998; 24: 1370-4.

75. Alster TS, Lewis AB, Rosenbach A. Laser scar revision: comparison of $\mathrm{CO}_{2}$ laser vaporization with and without simulaneous pulsed dye laser treatment. Dermatol Surg 1998; 24: 1299-302.
76. Norris J. The effect of Carbon dioxide laser surgery on the recurrence of kelesids. Plant Reconstr Surg 1991; 87:44-53.

77. Stuctior lid, Shaw (iY. An approach to management of keloids. Arch Otolarymgol Head Neck Surg 1992; $118: 63-7$.

78. Berman B, Bicley IIC. Adjunct therapies to surgical management of keloids. Dermatol Surg $1996 ; 22: 126-30$.

79. English RS, Shenefelt PD. Keloids and hyperteophic scars. Dermatol Surg 1999; 25: 631-8.

80. Sloan K, Haberman H, Iynde CW. Carbon dioxide laser-treatment of resistant verrucac vulgaris: retrospective analysis. J Cutan Med Surg 1998; 2: 142-5.

81. Lim JT, Goh CI.. Carbon dioxide laser treatment of periungual and subungual viral warts. Australas J Dematol 1992; 33: 87-91.

82. Mancuso JF, Abramow SP, Dimichino BR, Landsman MJ. Carbon dioxide laser management of plantar verruca: a 6-year follow-lp survey. J Foot Surg 1991; 30: 238-43.

83. Street ML, Roenigk RK. Recalcitrant periungual verrucae: the role of carbon dioxide laser vaporization. J Am Acad Dermatol 1990; 23: 115-20.

84. Sadick NS, Shea CR, Nicholson J, Gat $M$, Lunicuski S, Prieto VG. A comparative clinical and histologic study of hair transplantation using Er:YAG, Er:YAG/CO2, and standard punch techiques. Dermatol Surg 2001: 27 : $807-12$.

85. Chu EA, Rabinov CR, Wong BJ, Krugman ME. Laser-assisted hair transplantation: histologic comparison between $\mathrm{CO}_{2}$ and $\mathrm{H}_{\mathrm{O}} \mathrm{YAC}$ : lasers. Dermatol Surg 2001; 27: 335-42.

86. Oh CK, Cha JII, Lim JY, Jo JH, Kim SJ, Jang IS, et al. Treatment of vitiligo with suction epidermal grafting by the use of an ultrapulse $\mathrm{CO}_{2}$ laser with computerized pattern generator. Dermatol Surg 2001: 27: 565-8.

87. Sachdev M, Faad S/Shankar, Krupta DS. Pulsed erbium: YAG laser-assisted autologous epidermal punch grafting in vitiligo. Int J Dermatol 2000; 39: $868-71$. 


\section{CHAPTER 2}

\section{Laser resurfacing of actinic keratoses}

Quaedvlieg PJ, Ostertag JU, de Kort JM, Thissen MR, Krekels GA.

Evidence based treatments of Actinic keratoses: a systematic review of efficacy

J Dermatolog Treat. Accepted.

Ostertag JU, Quaedvlieg PJ, Neumann HA, Krekels GA.

Recurrence rates and long-term follow-up after laser resurfacing as a treatment for widespread actinic keratoses on the face and scalp.

Dermatol Surg. 2006 Feb;32(2):267-73.

Ostertag JU, Quaedvlieg PJ, vd Geer S, Nelemans P, Christianen ME, Neumann HA, Krekels GA.

A clinical comparison and long-term follow up of topical 5-fluorouracil vs laser resurfacing in the treatment of actinic keratoses.

Lasers Surg Med. Accepted. 
38 CHAPTER 2 


\title{
Evidence based treatments of actinic keratoses: a systematic review of efficacy
}

\author{
PATRICIA J.F. QUAEDVLIEG, JUDITH U. OSTERTAG, JACKLYN M.L. DE KORT, \\ MONIQUE R.T.M. THISSEN, GERTRUUD A.M. KREKELS
}

OBJECTIVES. To assess the literature for RCTs examining the effectiveness of the present treatment modalities of actinic keratosis (AK). METHODS. The electronic databases of Medline, Pubmed, Embase and Cochrane were used as information sources. The literature from July 1986 to July 2005 were divided according to study design, intervention (treatment modality of AK), effectiveness, recurrence, clearance rates, number of patients, number of lesions and duration of follow-up. There were no language restrictions. Only studies identified as randomised controlled trials (RCT) pertaining to treatment modalities of actinic keratosis, were included. Validity assessment and data abstraction was done by 2 authors, who independently examined the full text of all studies. Studies were assessed as high quality if randomisation and allocation were clear, analysis was done by intention to treat, follow-up was $>6$ months and clearance rates were included. RESULTS. One thousand onehundred sixty five articles were identified. Studies ( $\mathrm{N}=564)$ only describing treatment modalities and those pertaining to epidemiology or molecular biology of AK were excluded. Also non-RCT studies and those including transplant patients were excluded ( $N=575$ ). Therefore only 27 studies fulfilled the inclusion criteria. CONCLUSIONS. There is a paucity of well designed randomized controlled trials studying the effectiveness of treatment modalities for AK. From those studies, we deduce that 5 fluorouracil (5-FU) is the most-investigated therapy, RCTs for 5-FU suggest excellent efficacy. Newer therapies like PDT and the topical immune respons modifier imiquimod are becoming more widely studied. More RCTs are needed, and head -to-head studies would be helpful to delineate the best treatment for AK.

\section{Introduction}

Actinic keratosis (AK) is an increasing general health problem due to increased voluntary exposure to sunlight and lifestyle changes during the past 50 years. Also the growth of the elderly population contributes to the increase.

AKs are excecdingly common single or multiple intraepidermal lesions that occur primarily on sun-exposed skin surfaces and can subsequently develop into squamous cell carcinoma (SCC). ${ }^{1-13}$ In addition, transplant recipients have an increased propensity to develop multiple AK. ${ }^{14}$
The rationale for treating precanccrous lesions is to minimize the progression into invasive SCC. The evolution of $\mathrm{AK}$ into squamous cell carcinoma is a result of a complex sequence of events initiated by exposure to ultraviolet (UV) light. ${ }^{2}$

The rates of malignant transformation from AK to squamous cell carcinoma range from $0.025 \%$ to $20 \%$ per year for an individual lesion. Furthermore, other studies suggest that up to $60 \%$ of SCCS begin as AK. ${ }^{11,13}$

Currently, numcrous treatment options exist for AK with variable clinical cure rates. Some treatments are basically used for indi- 
vidual AKs and others for large treatment areas of so-called "ficld canceration". The most common treatment options are cryotherapy with liquid nitrogen, topical fluorouracil and curettage. Recently new treatment modalities have become available including the immune modulator imiquimod, photodynamic therapy, and topical $3 \%$ diclofenac in $2.5 \%$ hyaluronic acid gel. 15,16 Less commonly used therapies are dermabrasion, excision, chemical peel, laser ablation and topical isotretinoin. These treatments are used as monotherapy or simultaneously.

Although many different treatments are used for AK, there is a shortage of studies comparing treatment modalities in a randomised, prospective way. For this reason, we systcmatically reviewed the RCTs studying treatment of AK.

\section{Methods}

\section{Literature search}

We systematically reviewed all published litcrature listed in Medline, Pubmed, Embase and Cochrane electronic databases from July 1986 untill July 2005 using treatment and one of the following keywords: actinic keratosis (es), solar keratosis (es), senile keratosis (es), actinic cheilitis, premalignant skin disease or treatment.

\section{Selection and validity assessment}

All abstracts were analysed and encoded in a database program according to year of publication, 1st author, title, no restrictions to language, abstract, usefulness of abstracts, treatment options, study design, population, number of lesions and patients. Studies only describing treatment modalities or combination therapies and others (like etiology, epidemiology or molccular biology of AK) were excluded first. Studies with a design other than RCT and those with trans- plant recipients were excluded as well. All papers identified as possible randomised controlled trials, which have investigated treatment options for $A K$ and mentioned effectiveness, clearance and or recurrence rates number of patients and/or lesions and duration of follow-up were included. The studies were divided in 9 categories; 1) cryotherapy, 2) curettage+ coagulation, 3) 5-fluorouracil, 4) laser ablation, 5) photodynamic therapy, 6) chemical peel, 7) imiquimod, 8) topical retinoids, 9) others (excision, dermabrasion, topical diclofenac in hyaluronic acid difluororomethylornithine (DFMO), masoprocol, colchicines)

\section{Data extraction}

Two authors independently examined the full text of studies identified as possible RCT and recorded their methodological quality.

\section{Study characteristics and quantitative data synthesis}

Studies were assessed as high quality if randomisation and allocation were clear, and analysis was done by intention to treat (to get higher quality of the statistical analysis), and the follow-up was longer as 6 months (based on clinical experience) and clcarance and/or recurrence rates had to be mentioned. Studies that were powered to show significance were included. Studies were considered of being intermediate quality if it was not. In table 1 the stratification of the papers looked at by cvidence level is mentioned. A2 studies are randomized double-blinded controlled trials with sufficient numbers and quality. $B$ studies are randomzed controlled trials of moderate quality or insufficient number, or non randomized comparative studies. The outcome data described in the results as "response rates" (RR) includes the different terms used in the studies which included: complete response and total clearance and were 


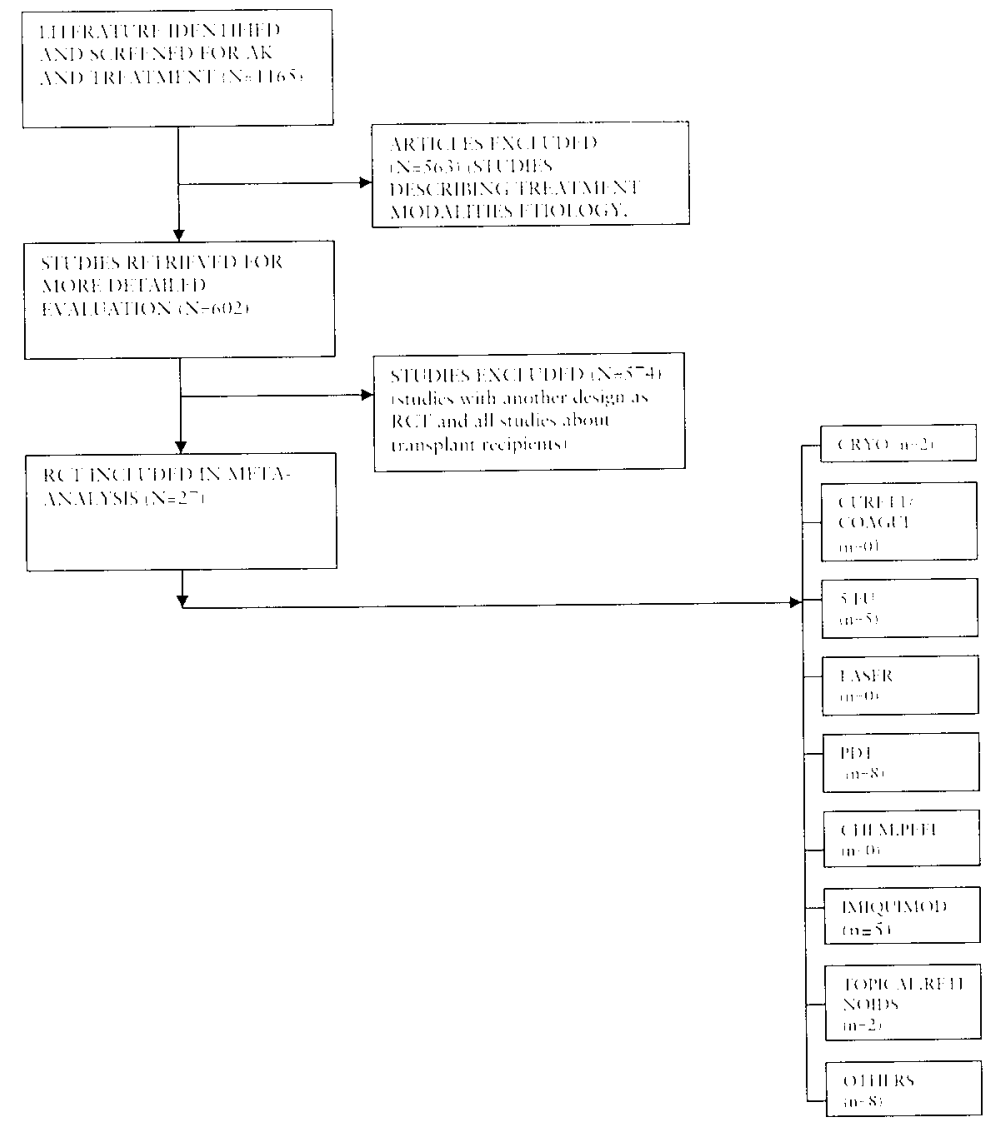

Fig 1. Flowchart of all studies.

defined as the percentage reduction of pretreatment lesion area and rated as completely cleared with no evidence of adherent scale on the surface of the treated skin. Lesion response, reduction in number of $\mathrm{AK}$, and partial response rates (= 50\%-75\% reduction in lesion size) were not always defined in the studies and therefore we mention them as RR*. For more specific details see table 1 . We did not do a statistical analysis because the different outcome measures used in the results were not comparable.

\section{Results}

\section{Trial Flow}

We identified 1165 articles on actinic kcratosis (Figure 1). We excluded 563 studies that did not meet inclusion criteria treatment modalities. Six hundred and two $(n=602)$ articles were included for further analysis. Of these 602 studies only 27 were identified as possible RCT of treatment for AK. Two studies were available only in abstract form. Of the remaining 27 studies, only 9 studies were powered to show significance, $22,29,31,32,34,35,374,3,44 \quad 12$ B studies $17,18,20-23,25-28,42$ and 15 A2 studies 29$31,3,3-41,43-44,46$ were classified. 


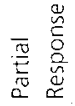

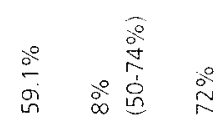

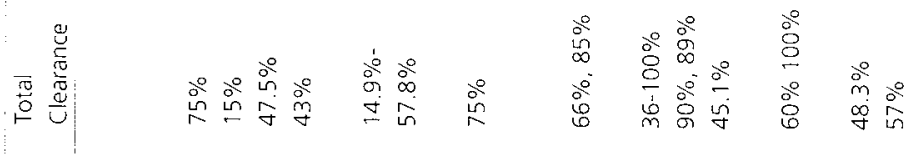

.

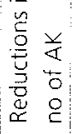

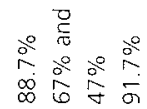

$\underset{\substack{\infty \\ m}}{\stackrel{\circ}{\infty}}$

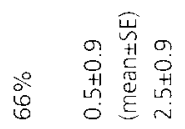

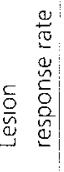

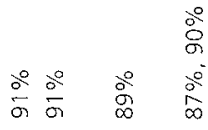

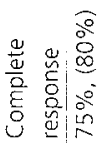

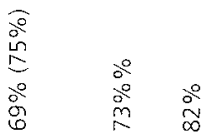

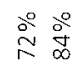

$\stackrel{\circ}{\stackrel{2}{2}}$

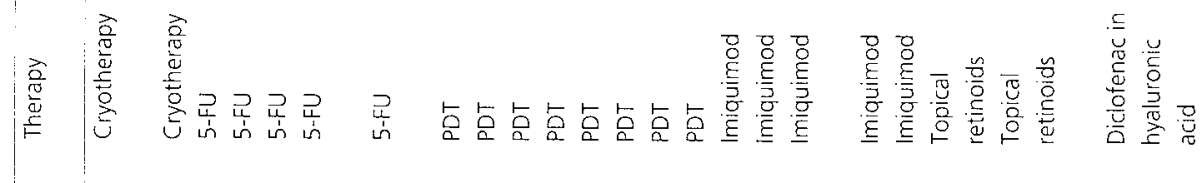

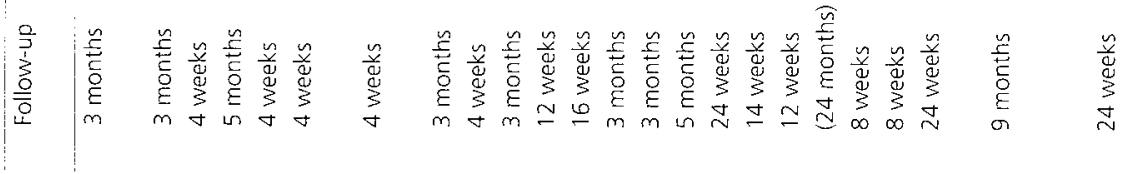

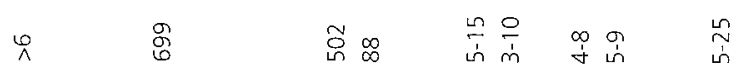

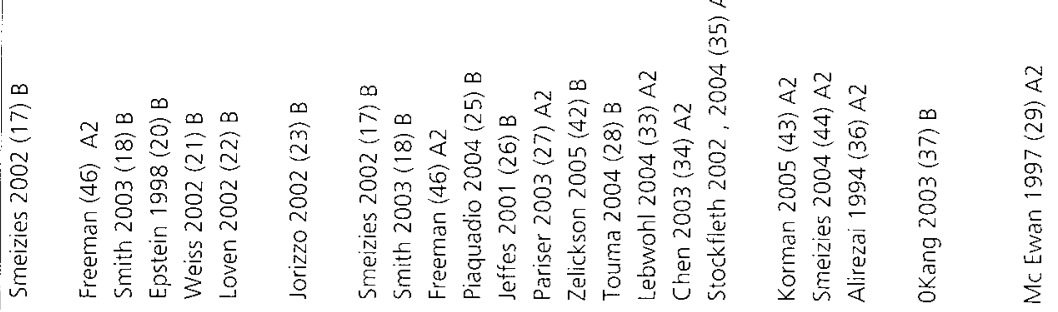




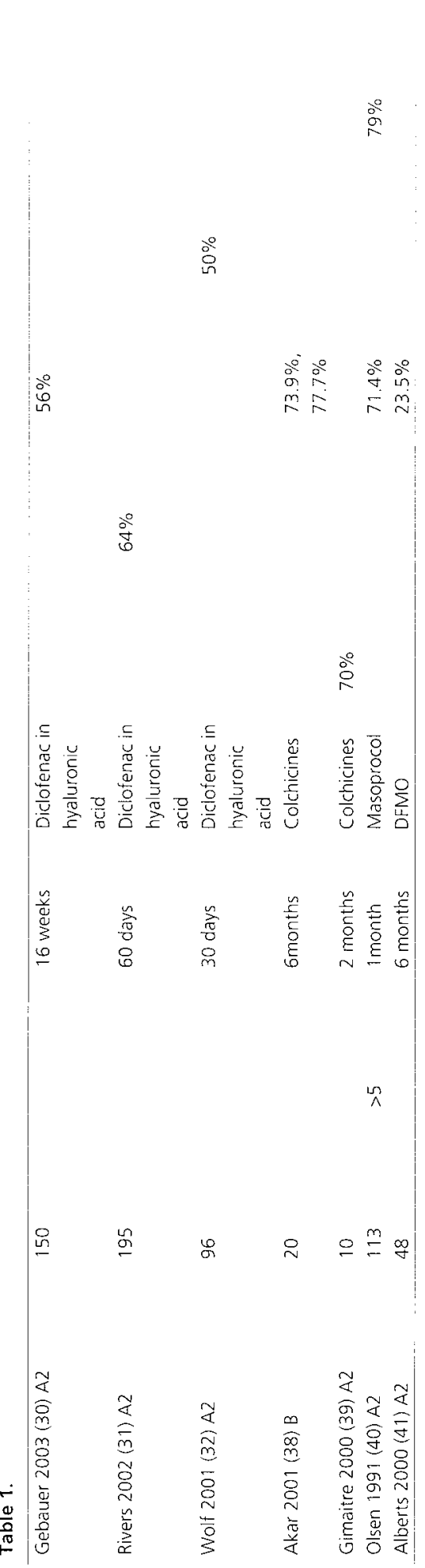

\section{Study characteristics}

Cryotherapy

Two RC.T studies ${ }^{17,46}$ of cryotherapy were found. One study compared cryotherapy of 193 patients, who had a total of $699 \mathrm{AK}$ with methylaminolacvulinate (MAL) PDT. Outcome measures were response rates, cosmetic outcome, and patient satisfaction. Overall complete response rates after 3 months were $69 \%$ for MAL-PDT and $75 \%$ for cryotherapy. These results were not statistically significant. Both treatments, were more effective for thin lesions (cryotherapy; RR: $75-80 \%$, follow-up: 3 months). The other study compared the lesion response, cosmetic outcome, patient satisfaction and tolerability of PDT, using topical methyl aminolevulinate (Metvix), to cryotherapy in 204 patients with AK. Lesion response was assessed clinically after 3 months. The lesion response rate was $91 \%$ in the methyl aminolevulinate PDT group, $68 \%$ in the cryotherapy group and $30 \%$ in the placebo PDT group. (RR* : 68\%, follow-up: 3 months)

\section{Curettage and Coagulation}

There were no randomised controlled studies about curettage and coagulation that mentioned recurrence and/or clearance rates.

\section{Topical 5-Fluorouracil}

We identified 5 RCT of 5-FU. One study compared 5-FU versus aminolevulinic acid (ALA) PDT ${ }^{18}$. The other 4 studies compared $0.5 \%$ FU with vehicle, ${ }^{20,23} 0.5 \%$ FU versus $5 \%$ FU [22] and $0.5 \%$ FU alone [21]. Follow-up varied from 4 weeks to 1 year.

Smith 18 compared the efficacy and tolerability ALA-PDT versus topical 5-FU in 36 patients. Treatment with topical 5-FU was as effective as ALA-PDT in clearing AK. Topical 5-FU was more effective than ALA- 
PDT with laser light ${ }^{18}$ (RR: $50-75 \%$ follow up: 4 weeks).

Of the other 4 studies intermittent pulse therapy with topical 5-FU (RR: 15\%, follow-up: 5 months,,$^{20}$ once daily administration of $0.5 \%$ FU cream for 1,2 or 4 wecks (RR*" $88.7 \%$, follow-up: 4 weeks), ${ }^{21} \mathrm{com}-$ parison of $0.5 \%$ and $5 \%$ FU (RR: $43 \%$, follow-up: 4 weeks), ${ }^{22}$ and 5 FU (RR: $57.8 \%$, follow-up; 4 wceks) ${ }^{2.3}$ showed statistically significant better results compared to vehicle .

\section{Laser Ablation}

No RCT about laser ablation was found. One pilot study reported about the clinical and histological effectiveness of erbium YAG laser in 5 patients with multiple facial lesions. At 3 months postoperative, there were a $93 \%$ decrease in the number of clinically visible AKs. The limitations of this study were the small number of patients and a short period of follow-up (RR: $93 \%$, follow-up: 3 months). ${ }^{24}$

\section{Photodynamic therapy}

Eight RCT were found examining PDT. The results of two RCTs comparing cryotherapy to MAL-PDT ${ }^{17,46}$ and $^{18}$ were mentioned before; the cosmetic o a study comparing ALA-PDT versus 5-FU utcome was significantly better in the PDT group compared to cryotherapy. ${ }^{17,46}$ Three studies which compared ALA-PDT versus vehicle showed all significant better results for treatment with ALA PDT (RR: 73\%, follow-up: 12 weeks), ${ }^{2.5}$ (RR: $85 \%$, follow-up: 16 wecks, 26 (RR: 82\%, follow-up: 3 months). ${ }^{27}$ Touma evaluated ALA-PDT with different incubation-times in 18 patients with a 5 months follow-up. At 5 months, the overall clearance rates were $87 \%$ and $90 \%$ with target AKs in the 1-, and 2- hour incubation groups. For total AKs, the overall clcarance for the 1- and 2-hour incubation times was $90 \%$ and $89 \%$, respectively. ${ }^{28}$ Zelickson $^{42}$ evaluated a novel light patch formulated for blue light delivery and topical activation of Al.A during PIT in 10 persons with 88 lesions. Half of the area was treated and the other half was left uncovered (RR: 36$100 \%$, follow-up 3 months).

\section{Chemical peeling}

There are no RCT about chemical pecl. In one non-RCT study ${ }^{19}$ Jessner's solution and $35 \%$ TCA was compared with $5 \%$ FU in a left to right fashion. Jessner's solution was not statistically significant better in reducing the number of AK (RR: 75\%, follow-up: 12 months).

\section{Imiquimod}

There are 5 studies, which compared the efficacy of $5 \%$ imiquimod cream with vehicle in the treatment of AK lesions on the face and balding scalp. In all these studies imiquimod was statistically better than the vehicle in comparing clearance rates and reduction of $A K$ lesions after treatment (RR: 45.1\%, follow-up: 24 weeks), ${ }^{33}$ ( RR: $72 \%$, follow-up: 14 weeks), ${ }^{34}$ (RR:100\%, followup: 12 weeks $)^{3.5}$ (RR*: 50-75\%, follow-up: 24 months 4.5 (RR: 48.3\%, follow-up: 8 weeks), ${ }^{43}$ (RR*:72\%, follow-up 8 weeks). ${ }^{44}$ See table 1.

\section{Topical retinoids}

Two studies were identified. Alirezai evaluated isotrctinoin $0.1 \%$ cream versus vehicle in 100 patients. At 24 weeks the reduction in number of $\mathrm{AK}$ was significantly greater for patients treated with isotretinoin $66 \%$ of paticnts had a reduction $>30 \%$ than with placebo $45 \%$ of patients with a reduction $>30 \%$ This difference was statistically significant. (RR*: $66 \%$, follow-up: 24 weeks for isotretinoin). ${ }^{36}$ Kang studied the efficacy of $0.1 \%$ or $0.3 \%$ adapalene gel in 90 patients over a 9 -months period. With $0.1 \%$ and $0.3 \%$ adapalene gel, the mean number 
of $\mathrm{AK}$ was reduced by $0.5 \pm 0.9$ (mean \pm SE) and $2.5 \pm 0.9$ respectively. Overall, $62 \%$ $(\mathrm{P}<0.01)$ and $66 \%(\mathrm{P}<0.01)$ of paticnts in the adapalene gel $0.1 \%$ and $0.3 \%$ groups, were considered to either have cleared or have marked, or moderate improvement in AK. This is compared to only $34 \%$ of the patients treated with vehicle. This difference was not statistically significant. ${ }^{37}$ Thirty four percent clearance in the vehicle group could be explained by the fact that 20 to $25 \%$ of all AK regress over the course of a year or the disappearance of the hyperkeratosis by softening due to the gel.

\section{Others}

Four topical $3 \%$ diclofenac in $2.5 \%$ hyaluronic acid, $29-322$ topical colchicines $(1.0$ and $0.5 \%)$ studies, 38,39 one masoprocol ${ }^{40}$ and 1 about difluoromethylornithine (DFMO) ${ }^{41}$ were identified. The results are detailed in Table 1.

\section{Discussion}

Despite the enormous number ( $N=1165)$ of AK treatment studies, few $(\mathrm{N}=27)$ quality RCT exist. Moreover, even less studies have active comparators. We realize that the choice of the number of patients should be more based on a both relevant statistical and clinical hypothesis and consequently the possible exploration to the general population.

In this review follow-up ranged from 28 days to a maximum of one year. The number of patients varies from 5 to 492 .

New therapies are often compared with vehicle and therefore response rates of the active treatments are mostly favourable and achieve significance. It may be more useful to compare these new therapies with the active treatment options like 5-FU, cryotherapy and curettage to sec of they are equally or even more effective. Also cost effectiveness can be compared.
We found only 3 comparative studies, $17,18,4$ to and in only 1 study was one treatment found statistically significant better. ${ }^{46}$

Of the 3 most commonly used treatment options, 5-FU has been investigated most. Reductions in number of AK from $47.5 \%$ to $91.7 \%$ were described and total clearance rates varied from $15 \%$ to $57.8 \%$. Advantages of 5 -FU include coverage of large areas of skin and the ability to target incipient lesions. Disadvantages include the length of treatment, significant inflammatory reactions, and concerns that the drug may not reach deep and hyperkeratotic lesions.

A general trend in the treatment of $A K$ is seen with new therapies like PDT and the topical immune response modifier imiquimod. Studies comparing PDT with vehicle and those which compared PDT with the standard therapies suggested the excellent efficacy of PDT. Overall clearance rates of $90 \%, 93 \%$ decrease in number AKs and complete response of $73 \%$ was found. The PDT studies are varied and thus difficult to compare. The revicwed studies with PDT have a total follow-up varying from 28 days to 5 months and the number of patients varied greatly. Although pain is still present, treatment with PDT may be more paticntfriendly, due to a shorter duration. Imiquimod was effective (RR and $R R^{*}:$ 45$100 \%$ in large groups of paticnts. Benefits include treatment of the entire thickness of the $A K$ lesion rather than the superficial portion of the lesion and the potential for the creation of immune memory to combat future lesions. Disadvantages arc brisk inflammatory reactions and the length of treatment. More RCT of PIT and imiquimod are necessary with large groups of patients and longer follow up. Some studies are difficult to compare with cach other because some use ambiguous terms like complete response rates, partial response rates, reduction of number $\mathrm{AK}$, clearance rates and improvement inconsequently. 
Therefore $95 \%$ confidence intervals of the RR should be calculated.

\section{Conclusion}

Various treatment options are used to treat actinic keratoses. Clinicians may takc numerous factors into consideration when choosing the most appropriate treatment for a patient and they rely on clinical data to guide them. These include the anatomical location, size and extent of the lesion(s), changes in lesion growth pattern, previous treatment, medical stability of the paticnt and patient preference of therapeutic options and the effectiveness of treatment. There is a need for randomised comparative prospective studies without the use of ambiguous terms (total clearance, partial response rates etc), but rather clearly defined end points.

\section{References}

1. Lebwohl M. Actinic keratosis: epidemiology and progression to squamous cell carcinoma. $\mathrm{Br}$ I Dermatol. 2003 Nov; 149 Suppl 66:31-3.| Embase, Pubmed]

2. Babilas $P$, Landthaler $M$, Szeimies RM. Hautarzt. 2003 Jun; 54(6):551-60; quiz 561-2.| Embase, Pubmed]

3. Green A, Beardmore G, Hart V, Leslie D, Marks $R$, Staines D.

Skin cancer in a Queensland population. J. Am. Acad Dermatol. 1988 Dec; 19(6): 1045-52.

4. Frost CA, Green AC. Epidemiology of solar keratoses. Br J Dermatol. 1994 Oct; 131(4): 455-64.

5. Marks R. Solar keratoses. Br J Dermatol. 1990 apr. ;122 suppl. 35:49-54.

6. Sober AJ, Burstein JM. Precursors to skin cancer. Cancer. 1995 Jan 15; 75 (2 Suppl): 645 50 .

7. Lober BA, Lober CW. Actinic keratosis is squanous cell carcinoma. South Med J. 2000 Jul; $93(7): 650-5$.

8. Schwartz RA. The actinic keratosis. A perspective and update. Dermatol Surg. 1997 Nov; 23(11): 1009-19; quiz. 1020-1.
9. Hacker SM, Howers IT. Squamous cell carcinoma of the skin. Will heightened awarenesh of risk factors slow its increase? Postgrad Med. 1993 Jun; 9.3(8): 11.5-21, 12.5-6.

10. Boutli F, Ziogra M, Delli F, Mavroudis (s, Chaidemenos (;, Mourellou (). Promising treatment of actinic keratoses with iniguimod $5 \%$. Int J of Immunotherapy. 2002; 18(3-4)

11. Ortonne JP. From actinic keratosis to squamous cell carcinoma. I3r J Dermatology. $2002 \mathrm{Apr}$; 146 Suppl 61:20-3. [Fmbase, Pubmed]

12. Cockerell CJ. Pathology and pathobiology of the actinic (solar) keratosis. Br J Dermatol. 2003 Nov; 149 Suppl 66:34-6.[ Embase, Pubmed]

13. Marks R, Rennie G, Selwood TS. Malignant transformation of solar keratoses to squamous cell carcinoma. Lancet. 1988 Apr 9; 1(8589):795-7. [Pubmed]

14. G.Dragieva, B.M.Prinz, J.Hafner, R.Dumner, G.Burg, U.Binswanger and W.Kempf. A randomized controlled clinical trial of topical photodynamic therapy with methyl aminolaevulinate in the treatment of actinic keratoses in transplant recipients. Br. J. of Dermatol. 2004; 151: 196-200.

15. Fu W, Cockerell CJ. The actinic (solar) keratosis: a 21 st-century perspective. Arch Dermatol. 2003 Jan; 139(1): 66-70. |Embase, Pubmed]

16. Lang PG Jr. Management of actinic keratoses. Compr Ther. 2003 Summer-Fall; 29(2-3): 10814. [Embase, Pubmed]

17. S7cimies RM, Karrer S, radakovic-Fijan S, Tanew A. Photodynamic therapy using topical methyl 5-aminolevulinate compared with cryotherapy for actinic keratosis: A prospective, randomised study. J Am Acad Dermatol. 2002:47:2: 258-262

18. Smith S, Piacquadio D, Morhenn V, Atkin D, Fitzpatrick R. Short incubation PDT versus 5 $\mathrm{FU}$ in treating actinic keratoses. J Drugs dermatol. 2003 Dec;2 (6): 629-35

19. Lawrence $N$, Cox SE, Cockerell CJ, Freeman $\mathrm{RG}$, Cruz PD. A comparison of the efficacy and safety of Jessner's Solution and $35 \%$ trichloroacetic acid vs $5 \%$ fluorouracil in the treatment of widespread actinic keratoses. Arch Dermatol. 1995 Febr; 131: 176-81

20. Epstcin E: Docs intermittent 'pulse' topical 5fluorouracil therapy allows destruction of actinic keratoses. J Am Acad Dermatol. 1998 Jan; $38(1): 77-80$ 
21. Weiss J, Menter A, Hevia O et all. Effective treatment of acrinic kcratosis with $0.5 \%$ fluorouncil cream for 1,2 , or 4 weeks. Cutis. 2002: August. 70: 22-9

22. I.oven K. Stein L, Furst K, Levy S. Evaluation of the efficacy and tolerability of $0.5 \%$ fluorouracil cream and $5 \%$ fluorouracil cream applied to each side of the face in patients with actinic keratoses. Clinical Therapeutics. 2002: $24: 6$

23. Jorizzo J, Stewart D, Bucko A, Davis SA et all. Randomised trial evaluating a new $0.5 \%$ fluorouracil formulation denonstrates efficacy after 1-, 2-, or 4-weeks treatment in patients with actinic keratoses Cutis 2002 70: 335-339.

24. Jiang $S B$, Levine VJ, Hehal KS, Baldassano $M$, Kamino $H$ and Ashinoff RA. Er: YAG Laser for the treatment of actinic keratoses. Dermatol Surgery 2000; 26:5:437-440.

25. Piacquadio DJ, Chen DM, Fraber $H F$ et all. Photodynamic therapy with aminolevulinic acid topical solution and visible blue light in the treatment of multiple actinic keratoses of the face and scalp. Arch.Dermatol. 2004: 140:4146.

26. Jeffes EW, McCullough Jl, Weinstein GD, Kaplan R, Glazer SD, Taylor JR. Photodynamic therapy of actinic keratoses with topical aminolevulinic acid hydrochloride and fluorescent blue light. J Am Acad Dermatol. 2001; 45; 96-104

27. Pariser DM, Lowe NJ, Stewart DM, Jarratt MT. Photodynamic therapy with topical methyl aminolevulinate for actinic keratosis: Results of a prospective randomized multicenter trial. J Am Acad Dermatol. 2003; 48: 227-32.

28. Touma D, Yaar M, hitehead S, Konnikov N, Gilchrest BA. A trial of short incubation, broadarea photodynamic therapy for facial actinic keratoses and diffuse photodamage. Arch Dermatol. 2004; 140; 33-40.

29. McEwan LE, Smith JG. Topical diclofenad hyaluronic acid gel in the treatment of solar keratoses. Australasian Journal of Dermatology 1997; 38,187-189

30. Gebauer K, Brown P, Varigos G. Topical diclofenac in hyaluronan gel for the treatment of solar keratoses. Australasian Journal of Dermatology 2003; 44: 40-43
31. Rivers JK, Arleted, Shear N. (iucuther I., Carcy W, Poulin Y. Topical treatment of actinic keratoses with $3.0 \%$ diclofenac in $2.5 \%$ hyaluronan gel. Br J of Dermatol. 20(02; 146; 94-100

32. Wolf JE, Taylor JR, Tschen E, Kang S. Topical $3.0 \%$ diclofenac in $2.5 \%$ hyaluronan gel in the gel treatment of actinic keratoses. Int. J. of Dermatol. 2001; 40: 709-713

33. Lebwohl $M$, Dinehart $S$, Whithing et all. Imiquimod $5 \%$ cream for the tratment of actinic keratosis: results from two phase III, randomized, double blind, parallel sroup, vehicle- controlled trials. J Am Acad Dermatol. 2004; 50: 714-721

34. Chen K, Yap L.M, Marks R, Shumack Short course therapy with imiquimod $5 \%$ cream for solar keratoses: A randomized controlled trial Australasian Journal of Dermatology 2003; 44; 250-255

35. Stockfleth E, Meyer T, Benninghoff B, et all. A randomised, double blind, vehicle controlled study to asses $5 \%$ imiquimod cream for the treatment of multiple actinic keratoses. Arch Dermatol. 2002; 138: 1498-1502

36. Alirezai M, Dupuy P, Amblard P, Kalis B et all. Clinical evaluation of topical isotretinoin in the treatment of actinic kcratoses. J Am Acad Dermatol. 1994; $30: 447-51$

37. Kang $S$, Goldfarb, Weiss JS et all. Assesment of adapalene gel for the treatment of actinic keratoses and lentigenes: A randomised controlled trial J Am Acad Dermatol. 2003; 49: 83-90

38. Akar A, Tastan HB, Erbil H, Arca F, Kurumlu $Z$, Gur AR. Efficay and safety assessment of $0.5 \%$ and $1 \%$ colchicines cream in the treatment of actinic keratoses. Journal of dermatologic treatment 2001; 12:199-203

39. Gimaitre $M$, Etienne A, Fathi M, Piletta PA, Saurat JH. Topical colchicines therapy for actinic keratoses Dematology 2000; 200: 346348

40. Olsen FA Abernethy ML, Kulp-Shorten C, et all. A double blind, vehicle controlled study evaluating masoprocol cream in the treatment of actinic keratoses on the head and neck. J Am Acad Dermatol. 1991; 31: 295-7.

41. Alberts DS, Dorr RT, Einspahr JG et all. Chemoprevention of human actinic keratoses by topical 2-(Difluoromethyl)-dl-ornithine. Cancer Fpimiology Biomarkers and Prevention 2000; 9: $1281-1286$ 


\section{CHAPTER 2}

42. Zelickson B.Counters J. Coles C and Solim M. light Patch:Preliminary Report of a novel form of blue light delivery for the treatment of actinic keratosis. Dermatol Surg. 2005; 31:37.5-378

43. Koman N, Moy R, Ling M, Matheson R, et all. Dosing with $5 \%$ Imiquimod cream 3 times per week for the treatment of actinic keratosis. Results of Two phase 3, Randomized, Doubleblind, Parallel-Group, Vehicle-Controlled Trials. Arch Dermatol 2005; 141:467-473

44. Smeizies RM, Gerritsen MJ, Gupta G et all. 2004 Imiquimod $5 \%$ cream for the treatment of actinic keratosis: results from a phase III, randomised, double blind, vehicle controlled, clinical trial with histology. J Am Acad Dermatol 2004 Oct; $51: 547-555$

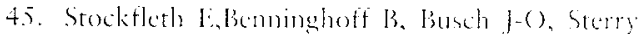
W. Ioser corn clearance of multiple actinic keratosis after topical treatment with imiquinod $(5 \%)$. I An Acad I)ermatel 2004; $50: 121$

46. Freeman M, Vinciullo (- Francis D), et all. A comparison of photodynamic therapy using topical methyl aminolevulinate (Metvix) with single cycle cryotherapy in pationts with actinic keratosis: a prospective, randomized study. J Dermatol Treat. 2003; 14:99-106 


\title{
Recurrence rates and long-term follow- up after laser resurfacing as a treatment for widespread actinic keratoses in the face and on the scalp
}

\author{
JUDITH U. OSTERTAG, PATRICIA J.F. QUAEDVLIEG, H.A. MARTINO NEUMANN,
} GERTRUUD A. KREKELS

BACKGROUND. Diffuse widespread actinic keratoses are difficult to treat, have a tendency towards higher recurrence rates and therefore require ablative treatment. Laser resurfacing is one of the treatment modalities that can treat whole surface areas. OBJECTIVE. To evaluate patients which underwent laser resurfacing for widespread actinic keratoses with long-term follow-up for recurrence rates, time until new lesions occur, and the most common side effects. METHODS. Retrospective case-control study from 25 patients who underwent laser resurfacing for widespread actinic keratoses on scalp, forehead or full face at our department. Follow-up varied from 7-70 months. Recurrence rates, adverse effects and improvement were analyzed through chart analysis. RESUL.TS. The mean average of follow up was 39 months. Forty-four percent of the patients had no recurrence during the time period. Fifty-six percent of the patients developed new lesions after treatment but only a few. Of the recurrences, $20 \%$ occurred within 1 year and $36 \%$ occurred after 1 year. The most common short- and long-term side effects were infections (12\%), hypopigmentation (48\%), hypcrpigmentation (8\%), acne (12\%), milia (12\%), scar formation $(8 \%)$ and atrophic and/or casy bruised skin $(20 \%)$. CONCLUSION. Laser resurfacing is an effective treatment modality for diffuse widespread actinic keratoses which long-term recurrence-free intervals.

\section{Introduction}

Actinic keratoses are cutaneous neoplasms that occur on sun-exposed skin surfaces. These premalignant lesions usually are a consequence of long-term solar radiation, but may also be caused by UV light exposure from artificial sources or exposure to polycyclic aromatic hydrocarbons. Persons with Fitzpatrick skin types I and II are more susceptible to developing actinic keratoses. The sites of predilection for actinic keratoses are the face (especially the forehead), the vertex of the scalp, and the dorsal hands. ${ }^{1,2}$ There is an increasing prevalence of actinic keratoses with increasing age. In the third decade of life the prevalence is less than $10 \%$. This rises more than $80 \%$ in fair complexioned persons at the ages of $60-69.3$ Men are more affected than women.

Estimates of malignant conversion have varied in literature from $0.25 \%$ to $20 \%$ for an individual lesion during a 1-year time course. ${ }^{4}$ Actinic keratoses are considered to be precursors of invasive squamous cell carcinoma and therefore require aggressive treatment. The risk of malignant transformation for an average patient with actinic keratoses followed up for 10 years would be $6.1 \%$ or $10.2 \%$ depending on the study analyzed. 5 Farly intervention in treating these lesions may avoid progression of these lesions to carcinomas, which have the potential for invasion and metastasis and may obviate the need for more aggressive 
surgical treatments. It is a challenge to treat widespread actinic keratoses because of the possible risks of side effects and high recurrence rates. Numerous treatment options are available for the treatment of actinic keratoses. Laser resurfacing, ${ }^{6-13}$ chemical peel, ${ }^{14,15}$ cryopeel $^{16}$ and dermabrasion ${ }^{17,18}$ are different options to treat whole surface areas. Although there are diverse treatment options for actinic keratoses, literature is lacking prospective randomized study's comparing these treatments. Laser resurfacing with the erbium:yttrium-aluminum-garnet (YAG) or $\mathrm{CO}_{2}$ laser has been proved to be effective in the treatment of actinically damaged skin. It provides the precise treatment ability of superficial ablation of the epidermis and the superficial papillary dermis of involved skin. It not only destroys the clinically affected skin, but also removes the layer of photodamaged skin in adherent arcas, thercby acting as treatment and possibly prophylaxis of recurrence of aktinic keratoses. It even might reduce the incidence of development of cutaneous malignancies.

In the past only a few studies describe patients with actinic keratosis treated with laser resurfacing. ${ }^{7} 12$ These were studies with few patients and short follow up time. Recently, Iyer and colleagues did a retrospective chart analysis with a long-term follow-up for patients who underwent full face laser resurfacing for widespread facial actinic keratoses. ${ }^{13}$

We had achieved remarkable results with laser resurfacing as treatment for patients with therapy-resistant, widespread actinic keratoses. We also noticed some side effects, even severe ones. ${ }^{19}$ We decided to evaluate all patients treated with laser resurfacing for widespread actinic keratoses on the face or scalp at our department to draw conclusions about recurrence rates and side effects.

\section{Methods}

Patients who were treated during the past 5 years for their widespread actinic keratoses with laser resurfacing at the University Hospital of Maastricht, Department of Dcrmatology were evaluated. All patients had a long history of recurrent, multiple, widespread actinic keratoses. Attention was paid to Fitzpatrick skin type, location, sun exposure, immunosuppression, history of malignancy, other previous treatments of their actinic keratoses, and general medical history. We also looked for which laser was used, laser settings, and the number of passes used. Patients were treated with the erbium: $Y A G$ and/or $\mathrm{CO}_{2}$ laser (Derma $\mathrm{K}$, Silk-touch-Feather-Touch, Lumenis Ltd.). In all patients the usual laser setting were applied: $\mathrm{CO}_{2} \mathrm{ST}, 200 \mathrm{HP}, 9 \mathrm{~mm}, 18-20 \mathrm{~W} /$ $\mathrm{CO}_{2}$ FT, 260HP, 9-12mm, 34-36W /

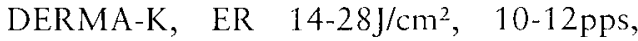
$\mathrm{CO}_{2}, 2-4 \mathrm{~W}, 50 \%$ DC / DERMA-K, ER 2 $\mathrm{J} / \mathrm{p}, 10-12 \mathrm{pps}$.

Prominent keratotic lesions were first removed with curettage. Then in all patients, the same depth of laser abalation was tried to reach down in to the papillary dermis with one or two passes. The residual actinic keratoses were treated with extra passes. Pre- and postoperatively, the patients were treated with ciprofloxacin 250 mg twice daily for 10 days. Patients who had a history of herpes simplex were treated prophylactically with valacyclovir $500 \mathrm{mg}$ once daily. The follow-up of patients was at 1 and 2 weeks, 1, 3, 6, 12 months and then annually. Time to recpithelialization, and side effects such as crosions, irratation, erythema, edema, crust formation, infections, hypopigmentation, hyperpigmentation, acne, milia, scars, and pain were scored. The recurrence rates, time until recurrence, actinic damage before and after treatment was evaluated. If patients had a recurrence they were additionally treated with liquid 
nitrogen. Actinic damage was classificd as 0 to $25 \%, 25$ to $50 \%, 50$ to $75 \%$, and 75 to $100 \%$ of the surface before and after treatment. To determine all this variables, the patients records were reviewed and the photographs taken before and after treatment were evaluated by two dermatologist, one who treated the patient and one independent dermatologist.

\section{Results}

Most important results are summarized in Table 1. The male to female ratio was $60: 40 \%(15: 10)$. The average age was 69 years (range $52-84$ years). The location of treated area was the forehead $(32 \% ; 8$ of $25)$, the vertex $(8 \% ; 2$ of 25$)$, the full face $(32 \% ; 8$ of 25$)$, the cheeks $(4 \% ; 1$ of 25$)$, and the forchead and vertex $(28 \% ; 7$ of 25$)$.

Forty-four percent (11 of 25) of the patients had Fitzpatrick skin type 1, 36\% (9 of 25) had skin type II, and $16 \%$ ( 4 of 25 ) had skin type III. The paticnts had already been treated for actinic keratoses before: $76 \%$ with cryotherapy, $48 \%$ with topical 5 fluorouracil, $16 \%$ with chemical peeling (Jessner trichloroacetic acid or glycolic acid peel), $16 \%$ with systemic retinoids, $4 \%$ with dermabrasion and $16 \%$ with other modalities. Of the 23 patients $78 \%$ had 75 to $100 \%$ actinic damage, $9 \%$ had 50 to $75 \%$, and another $9 \%$ had 25 to $50 \%$ before the treatment. We had no information of the actinic damage before and after treatment of two patients. Forty-four percent (11 of 25) of the patients had a history of malignancies in the treated area, $73 \%$ (8 of 11) had one or two squamous cell carcinomas, $45.5 \%$ (5 of 11) had one, two or three basal cell carcinomas.

The laser resurfacing was done in 7 cases with the erbium:YAG laser in combination with the $\mathrm{CO}_{2}$ for hemostasis, in two cases with the erbium:YAG laser alone, in 16 with the $\mathrm{CO}_{2}$ laser. Time to reepithelialization varied from $5-1.5$ days (mean 9.8 days). Only one patient suffered from delayed wound healing up to 30 days owing to infection. Side effects occurred within 6 months in $80 \%$ of the patients, and $56 \%$ had side effect after 6 months. The most common short- and long-term side effects within and after six months were hypopigmentation, itching and atrophy and easy bruising skin (Table 2).

Total follow up time varied from 7 to 70 months, with an average of 39 months. Of all patients, $44 \%$ (11 of 25 ) had no recurrence and $56 \%$ (14 of 25 ) had a recurrence of actinic keratoses. The number of recurrences varied from 1 to 4 lesions in all patients except one, who had a recurrence of 15 lesions. Twenty percent ( 5 of 25 ) of the recurrences occurred within 1 year and $36 \%$ (9 of 25 ) after 1year. Overall, the recurrences developed after a mean time of 23 month. There was no statistical difference in the apparatus used in relation to the recurrences. The obtained depth of ablation was the same in all patients, so there was no correlation between ablation depth and recurrence of actinic keratoses. Before treatment, the actinic damage was 75 to $100 \%$ in $78 \%$ (18 of 23) of the patients; after treatment, $78 \%$ (18 of 23 ) had actinic damage of 0 to $25 \%$. Of the patient with severe actinic damage, $72 \%$ (13 of 18 ) had a clinical improvement of 75 to $100 \%$. Three patients developed malignancies in the treated areas: one patient developed a basal cell carcinoma, one patient developed two basal cell carcinomas, and one patient developed two squamous cell carcinomas and one basal cell carcinoma. 
Table 1. Results

\begin{tabular}{|c|c|c|c|c|c|c|c|c|c|}
\hline $\begin{array}{l}\text { Patient } \\
\text { number }\end{array}$ & $\begin{array}{l}\text { Age } \\
\text { year }\end{array}$ & Sex & Treated area & Skin type & nr 1 & $\begin{array}{l}\text { Laser } \\
\text { used }\end{array}$ & $\begin{array}{l}\text { Follow up } \\
\text { months }\end{array}$ & $\begin{array}{l}\text { Recurrence } \\
\text { number }\end{array}$ & $\begin{array}{l}\text { Time until } \\
\text { recurrence } \\
\text { month }\end{array}$ \\
\hline 1 & 58 & $F$ & Full Face & 1 & 1 & $\mathrm{CO} 2$ & 45 & 1 & 45 \\
\hline 2 & 52 & $F$ & Full Face & 1 & 2 & ER-Yag / CO2 & 25 & 3 & 3 \\
\hline 3 & 61 & F & Full Face & $\|$ & 3 & ER-Yag / CO2 & 10 & 0 & no \\
\hline 4 & 78 & $M$ & $\begin{array}{l}\text { Forehead and } \\
\text { Scalp }\end{array}$ & $\|$ & 4 & ER-Yag/CO2 & 34 & 4 & 24 \\
\hline 5 & 67 & $M$ & Forehead & $\|$ & 5 & $\mathrm{CO} 2$ & 70 & 1 & 12 \\
\hline 6 & 57 & $\mathrm{~F}$ & Full Face & III & 6 & ER-Yag / COZ & 26 & 0 & no \\
\hline 7 & 61 & $\mathrm{~F}$ & Full Face & III & 7 & $\mathrm{CO} 2$ & 21 & 0 & no \\
\hline 8 & 59 & $F$ & Full Face & 1 & 8 & $\mathrm{CO} 2$ & 25 & 0 & no \\
\hline 9 & 80 & $M$ & Forehead & 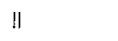 & 9 & ER-Yag & 36 & 3 & 4 \\
\hline 10 & 71 & $M$ & $\begin{array}{l}\text { Forehead and } \\
\text { Scalp }\end{array}$ & 1 & 10 & $\mathrm{CO} 2$ & 40 & 4 & 6 \\
\hline 11 & 72 & $M$ & $\begin{array}{l}\text { Forehead and } \\
\text { Scalp }\end{array}$ & ॥ & 11 & $\mathrm{ER}-\mathrm{Yag} / \mathrm{CO} 2$ & 36 & 15 & 24 \\
\hline 12 & 77 & $M$ & $\begin{array}{l}\text { Forehead and } \\
\text { Scalp }\end{array}$ & 1 & 12 & $\mathrm{CO} 2$ & 33 & 0 & no \\
\hline 13 & 85 & M & Forehead & 1 & 13 & $\mathrm{CO} 2$ & 69 & 4 & 24 \\
\hline 14 & 63 & $\mathrm{~F}$ & Full Face & ili & 14 & $\mathrm{CO} 2$ & 67 & 2 & 40 \\
\hline 15 & 69 & $M$ & $\begin{array}{l}\text { Forehead and } \\
\text { Cheeks }\end{array}$ & I & 15 & $\mathrm{CO} 2$ & 67 & 3 & 49 \\
\hline 16 & 84 & $M$ & $\begin{array}{l}\text { Forehead and } \\
\text { Scalp }\end{array}$ & " & 16 & $\mathrm{CO} 2$ & 12 & 0 & no \\
\hline 17 & 76 & $\mathrm{~F}$ & Forehead & 1 & 17 & $\mathrm{CO} 2$ & 29 & 0 & no \\
\hline 18 & 78 & $M$ & Scalp & 1 & 18 & ER-Yag / COZ & 30 & 3 & 3 \\
\hline 19 & 64 & M & $\begin{array}{l}\text { Forehead and } \\
\text { Scalp }\end{array}$ & 1 & 19 & $\mathrm{CO} 2$ & 35 & 0 & no \\
\hline 20 & 58 & $M$ & $\begin{array}{l}\text { Forehead and } \\
\text { Scalp }\end{array}$ & $!$ & 20 & $\mathrm{CO} 2$ & 58 & 1 & 7 \\
\hline 21 & 76 & $M$ & Forehead & $\mathrm{nn}$ & 21 & $E R-Y a g$ & 16 & 0 & no \\
\hline 22 & 71 & $M$ & Scalplp & $\|$ & 22 & ER-Yag $/ \mathrm{CO} 2$ & 48 & 0 & no \\
\hline 23 & 65 & $\mathrm{~F}$ & Full Face & $\|$ & 23 & $\mathrm{CO} 2$ & 52 & 2 & 47 \\
\hline 24 & 79 & $M$ & Forehead & III & 24 & $\mathrm{CO} 2$ & 52 & 0 & no \\
\hline 25 & 70 & $F$ & Forehead & 1 & 25 & $\mathrm{CO} 2$ & 52 & 1 & 30 \\
\hline
\end{tabular}

Table 2. Adverse effects

\begin{tabular}{lccc}
\hline Adverse Effects & $<6$ months & $>6$ months \\
Infection & $2 / 258 \%$ & $1 / 254 \%$ \\
Hypopigmentation & $1 / 254 \%$ & $11 / 2544 \%$ \\
Hyperpigmentation & $2 / 258 \%$ & none \\
Acne & $1 / 254 \%$ & $2 / 258 \%$ \\
Milia & $2 / 258 \%$ & $1 / 254 \%$ \\
Scar & $1 / 254 \%$ & $1 / 254 \%$ \\
Itching & $7 / 2528 \%$ & $7 / 2528 \%$ \\
Pain & $1 / 254 \%$ & none \\
Atrophy / Easy bruising skin & $5 / 2520 \%$ & $5 / 2520 \%$ \\
Persistent erosions and crusting & $2 / 258 \%$ & $2 / 258 \%$
\end{tabular}




\section{Discussion}

Because actinic keratosis is a premalignant skin disease and a possible risk factor for malignant transformation to squamous cell carcinoma, treatment is required (20). Although numerous treatment options are available, recurrences develop very soon, often within months after treatment. Therefore, for patients with widespread actinic keratoses, it is important to find a treatment modality to cure or decrease the number of lesions. Also, it is important to delay the time until recurrence of the lesions. For widespread actinic keratoses, the treatment modalities are limited to 5-fluorouracil, chemical peeling, dermabrasion, cryopeel, laser resurfacing and newer modalities like photodynamic therapy and imiquimod. Therapies that treat whole surface areas, such as laser resurfacing, not only destroy the clinically affected skin but also adjacent actinically damaged skin. This may result in fewer recurrences and might be prophylactic for the development of actinic keratoses and cutaneous malignancies.

In the past, many articles are published on laser resurfacing but mostly for cosmetic reasons and not with this specific indication. In the literature, only 7 publications with small case series regarding treatment of actinic keratoses with laser resurfacing reported the clearance and recurrence rates. ${ }^{7-13}$ Compared to others, such as Trimas and colleagues and Jiang and colleagues $^{7,12}$ we had a higher percentage of recurrence but a much longer follow-up time. As described in the results, our recurrence rate was $56 \%$ and the amount of recurrent lesions varies from 1 to 4; only one patient developed 15 lesions. Despite this percentage, of all patients which had a recurrence, $64 \%$ (9 of 14 ) occurred after an average of 32.7 months. Seventy-eight percent of the patients showed 75 to $100 \%$ improvement of the actinic damage in the treated area. These parameters indicate that laser resurfacing shows dramatic improvement on the number of actinic keratoses and actinic damage of the skin. Further, laser resurfacing shows long times of recurrence free intervals. Iyer and collcagues also described a long recurrence free period after treatment with laser resurfacing(13). We found similar results regarding recurrence rates; $80 \%$ versus $87.5 \%$ of the patients remained lesion free for one year. After mean long-term follow-up, the recurrence rates were $56 \%$ versus $50 \%$.

Fulton and colleagues noted that despite treatment with $\mathrm{CO}_{2}$ laser resurfacing, skin malignancies developed. ${ }^{10}$ They concluded that laser resurfacing is not as effective as dermabrasion and deep chemical peel for the prophylaxis of basal cell carcinomas. Wc cannot support this statement. Like Iyer and colleagues, ${ }^{13}$ we also had 3 of 2.5 patients who developed nonmelanoma skin cancer in the treated area. Although we had the same experience, in our opinion, it is difficult to draw conclusions because the tumors might already be preexistent before treatment but clinically not suspect or visible. Our patients who did develop malignancies had a history of several skin malignancies in the area prior to treatment, so these patients are at risk to develop new non-melanoma skin cancer. It is known that the main risks for development of new skin cancers are male patients who already had multiple skin cancers. Further, patients at high risk continue to develop new tumors at a constant rate, even after 10 years of review. This suggests that in this group, once enough exposure of UV light has occurred to cause a skin cancer, even when treatment has been applied, new skin cancer formation occur despite protection. ${ }^{21,22}$ However there is evidence of a consistent decrease in P53 immunostaining in the interfolliculair epidermis after treatment of photodamaged skin with $\mathrm{CO}_{2}$ laser resurfacing. Since $P 53$ mutation or 
overexpression is observed in a majority of cases of cutaneous carcinoma, the post-laser treatment repopulation of the epidermis with P53-negative keratinocytes should decrease the risk of malignant progression. 23

The amount of side effects we found in our patients is remarkable, especially the longterm side effects of hypopigmentation, itching and atrophic skin. This might be due to the fact that $68 \%$ (17 of 25 ) of the patients where treated on the forehead and/or the scalp region, which are more susceptible to side effects, especially in older patients with already preexistent atrophic skin. The two patients with persistent erosions and crusting where also treated in the scalp region. Another explanation might be that 16 of the 25 patients were treated with $\mathrm{CO}_{2}$ laser alone, and in 7 of the 25 patients erbium: YAG laser in combination with the $\mathrm{CO}_{2}$ laser for hemostasis was applied. It is known that $\mathrm{CO}_{2}$ laser has a higher risk of adverse effects and complications than erbium:YAG laser resurfacing. We found no difference in clinical outcome regarding recurrence rates whether the $\mathrm{CO}_{2}$ laser or erbium: YAG laser was used. Even though our study concerns a small group of patients, one could draw the conclusion that the use of the erbium:YAG laser with or without the $\mathrm{CO}_{2}$ laser is preferred because of fewer side effects, especially in at-risk areas such as the scalp. Although we know that laser resurfacing has side effects, side effects also occur with other treatment modalities, such as cryotherapy and chemical peeling, even severe ones (19). In particular, erosions, erythema, and crus tformation are the usual side effects inherent in almost all the treatment modalities.

Although this is a retrospective study with a small group of patients, it is one of the few publications of patients with widespread actinic keratoses on the face or scalp treated with laser resurfacing. It concerns a group of patients with recurrent severe actinic keratoses in whom other therapy modalitics had failed. Although there was a great spreading of the follow up (7 to 70 months), most of the patients ( $88 \%$ ) had a follow up of $>12$ months with a mean of 42 months. All of our patients where treated and followed by the same dermatologist. Although different lasers were used, the technique of treatment was always consistent: curettage, resurfacing until the papillary dernis was reached, and extra passes at the residual visible lesions.

In the literature, there is lack of prospective randomised studies that compare different treatment modalities for actinic keratoses. Mostly, there is literature pertaining the effectiveness of one treatment. It would be interesting to conduct a prospective randomised study of patients with widespread actinic keratoses and to compare laser resurfacing with other treatment modalities, such as cryotherapy, chemical pecl, topical 5fluorouracil or imiquimod.

\section{Conclusion}

In conclusion, our results show that laser resurfacing is a good treatment modality for widespread actinic keratoses with long recurrence-free intervals. We recommend laser resurfacing as treatment modality for patients with widespread actinic keratoses in whom other treatments modalities have failed. Care has to be taken on risk areas, such as the scalp.

A reduction in actinic keratoses trough treatment with laser resurfacing cannot prevent them completely but may offer a reduction of transformation into and development of squamous cell carcinoma. Further prospective studies in regard to this issue would be interesting. 


\section{References}

1. Schwartz R.A. Actinic keraroses. Skin cancer recognition and managment. New York Springer Verlag 1988; 4-10

2. Callen J.P, Bickers DR and Moy RA. Actinic keratoses. J Am Acad. Dermatol.1997; 36(40: $650-3$

3. Schwarts R.A. the actinic keratosis. A perspective and update. Dermatol Surg 1997; 23(11): 1009-19;quiz 1021-1

4. Marks R. and Rennie G, Selwood TS. Malignant transformation of solar keratoses to squamous cell carcinoma. Lancet 1988; 1: 296-7

5. Dodson J.M. De Spain J, Hewet JE, et al, Malignant potential of actinic keratoses and the controversy over treatment. A patient oriented perspective. Arch Dermatol 1991; 127(7): 1029 31

6. Fitzpatrick RE, Goldman MP, Satur MN, Tope WD. Pulsed carbondioxide laser resurfacing of photoaged skin. Arch Dermatol 1996; 132:395402

7. Trimas. S.J. Ellis DA, Metz RD. The carbondioxide laser. An alternative for the treatment of actinically damaged skin. Dermatol Surg. 1997; 23(10): 885-9

8. Drnovsek-Olup B, Veldlin B. Use of Er:YAG lasers for benign skin disorders. Lasers Surg Med 1997: 21(1): 13-9

9. Chiarello $\mathrm{SE} . \mathrm{CO}_{2}$ laser for actinically damaged skin. Dermatol Surg 1997; 23: 885-889

10. Fulton JE, Rahimi A.D, Helton P, Dahlbergk, Helly AG. Disappointing results following resurfacing of facial skin with $\mathrm{CO}_{2}$ lasers for profylaxis of keratoses and cancers. Dermatol Surg 1999 Sept; 25 (9) 729-32

11. Massey RA, Eliezri YD. A case report of laser resurfacing as a skin cancer prophylaxis. Dermatol Surg 1999; 25: 513-516

12. Jiang SB, Levine VJ, Nehal KS, Baldassano $M$, Kamino H, Ashinoff RA. Er: Yag laser for the treatment of actinic keratoses. Dermatol Surg 2000;26:437-440

13. Iyer S, Friedli A, Bowes L, Kricorian $G$ et all. Full face Laser Resurfacing: Therapy and Proohylaxis for Actinic Keratoses and NonMelanoma Skin Cancer. Lasers Surg Med.2004 34:114-119
14. Lawrence N. (iox SI: Cisckerell C. fremant $R$ (i, Cruise Pl). A comparison of the efficacy and safety of Jessner's solution and $35 \%$ tricloracetic ys. $5 \%$ fluorouracil in the treatment of widespread facial actinic keratoses. Arch Dermatol 1995; 131: 176-181

15. Witheiler DD, Lawrence N, Cox Sc, Cruz C. Long term Efficacy and safety of Jessner's Solution $35 \%$ vs $5 \%$ Fluorouracil in the treatment of widespread Actinic Keratoses. Dermatol Surg 1997; 23: 191-196

16. Chiarello SE. Cryopeeling (extensive cryosurgery) for treatment of actinic keratoses: An update and comparison. Dermatol Surg $2000 ; 26(8): 728-732$

17. Coleman WP, Yarbourough JM, Mandy SH. Dermabrasion for prophylaxis on the photoaged face. Dermatol Surg 1997; 22: 17-21

18. Benedetto AV, Griffin TD, Benedetto EA, Humeniuk HM. Dermabrasion: Therapy and prophylaxis of the photoaged face. JAAD1992; 27: 439-447

19. Quaedvlieg P.J.F, Ostertag J.U, Krekels G.A, Neumann H.A. Delayed woundhealing after three different treatments for widespread actinic keratosis on the atrophic bald scalp. Derma Surg. 2003; 29(10):1052-6

20. Czarnecki D, Mechan C, Bruce F, Culjak G. The Majority of Cutaneous Squamous Cell Carcinomas Arise in Actinic Keratoses. J Cutan Med Surg 2002; 6(3):207-9

21. Czarnecki $C$, Czarnecki D. Patients who have multiple skin cancers develop new skin cancers at a constant rate. Arch Dermatol 2002; 138: 125

22. Czarnecki D, Mar A, Staples M, Giles G, Meehan C. The development of nonmelanocytic skin cancers in people with history of skin cancer. Dermatology. 1994; 189: 364-7

23. Orringer J.S. MD, Johnson T.M. MD, Kang $S$. MD, et all. Effect of Carbondioxide Laser resurfacing on Epidermal p.53 Immunostaining in Photodamaged Skin. Arch. Dermatol. 2004;140:1073-7 
56 CHAPTER 2 


\section{A clinical comparison and long term follow-up of topical 5-fluorouracil versus laser resurfacing in the treatment of widespread actinic keratoses}

JUDITH U. OSTERTAG, PATRICIA J.F. QUAEDVLIEG, SIMONE VAN DER GEER, PATTY NELEMANS, MIRANDA E.M.C. CHRISTIANEN, H.A. MARTINO NEUMANN, GERTRUUD A.M. KREKELS

BACKCROUND AND OBJECTIVES: Many treatment modalities exist for actinic keratoses (AK). Topical 5-fluorouracil has been one of the standard treatments. Laser resurfacing is a morc recent treatment option. In the literature prospective randomized studies comparing these treatments are lacking. STUDY DESIGN/ PATIENTS AND METHODS: Prospective randomized study to compare topical 5fluorouracil (5-FU) with Er:YAG laser resurfacing. Fifty-five patients with multiple AK on the scalp and or the face were included. Clinical and histopathological evaluation took place at 3, 6 and 12 months after treatment. RESULTS: At 3,6 and 12 months after treatment, there were significantly less recurrences in the laser group compared to the group of patients treated with 5-FU. Side-effects did occur more frequently in the laser group, especially erythema and hypopigmentation. CONCILISIONS: Compared to treatment with topical 5-FU, Er:YAG laser resurfacing is more effective regarding recurrence rates. Although significantly more side-effects occur, laser resurfacing is a useful therapeutic option especially in patients with widespread actinic keratoses.

\section{Introduction}

Actinic keratoses (AK) are common, suninduced epithelial lesions. " They have always been regarded as 'premalignant'. Recently, it is proposed to classify them as 'incipient intraepidermal squamous cell carcinoma' or 'keratinocytic intraepidermal neoplasm', because there seems to be a continuum with squamous cell carcinoma. 2,3 AK must be treated to prevent their progression to invasive malignant non-melanoma skin cancer. $4,5,6,7$ Risks of $0.025-16 \%$ are reported in literature. The risk is higher with increase of the number of AK lesions and with time. 8,9 There are many effective treatment modalities for AK: cryosurgery, curettage, electrosurgery, excision, topical 5 - fluorouracil (5-FU), chemical peeling, dermabrasion, laser surgery, photodynamic therapy, systemic retinoids, topical tretinoin, intralesional interferon, diclofenac, imiquimod $10,11,12,13,14,15$ For decades 5-FU has been one of the standard treatments for AK. ${ }^{16}$

Although there are multiple treatment options for AK, literature is lacking prospective randomized studies comparing these treatments. In the past we noticed good long term clinical results in treating widespread $\mathrm{AK}$ with laser resurfacing at our department. Laser resurfacing with $\mathrm{CO}_{2}$ (Carbon Dioxide) and or Er:YAG (Erbium:Yttrium-Alluminum-Garnet) is considered by many authors to be a fine 
treatment in patients with widespread AK. ${ }^{7-2.5}$ In order to have more evidence based information about recurrence rates and adverse effects we decided to perform a randomized clinical trial to compare Er:YAG laser resurfacing (laser resurfacing) with one of the standard treatment modalities, 5-FU.

\section{Patients and methods}

\section{Study Design}

Our randomized controlled trial evaluated the effectiveness of 5-FU and that of laser resurfacing in the treatment for $\mathrm{AK}$. The main aim of the study was to compare the recurrence rates and the improvement of actinic-damage in patients who were assigned to the topical 5-fluorouracil group (FU-group) and those who were assigned to the laser resurfacing group (LA-group). We also assessed side effects of both treatments.

Power analysis was performed. The most important outcome was recurrence rate. Based on literature, recurrence rates for 5 $\mathrm{FU}$ and $\mathrm{CO}_{2}$ laser were estimated 0.25 and 0.01 respectively. With an expected dropout rate of $10 \%$ after one year, it was calculated that 50 patients had to be included. Randomization took place in permuted blocks. Eventually 27 patients were treated with 5-FU and 28 with laser resurfacing.

\section{Patients}

Consecutive patients referred to the Division of Dermatology of the University Hospital of Maastricht, Maastricht, The Netherlands, between October 2001 and February 2004 with clinically widespread AK on the scalp and or the face, as confirmed with biopsy, were considered for the study. Patients had to give written informed consent to participate in the study. The study protocol was approved by the Medical Ethi- cal Commission of the University of Maastricht.

At baseline, a clinical history was taken detailing risk factors for AK. Patients with age above 85 years, life-expectation less than three years, bad general health, former total skin treatment with laser or dermabrasion and untreated facial skin cancer were excluded from the study. Fifty-five patients with an age range of 52-85 (mean 72) with multiple AK on the scalp and or the face were included in this study.

\section{Treatment}

Patients in the FU-group were instructed to use the 5\% 5-fluorouracil (Efudix $(B)$ ) cream for 4 weeks, twice daily in a thin even layer on the entire treatment arca. In addition written instructions were given. After 2 weeks they were clinically evaluated and motivated to continue therapy. After 4 weeks patients were again clinically evaluated. If the desired clinical inflammatory response, scaling, crosions and crust formation was achieved according to the investigator, therapy was stopped. Otherwise the patient was advised to continue the therapy for another 1 to 3 weeks until the desired effect was reached. After treatment, chloorhexidine cream was used twice daily until re-epithelialization was completed.

Patients in the LA-group started with oral prophylactic antibiotics (Ciproxin ${ }^{B}$ $250 \mathrm{mg}$ twice daily) and antivirals (Zelitrex® $500 \mathrm{mg}$ once daily; if a patient previously had had a herpes simplex infection, he was advised to use the Zelitrex ${ }^{\circledR}$ twice daily) 1 day before treatment and this was continued 1 week after treatment. Before laser resurfacing, the treatment area was anaesthetized with local infiltration and/ or nerve blocks. We used the Derma-K laser (Lumenis ${ }^{\mathrm{TM}} \mathrm{Ltd}$ ). The Er:YAG mode was used, in combination with $\mathrm{CO}_{2}$. The energy that was given varied from 7 to 28 $\mathrm{J} / \mathrm{cm}^{2}$ in the Erbium mode, 10 to 12 pulses 
Table 1. Photoaging scale

\begin{tabular}{|c|c|c|c|c|c|c|}
\hline Wrinkles & Score & Skin color & Score & Keratoses & Score & photoaging score \\
\hline None & 0 & mild pigment & 0 & none & 0 & \\
\hline in motion & 1 & lentiges & 1 & palpable & 1 & mild total score $0-3$ \\
\hline at rest & 2 & $\begin{array}{l}\text { dyschromia / } \\
\text { teleantiectasia }\end{array}$ & 2 & visible & 2 & moderate total score $4-6$ \\
\hline only & 3 & Yellow gray & 3 & $\begin{array}{l}\text { prominent/ } \\
\text { malginancies }\end{array}$ & 3 & severe total score $7-9$ \\
\hline
\end{tabular}

per second with $50 \% \mathrm{CO}^{2}$, varying from 2 to 4 Watt. The skin was ablated layer-bylayer until the papillary dermis was reached. On the more hypertrophic lesions1 or 2 extra passes were given. After laser treatment, patients used SilonTSR ${ }^{(1)}$ dressings during 3 to 4 days, followed by acetic acidcompresses and vaseline daily. Fifteen patients underwent treatment of the forehead, in twenty-two patients the scalp was treated and 16 patients were treated at the scalp as well as at the forehead. Only one patient had full-face treatment.

\section{Evaluation}

All patients were followed for a period of 1 year. Clinical evaluation was performed by two investigators; the first two authors. Among all patients clinical evaluation took place at 2 and 4 weeks, and at 3, 6 and 12 months after treatment. In the LA-group extra evaluations took place at 3 days and 1 week after treatment. With the clinical evaluations the following parameters were recorded: number of $\mathrm{AK}$, the surface of actinic damage $(0-25 \%, 25-50 \%, 50-75 \%$ and $75-100 \%$ ) and a photoaging score (Table 1). This photoaging scale is a simplified form of the Glogau score to classify photo-aging. ${ }^{26}$ Before treatment the above mentioned parameters were recorded. During follow up, at 3, 6 and 12 months after treatment, the number of $A K$ and modified photoaging score were recorded again and improvement of surface of actinic damage (no improvement, 0-25\%, 25-50\%, 50$75 \%$ and $75-100 \%)$ plus adverse effects were evaluated. Histopathological evaluation took place 3 months after treatment. Skin biopsies were obtained in the same area as the biopsy before treatment. In case of recurrence at times of clinical evaluation, another biopsy was taken to confirm the diagnosis of recurrence of AK.

\section{Statistical analysis}

The data was analyzed according to the intention to treat principle. Between-group differences in proportions were compared using the Chi-Square test and betweengroup differences in mean scores were evaluated using the Independent Samples T-test. A p-value $<0.05$ was considered to be statistically significant.

The primary outcome was the proportion of patients with recurrence of $A K$ according to clinical evaluation within one year after treatment. Secondary outcomes were the proportion of patients with recurrence of $A K$ according to histopathological evaluation 3 months after treatment, and the proportion of patients with recurrent AK (according to clinical evaluation) at 3,6 and 12 months after treatment, respectively. The treatment groups were also compared with respect to the proportion of patients with improvement in photoaging score, the proportion of patients with improvement of surface with actinic damage and the decrease in number of actinic lesions (as compared with the number of lesions before treatment) and the proportion of patients with adverse effects at 3,6 and 12 months after treatment. 
Table 2. Baseline characteristics

characteristics
mean age (SD)
mean no. of lesions (SD)
treatment areas
frontal
scalp
frontal + scalp
full face
men

skin type

2

3

AK surface before treatment

$1\{0-25 \%\rangle$

$2(25-50 \%)$

$3(50-75 \%)$

$4(75-100 \%)$

glogau score before treatment

mild

moderate

severe

history of malignancy in treatment area

previous treatment

$\mathrm{N}=$ number, $\mathrm{SD}=$ standard deviation

$\begin{array}{lc}\text { Laser } \mathbf{N}=\mathbf{2 8} & 5-\mathrm{FU} \mathbf{N}=\mathbf{2 7} \\ 70.1(8.4) & 73.0(8.6) \\ 14.9(5.4) & 15.3(4.9) \\ \mathbf{N} & \mathrm{N} \\ 8 & 8 \\ 10 & 11 \\ 10 & 7 \\ 0 & 1 \\ \mathbf{N}(\%) & \mathbf{N}(\%) \\ 27(96.4 \%) & 23(85.2 \%) \\ 11(39.3 \%) & \\ 17(60.7 \%) & 9(33.3 \%) \\ 0(-) & 14(51.9 \%) \\ & 4(14.8 \%) \\ 1(3.6 \%) & \\ 2(7.1 \%) & 1(3.7 \%) \\ 11(39.3 \%) & 4(14.8 \%) \\ 14(50.0 \%) & 12(44.4 \%) \\ & 10(37.0 \%) \\ 0(-) & \\ 25(89.3 \%) & 1(3.7 \%) \\ 3(10.7 \%) & 23(85.2 \%) \\ 16(57.1 \%) & 3(11.1 \%) \\ 22(78.6 \%) & 10(37.0 \%) \\ & 19(67.3 \%) \\ & \end{array}$

\section{Results}

Fifty males and five females (man women ratio $91 \%: 9 \%$ ) with an average age of 72 years (range $52-85$ years) were included in the study. Both groups were comparable considering most baseline characteristics (Table 2). There were more patients with previous malignancies in the treatment area in the LA-group. 52 Paticnts completed the total follow up of one year. One patient from the FU-group died between 6 and 12 months follow up due to a cause not related to treatment. Two patients were lost to follow up.

Re-epithelialization time after laser resurfacing ranged from 4-15 days (mean 7 days).

8 Patients needed treatment with 5-FU for more than 4 weeks. The mean treatment time was 4.5 weeks.

\section{Recurrence}

Recurrence rates at 3 and 6 months after treatment were statistically significantly different for the two treatment modalities, as were the recurrence rates after one year and within one year after treatment. There were significantly less recurrences in the LAgroup (Table 3). No differences were found in recurrence rates between treatment areas in both groups.

Biopsies, taken 3 months after laser resurfacing, showed a reversal of actinic damage in the epidermis, an increase in subepidermal fibroplasia and a decrease in solar clastosis in the superficial papillary dermis. In biopsies of patients treated with 5-FU there was a reversal of actinic damage in the epidermis as well, but there was less decrease in solar elastosis in the dermis. Histological proven recurrence occurred significantly more frequently in the FU-group 
Table 3. Recurrence rates

\begin{tabular}{llll}
\hline Follow-up & $\mathrm{LA}(\mathrm{n}=28)$ & $\mathrm{FU}(\mathrm{N}=27)$ & p value CS \\
3 months & $5(21.7 \%)$ & $16(61.5 \%)$ & 0.005 \\
6 months & $5(21.7 \%)$ & $15(57.7 \%)$ & 0.011 \\
1 year & $7(25.9 \%)$ & $15(60.0 \%)$ & 0.013 \\
within 1 year & $11(40.7 \%)$ & $21(80.8 \%)$ & 0.003 \\
$\mathrm{n}=$ number; $\mathrm{CS}=\mathrm{Chi}$-Square & & &
\end{tabular}

Table 4. Patient mean percent lesions cleared

\begin{tabular}{llll}
\hline Follow-up & Laser & 5 -FU & p value T-test \\
6 months after treatment & $94.4 \%$ & $79.2 \%$ & 0.022 \\
12 months after treatment & $91.1 \%$ & $76.6 \%$ & 0.048
\end{tabular}

than in the LA-group ( $48 \%$ versus $14 \%$, $\mathrm{p}=0.026$ ).

\section{Number of lesions before and after treatment.}

Overall, there was a reduction from a total of $830 \mathrm{AK}$ to $98 \mathrm{AK}, 1$ year after treatment.

The mean decrease in number of actinic lesions per patient (as compared with the number of lesions before treatment) was 13.2 in the FU-group versus -13.8 in the LAgroup at 3 months. At 6 and 12 months the mean decreases were -12.5 (in the FUgroup) versus - 13.9 (in the LA-group) and 12.4 (in the FU-group) versus -14.2 (in the LA-group), respectively. These differences were not statistically significant $(p>0.05)$. The mean percentage of lesions cleared per patient however, is significantly higher in the LA-group compared to the 5-FU group at 6 and 12 months after treatment (Table 4).

\section{Proportion of patients with a decrease in photoaging score.}

After 3 months the photoaging score improved in $13 / 26(50 \%)$ of patients in the FU-group versus $15 / 23(65 \%)$ of patients in the LA-group ( $p=0.39)$. After 6 months an improvement was observed in $13 / 26(50 \%)$ in the FU-group versus $18 / 23(78 \%)$ in the
LA-group ( $p=0.07)$. At 12 months after treatment, the proportions with improvement in Glogau score were 10/23 $(43 \%)$ of patients in the FU-group versus 17/23 $(74 \%)$ of patients in the LA-group $(\mathrm{p}=0.07)$.

Proportion of patients with improvement of surface with actinic damage.

There was no statistically significant difference in improvement of surface with actinic damage between both groups 3, 6 and 12 months after therapy.

\section{Side-effects}

During and directly after treatment all patients suffered from erythema. Edema and infections were seen significantly more in the LA-group. Crust formation was seen significantly more in the FU-group. Other sideeffects were pain, irritation and others (mostly itching).

3 Months of follow up showed significantly more erythema and other side effects (mostly itching) in the LA-group. Side effects as pain, irritation, crustae, hypopigmentation, acne, milia, and scars were not significantly different.

At 6 months of follow up erythema, hypopigmentation, acne and milia were seen significantly more in the LA-group. Irritation, crust formation and other side effects 


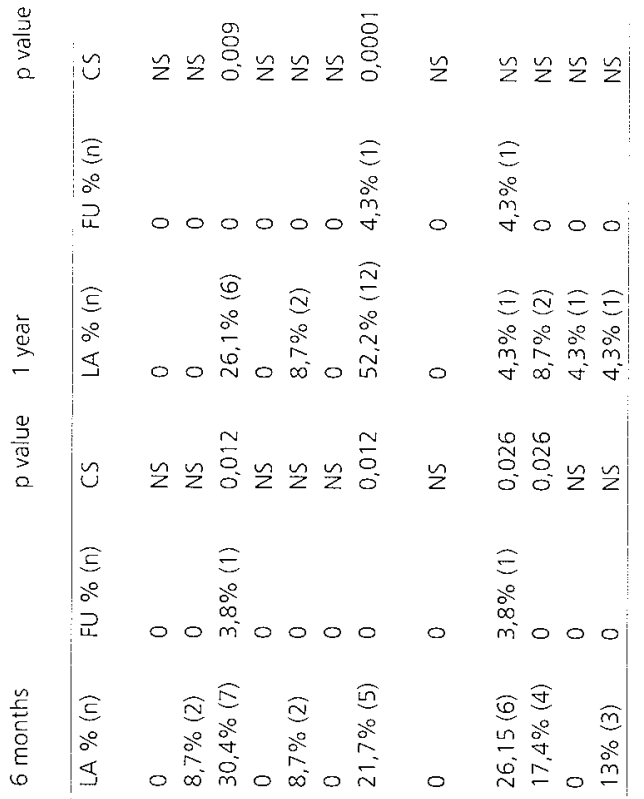

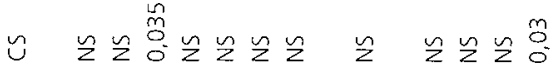

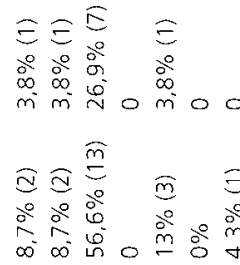

$\overline{8} \overline{8}^{\circ}$ $=\widehat{\mathrm{g}}$

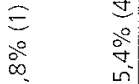
$\circ$ mi

ब응

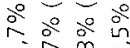
$\bar{v} \underset{\infty}{\infty} \stackrel{m}{\forall} \underset{q}{m}$

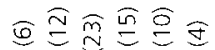

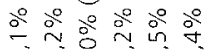
ஸे जิ were seen, but there were no statistical differences.

Long term side effects at 1 year follow up showed significantly more erythema and hypopigmentation in the LA-group. Crust formation, acne, milia, scars and other side effects were seen but were not significantly different between both groups. (Table 5)

\section{Discussion}

In patients with widespread AK with vague, ill defined borders in a setting of diffuse background photodamage, the idcal treatment would not only destroy clinically affected skin, but also remove the layer of photo-damaged skin in adjacent areas thereby acting as treatment and prophylaxis of AK and possibly of cutaneous malignancics $^{23,27-29}$ These field specific therapies can be divided into two categories: field destruction like laser resurfacing, dermabrasion and chemical peels and topical chemotherapy. 5

Topical 5-FU has been the standard therapy for the treatment of AK. Especially for widespread AK, 5-FU is suitable. Its efficacy has been compared to other therapies. ${ }^{10,12,30,31}$ Overall, 5-FU shows good results and the costs are low. However, the side effects, Jike pain, erythema, erosions and unsightliness induced by treatment, are unacceptable for many patients, many of whom stop treatment prematurely. Longterm follow-up shows that a significant number of patients continue to either have recurrent or new AK. ${ }^{30,31}$ Typically, 5-FU has to be applied twice daily for 2-4 weeks until the lesions show inflammatory reactions such as erythema, erosions and crust formation. After this inflammatory and lesion disintegration phase, the healing phase starts, and lasts $1-2$ wceks. ${ }^{16,32}$ With laser treatment, patients are treated in one day and re-epithelialization is complete after 4-15 days. In our study, 8 of 27 patients $(30 \%)$ had to apply 5 -FU for even more 
than 4 weeks. Compared to laser resurfacing, treatment with 5-FU takes a long period of time and during treatment, the treatment area is painful and cosmetically disturbing, due to a significant skin irritation. A high rate of non-compliance has been associated with the onset of these undesirable adverse effects, especially in patients with very extensive solar damage. ${ }^{5,28,32}$

Both LA and 5-FU are capable to improve overall photodamage. As our results show, there is an improvement in photoaging Glogau score and a decrease in surface with actinic damage, in both groups. Laser resurfacing however, is more effective in decreasing the Glogau photoaging score and the patient mean percent decrease in lesion number is significantly higher after LA compared to 5-FU.

There are no good large studies demonstrating the effectiveness of $5 \% 5$-FU. Reductions in number of AK from $47.5 \%$ to $91.7 \%$ are described and total clearance rates vary from $15 \%$ to $57.8 \% .^{12,29}$

Er:YAG laser and $\mathrm{CO} 2$ laser have been used previously to treat $A K$ lesions in the face and or on the scalp. In literature only case-reports and small studies with overall short follow-up can be found. 17,18,20-2.3,3.3 Prospective uncontrolled studies about CO2-laser and Er:YAG laser treatment describe 15 to 35 patients, with follow-up ranging from 3 to 24 months. ${ }^{17,18,20,22}$ In addition, there are some case-reports about $\mathrm{CO}_{2}$ laser, with follow-up from 6 to 52 months $[21,33]$, and one retrospective study about Er:YAG laser describing a follow-up period of 1 to 2 years. ${ }^{23}$

In our study recurrences within 1 year occurred in $40.7 \%$ in the LA-group, this was significantly less than in the FU-group $(80.8 \%)$. No data of about recurrence rates of $\mathrm{AK}$ after laser resurfacing are available from prospective randomized controlled studies. Fulton and lyer, case series and a retrospective study, report a lower recurrence rate 12 months after laser treatment,
$14.3 \%$ and $13 \%$ respectively. 20,23 Trimas, Drnovsek and Massey did not see any recurrence at all, with a follow up varying from 6 to 24 month. 17,18,21

Histological cvaluation at 3 month revealed recurrence in 3 patients treated with laser resurfacing, however clinically, a recurrence was secn in 5 parients in the same group. This suggests that recurrence rates can be overestimated, and probably also underestimated, and that histological investigation is essential to determine the efficacy of the treatment. ${ }^{34}$ In most studies however no histological examinations before and/ or after treatment are performed. 17,18,21,2.3 Besides low recurrence rates, the total number of AK lesions in the LA-group was reduced, a total reduction of $94 \%$. This is comparable to earlier studies. 22,23 In some studies malignant lesions are found in the area treated with laser. ${ }^{20,33}$ After treatment we found one squamous cell carcinoma in each group. Fulton also found malignant lesions after laser resurfacing; he concludes that laser treatment is not effective for prophylaxis of AK. ${ }^{20}$ Stratigos states that these malignant cells must have been in the skin before treatment, but that they were not clinically obvious, because theoretically, all cpithelial tumors should be removed after laser resurfacing. The malignant lesions could probably originate from follicular cells that were not damaged during the resurfacing. 33

In our study, all patients from both groups suffered from erythema during and directly after treatment. This is common after laser resurfacing ${ }^{35,36,37}$ as well as after 5-FU. ${ }^{16}$ Edema and wound infections were seen significantly more in the LA-group. These infections were all treated successfully with topical fucidic acid (Fucidin $\left.{ }^{\circledR}\right)$. After one year, we saw significantly more crythema and hypopigmentation in the LAgroup. These long term side-effects after laser resurfacing have been described before. Persistent crythema is one of the 
mild long term side effects, prolonged hypopigmentation is classificd as a moderate complication.35-37 Our high rate of persistent erythema could be due to the fact that in many cases the scalp was treated, an area more susceptible to adverse effects. Manuskiatti found hypopigmentation as the most common long term side-effect, especially in patients with more severe photodamaged skin who were treated more aggressively. Pigment changes were found in $26 \%$ of the patients. 38 Our hypopigmentation rate is higher; this is probably due to the fact that we treated the scalp. Another explanation is that our treatment was not aimed at improvement of wrinkles, but of severe $A K$. This probably requires a more aggressive procedure. In addition we did not correct for pscudo-hypopigmentation. Quadvlieg et al. mention delayed wound healing on atrophic bald scalp after laser resurfacing, with depigmentation and teleangiectasia as long-term complications. ${ }^{39}$ The other adverse effects in our study were comparable to the rates mentioned in literature. ${ }^{35-37}$ Overall, patients treated with laser resurfacing were satisfied with the clinical results and did not consider the long term side effects as cosmetically annoying.

Regarding the cost aspect for each treatment modality, initial treatment with 5 -FU is less expensive compared to laser resurfacing. However, higher recurrence rates occur in a shorter period of time, requiring a period of re-treatment. Additionally there is probably a higher rate of malignancy with the need for surgical therapy, all resulting in frequent down time periods. All these facts will eventually raise the overall costs dramatically. Initially, laser resurfacing is a more expensive treatment. It provides however a shorter down time, relatively more clearance per patient, less recurrences and probably less malignancies. In some patients this may be eventually more cost-effective, especially in patients with high recurrence rates after other therapies used in the past and with malignancy in history.

To our knowledge this is the first prospective randomized study, comparing Er:YAG laser resurfacing with another treatment modality for widespread AK. We performed histological examinations before and after treatment, next to clinical examinations. In addition, there was a relatively long follow-up. We noticed that patients in the LA-group had fewer recurrences and less AK lesions at the end of follow-up, compared to the 5-FU-group. We did sec however, more side-effects in the LA-group, especially erythema and hypopigmentation.

In conclusion, this study provides evidence that Er:YAG laser resurfacing is an effective treatment modality for widespread $A K$ and does have a place in the

treatment-spectrum of $\mathrm{AK}$, aimed at large surfaces. Compared to treatment with 5-FU, we conclude that Er:YAG laser resurfacing is significantly more effective than topical 5-FU. The treatment and healing period is much shorter with laser resurfacing and therefore the duration of cosmetically disturbing side effects and pain is shorter. However, more side-effects occur after laser resurfacing. We would recommend this field treatment for patients with diffuse widespread $A K$, patients with $A K$ resistant to other treatment modalities, and for patients with multiple malignant lesions in history.

\section{References}

1. Salasche S.J. Epidemiology of actinic keratoses and squamous cell carcinoma. I Am Acad Dermatol, $2000 ; 42(1 \mathrm{Pt} 2): 4-7$.

2. Cockerell C.J. Pathology and pathobiology of the actinic (solar) keratosis. Br J Dermatology, 2003;149(suppl.66): 34-36.

3. Cockerell C.J, Wharton JR. Now histopathological classification of actinic keratosis (incipient intraepidemal squamous coll carcinoma). J Drugs Dermatol 2005:4(4):462-7. 
4. Moy R.1.. C.linical presentation of acrimic keratoses and squamous cell carcinoma. I Am Acad Dermatol, 2000:42(1 P+2):8-10.

5. FU W, Cockerel C.J. The Actinic (Solar) Keratosis. A 21 -st Century Perspective. Arch Dermatol. 2003;139:66-70.

6. Anwar J, Wrone DA, Kimyai-Asadi A, Alam M. The development of actinic keratosis into invasive squamous cell carcinoma: evidence and evolving classification schomes. Clin Dermatol. 2004;22:189-196.

7. Czarnecki D, Meehan (J), Bruce F, Culjak G. The majority of cutaneous squamous cell carcinomas arise in actinic keratoses. J Cutan Med Surg 2002;6(3):207-9.

8. Long CC, Turner RJ, Marks R. Actinic keratosis: the bald facts. Arch dermatol 1996;132:1132-33.

9. I.ebwohl M. Actinic keratosis: epidemiology and progression to squamous cell carcinoma. $\mathrm{Br}$ J Dermatology 2003;149(suppl.66): 31-33.

10. Turrone, W.D., Saini R, Caglar S et all. Topical therapy for actinic keratoses, I: 5-Fluorouracil and imiquimod. Cutis 2003;71:365-70.

11. Drake L..A, Ceilley R.I, Cornelison R.L. Guidelines of care for actinic keratoses. Committee on Guidelines of Care. J Am Acad Dematol 1995;32(1):95-8.

12. Jorizzo Jl.. Current and novel treatment options for actinic keratosis. I Cutan Med Surg 2005;13-21.

13. Dinehart S.M. The treatment of actinic keratoses. I Am Acad Dermatol 2000;42(1 Pt 2): $25-8$.

14. Marmur E.S., C.D. Schmults, and D.J. Goldberg. A review of laser and photodynamic therapy for the treatment of nonmelanoma skin cancer. Dermatol Surg 2004;30(2 Pt 2): 264-71.

15. Edwards $\mathrm{L}$, Levine $\mathrm{N}$, weidner $\mathrm{M}$. Effect of intralesional alpha 2-interferon on actinic keratoses. Arch Dematol 1986;122(7):779-82.

16. Goette D.K. Topical chemotherapy with 5fluorouracil. A review. J Am Acad Dermatol 1981:4(6):633-49.

17. Trimas S.J., D.A. Ellis, and R.D. Metz. The carbon dioxide laser. An alternative for the treament of actinically damaged skin. Dermatol Surg 1997;23(10):885-9.

18. Drnovsek-Olup B, Veldlin B. Use of Er:YAG lasers for benign skin disorders. Lasers Surg Med 1997;21(1):13-9.

19. Chiarello SE. CO2 laser for actinically damaged skin. Dernatol Surg 1997;23:885-889.

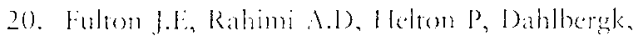
Helly A.c. Disappointimg results following resurfacing of facial skin with $C(O) 2$ lasere for protylaxis of kerieoses and cancers. Dermatol Surg 1999 Sept:25(9):729-32.

21. Massey R.A, Fliezri Y.D. A case report of laser resufacing as a skin cancer prophylaxis. Dermatol Surg 1999;2.5:51.3-516.

22. Jang S.B., levine V.J, Nehal K.S et al. Li:YAC; laser for the treatment of actinic keratoses. Dermatol Surg 2000;26(5):4.37-40.

23. Iyer S, Friedli A, Bowes 1 , et al. Full face laser resurfacing: therapy and proplyylaxis for actinic keratoses and non-melanoma skin cancer. I asers Sury Med 2004;34(2):114-9.

24. David L.M., et al. Laser abrasion for cosmetic and medical treatment of facial actinic damage. Cutis 1989:43(6):583-7.

25. Fitzpatrick, R.E, Goldnan M.P, Satur N.M, et al. Pulsed carbon dioxide laser resurfacing of photo-aged facial skin. Arch Dematol 1996;132(4):395-402.

26. Glogau RG. Physiologic and structural changes associated with aging skin. Derm Clin 1997;15(4):555-559.

27. Yu T.C, Z. Rahman, and B.S. Ross. Actinic keratoses-surgical and physical therapeutic modalities. Cutis 2003;71(5):381-4.

28. Spencer JM, Hazan C, Hsiung SH, Robins P. Therapcutic decision making in the therapy of actinic keratoses. I Drugs Dermatol. 2005 MayJum;4(3):296-301.

29. Jorizzo Jl, Camcy PS, Ko WT, Robins P et al. Treatment options in the management of actinic keratosis. Cutis 2004;74(6 Suppl):9-17.

30. Lawrence $N$, Cox SE, Cockerdl CJ, Frecman $R G$ et al. A comparison of the efficacy and safety of Jessner's solution and $35 \%$ trichloroacetic acid vs $5 \%$ fluorouracil in the treatment of widespread facial actinic keratoses. Arch Dermatol. 1995;131:176-181.

31. Witheiler D.D, Lawrence N, Cox S.F, et al. Long-term efficacy and safery of Jessner's solution and $35 \%$ richlorvacetic acid vs $5 \%$ fluorouracil in the treatment of widespread facial actinic keratoses. Dermatol Surs 1997;23(3): 191-6.

32. Labandeira J, Pereiro J $\mathrm{M}$, Valdes $\mathrm{F}$, Toribio $\mathrm{J}$. Intermittent Topical 5-fluorouracil is effective without significant irritation in the treatment of actinic keratoses but prolongs treatment duration. Dermatol Surg 2004;30:517-520. 
33. Stratigos AJ, Tahan S, Dover JS. Rapid development of nonmelanoma skin cancer after $\mathrm{CO} 2$ laser resurfacing. Arch Dernatol 2002;138:696-97.

34. Venna SS, Lee I), Stadecker MJ, Rogers (iS. Clinical recognition of actinic keratoses in a high risk population. How good are we? Arch Dermatol 2005;141:507-9.

35. Alster TS, Lupton JR. Frbium:Yag cutaneous laser resurfacing. Dermatol Clin 2001; 19(3):453-466.

36. Namni, C.A. and T.S. Alster, Complications of cutaneous laser surgery. A review. Dermatol Surg, 1998;24(2):209-19.
37. Alster, 'T.S. and J.R. I uptom. Prevention and treament of side effects and complications of cutancous laser resurfacing. Plast Recomser buig 2002;109(1):308-18.

38. Manuskiatri, W., R.F. litypatrick, and W.I. Goldman. Long-term effectireness and sideeffects of carbon dioxide laser resurfacing for photoaged facial skin. J Am Acad Dermatol 1999; 40(3):401-11.

39. Quaedvlieg P.J, Ostertag J.U, Krekels Ci. Neumann H.A.M. Delayed wound healing a f fer three different treatments for widespread actinic keratosis on the atrophic bald scalp. Dermatol Surg 2003;29(10): 1052-6; discussion 1056 . 


\section{CHAPTER 3}

\section{Laser resurfacing of congenital melanocytic naevi}

Lapiere K, Ostertag JU, vd Kar T, Krekels GA.

A neonate with a giant congenital naevus: new treatment option with the erbium:

YAG laser.

Br J Plast Surg. 2002 Jul;55(5):440-2.

Ostertag JU, Quaedvlieg PJ, Kerckhoffs FE, Vermeulen AH, Bertleff MJ, Venema AW, vd Geer S, Krekels GA.

Congenital naevi treated with Erbium:Yag laser (Derma-K) resurfacing in neonates: clinical results and review of literature.

Br J Dermatol 2006;154:889-895 
68 CHAPTER 3 


\title{
A neonate with a giant congenital naevus: new treatment option with the erbium:YAG laser
}

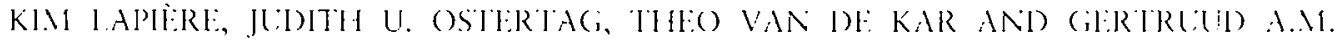 \\ KRFKRIS
}

We report a neonate with a giant congenital nacvus on the scalp, who was treated with the erbium: YAC; laser when she was 9 dars old. This treatment option proved to be a valuable alternattive approach to this problem.

The erbium:YAC (erbium:ytrium-aluminium-garnet) haser is a $2940 \mathrm{~nm}$ tissueablation haser with a higher absorption coefficient for water and a lower optical penetration depth than the $\left(C_{2}\right)_{2}$ laser. The depth of vaporisation is $20-40 \mu \mathrm{m}$ per laser pass, so very superficial peels can be achieved. Compared with the $\left(\mathrm{O}_{2}\right.$ laser, treatment with the crbium:YAC; laser leads a shorter re-epithelialization time and a shorter duration of erythema, for the same depth of injury. I, Ihis laser has already been used for a diversity of cutancous resurfacing procedures. With the erbium:YAC laser it is possible to accurately ablate the epidermis inte the papillary dermis layer by layer.

We report the use of this laser to treat a giant congenital naevus of the scalp in a 9 day-old girl.

\section{Case report}

$A$ baby girl born at full-term following a normal pregnancy presented with a $10 \mathrm{~cm} x$ $6 \mathrm{~cm}$ large sharply demarcated hyperpigmented lesion on the right side of her scalp and forehead. The surface of this lesion was party papillomatous with the groweth of coarse terminal hairs (Fig. 1). She was otherwise healthy, took breast feeding and required no medication. An MRI scan of the brain showed no involvement of the underlying meninges. A clinical diagnosis of a giant congenital maevus was made.

The parents gave their informed comsent for treatment, so at 9 days old she underwent general anaesthesia and treatment with the erbium:YAC laser (Derma K, HSC: Medical Systems Inc). The laser setrings were as follows: erbium-mode; flucnce $14 \mathrm{~J}$ $\mathrm{cm}^{2} ; 3 \mathrm{~mm}$ spot size; frecuency $8-10$ pulses $s 1$. At this setting, the entire naevus was treated in two or three passes with overlap. At the end point, the resurfaced skin was pink and shiny with pin-point bleeding (lig. 2). Some pigment remained in the follicles, and was treated separately at a lower fluence, $7 \mathrm{Jcm}^{-2}$. Some blood vessels were coagulated by using the $\mathrm{C}_{2} \mathrm{O}_{2}$ mode, $4 \mathrm{~W}$.

The wound was dressed with a hydrocellular polyurethane dressing (Allevyn). Postoperatively, there was a slight decrease in blood hacmoglobin, which recovered without treatment. Wound cultures were taken 2 days postoperatively and showed no bacterial growth; 1 week postoperatively there was growth of Staphylocoscus anyeus, which was left untreated without conseguence. Further follow-up was unremarkable, and nomal re-epithelialization was complete in 10 days. At 16 months follow-up there was no evidence of 


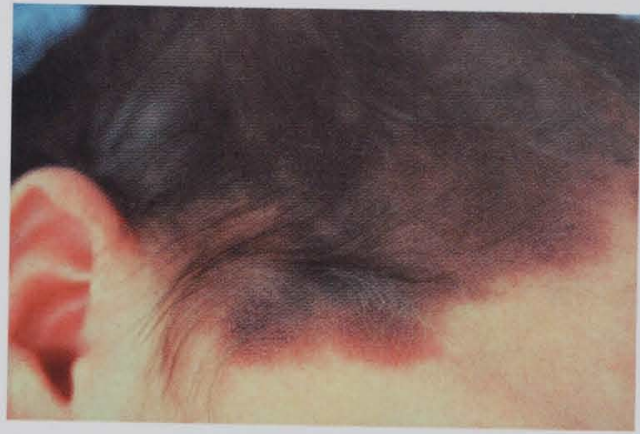

Figure 1: A newborn with a giant congenital naevus on the scalp and forehead (shown at 7 days old).

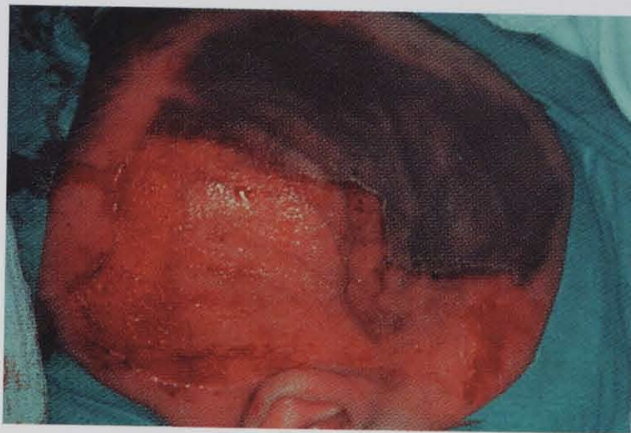

Figure 2: Appearance during treatment with the erbium:YAG laser; note the treated portion of the lesion, showing removal of pigmentation, pink shiny resurfaced skin and pin-point bleeding.

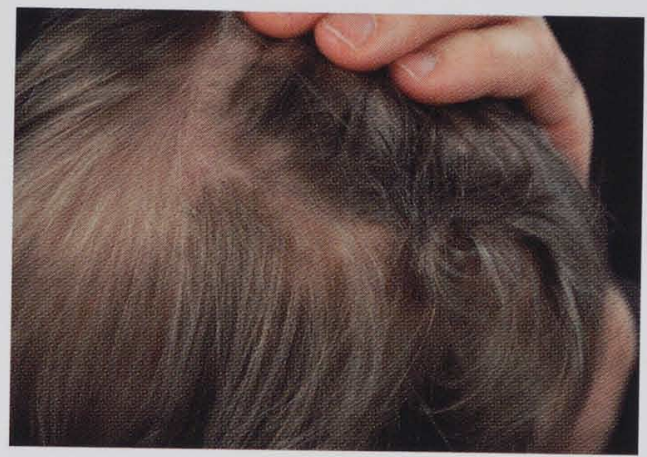

Figure 3: Appearance 16 months after erbium:YAG laser treatment re-pigmentation, hair growth was normal and an excellent cosmetic result had been achieved (Fig. 3).

\section{Discussion}

Congenital naevo-melanocytic naevi (CMN) are, by definition, present at birth. The prevalence is equal in males and females, and they have been described in all races. Congenital naevi are present in $1 \%$ of all Caucasian newborns, and the majority are smaller than $3 \mathrm{~cm}$ in diameter. Larger naevi are present in one in every 200020,000 newborns. Lesions larger than 20 $\mathrm{cm}$, real giant naevi, occur in one in 500,000 newborns. ${ }^{3}$

For descriptive purposes, naevi can be classified according to diameter: small naevi measure less than $1.5 \mathrm{~cm}$, intermediate naevi measure up to $20 \mathrm{~cm}$ and giant naevi measure over $20 \mathrm{~cm}$ (expected diameter at adult age). 3,4

The pathogenesis of CMN is not yet known. They are presumed to occur as the result of a developmental defect in neuralcrest-derived melanoblasts. ${ }^{3}$

Histological examination of CMN shows naevomelanocytes in well-ordered clusters in the epidermis and in sheets and nests in the dermis. ${ }^{3}$ In giant CMN the naevoid cells can extend more deeply into the deep dermis and adnexal structures, and may even be seen in fat and muscle. Naevoid cells may also be found in the hair follicles, in erector pili muscles, within the nerve sheath and in blood vessels. ${ }^{5}$ However, it has been shown that, in the newborn, the naevus cells lie mainly in the upper dermis. Later, the cells migrate more deeply, as the lesion matures. ${ }^{5-8}$ One study showed that the naevoid cells in the upper dermis were heavily pigmented and HMB-45 positive, while the lower dermis contained a lessdense diffuse infiltration of non-pigmented naevoid cells, which were HMB-45 negative. $^{9}$ 
In the management of congenital natevi two main problems need to be considered. First, these lesions have the potential for malignant change, neccssitating prophylactic removal. Second, there are cosmetic considerations, particularly for giant lesions and those located on the face and scalp. The main indication for treatment of $\mathrm{CMN}$ results from the increased risk of malignant change within the naevus. The lifetime risk for the development of melanoma in large CMN has been estimated to be $5-6.3 \% .8,10$ This is a 17 -fold increase in relative risk compared with the general population. Sixty percent of these melanomas arise before the age of 10 years. ${ }^{8}$ Once a melanoma develops, the prognosis is very poor: onethird of patients die within a year. The risk of mortality from melanoma is 1000 times higher in patients with giant CMN than in the general population. ${ }^{10}$

Treatment options can be divided into two main groups. One approach is the complete excision of the lesion. This method is the most effective at eliminating the oncogenic potential; however, it is not technically possible in every case. Large lesions in the head and neck area present a difficult surgical problem, even if complex reconstructive surgical procedures are undertaken using tissue expanders, serial excisions or: split-skin grafts. ${ }^{11}$

An alternative approach is a more superficial and partial removal of the lesion to reduce the number of pigmented cells and so reduce the risk of malignant transformation. ${ }^{8}$ In these cases, it is important to treat the lesion as early as possible, because partial removal in the early phases can remove the majority of the most active, most pigmented and HMB-45 positive cells, which are localised in the upper dermis. Later in life, the naevoid cells migrate deeper into the dermis, and become too deep to be removed by a superficial procedure. ${ }^{5-7,9,11,12}$ This superficial approach may use dermabrasion, ${ }^{8}$ curettage, ${ }^{5-7,9,12}$ tangential exci-

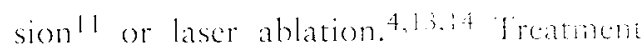
early in life is easier because there is a natural cleavage plane between the upper and the deeper dermis. $5,6,9,15$ Farly treatment also gives a better cosmetic result, with less or no re-pigmentation. 6,7

We describe a new treatment in the neonatal period with the erbium:YAG laser. We chose the erbium:YAG laser for several reasons. With this type of laser it is possible to very precisely control the depth of ablation, with minimal thermal damage to the subjacent structures. The depth of vaporisation is 2-4 $\mu \mathrm{m}$ for each $1 \mathrm{~J} \mathrm{~cm}^{-2}$, so at fluences of $10-20 \mathrm{~J} \mathrm{~cm}^{-2} 10-40 \mu \mathrm{m}$ of tissue with each pass. Unlike the $\mathrm{CO} 2$ laser, the erbium:YAG laser does not reach a plateau of tissue ablation: the number of passes used is linearly correlated with the depth of vaporisation. Another great advantage of the erbium:YAG laser is that at these fluences the amount of thermal necrosis remains constant $(15-40 \mu \mathrm{m})$ however many passes are made. So there is far less thermal damage to subjacent structures than with the CO2 laser, resulting in fewer side effects, such as scarring and pigmentary changes, and a decreased recovery period. 1,2

The precise depth control possible with the erbium:YAG laser means that we can adjust the treatment according to what we see clinically during the resurfacing: residual pigmentation can be treated with an extra pass, while areas with no more pigment can be skipped. The only disadvantage of the erbium:YAG laser is that the coagulation effect on the blood vessels is smaller than with the $\mathrm{CO}_{2}$ laser, so treated areas are more likely to bleed. To improve haemostasis, we can combine the erbium: $Y A G$ laser with a low-fluence $\mathrm{CO}_{2}$ laser (Derma $\mathrm{K}$ has an erbium and a $\mathrm{CO}_{2}$ mode). 1,2 The procedure can be done very quickly, so that only a short period of general anaesthesia is necessary, which is well tolerated by a healthy newborn. The technique is very safe in experienced hands, and 
gives an excellent cosmetic result. There fore, we strongly recommend the early tratment of these C.MN, not only for oncological control but also to prevent stigmatisation in later life. With the crbium:YAG laser we can offer our paticnts a safe treatment with excellent cosmesis.

\section{References}

1. Acland KM, Barlow RJ. lasers for the dermarologist. Br J Dermatol 2000; 143: 244-5.5.

2. Ratner D, Tse $Y$, Marchell N, Goldnan MP, Fitzparrick RE, Fader DJ. Cutaneous laser resurfacing. J Am Acad Dermatel 1999; 41:36.5-89.

3. Rhodes AR. Benign neoplasias and hyperplasias of melanocytes. In Fitzpatrick TB, ed. Dermatology in General Medicine, 5th ed. New York: McGraw-Hill, 1999: 1018-51.

4. Kay AR, Kenealy J, Mercer NSG. Successful treatment of a giant congenital melanocytic naevus with the high energy pulsed $\mathrm{CO} 2$ laser. Br J Plast Surg 1998; 51: 22-4.

5. Moss ALH. Congenital 'giant' naevus: a preliminary report of a new surgical approach. $\mathrm{Br} J$ Plast Surg 1987; 40: 410-19.

6. Johnson HA. Permanent removal of pigmentation from giant hairy naevi by dermabrasion in carly life. Br J Plast Surg 1977; 30: 321-3.

7. Miller CJ, Becker DW. Removing pigmentation by dermabrading naevi in infancy. $\mathrm{Br} J$ Plast Surg 1979; 32: 124-6.

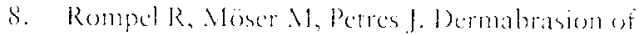
consental nevecollutal neve experience in 215 patients. Devmatologs: 1997;194:261-7.

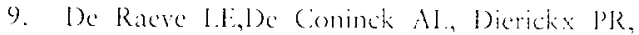
Rosecuw I)!. Neonatil curettage of giant congenital melanocytic nevi. Arch Dermatol $1996 ; 1.32: 20-2$.

10. Swerdlow AJ, English JSC, Qiano 7. The risk of melanoma in patients with congenital nevi: a cohort study. J Am Acad Dermatol 1995; 32: 595-9.

11. Lawrence CM. Treatment options for giant congenital naevi. Clin Exp Dermatol 2000; 25: $7-11$.

12. Casanova D, Bardot J, Andrac-Meyer I., Magalon G. Early curettage of giant congenital naevi in children. Br.J Dermatol 1998;138:3415 .

13. Michel JI, Chalencon F, Mazzocchi C, Roux V, Metafiot $H$, Cambazard $F$. Traitement par laser $\mathrm{CO} 2$ resurfacing des naxus congénitaux géants. Ann Dermatol Venereol 2000; 127: 661.

14. Arons MS. Successful treament of a giant congenital melanocytic naevus with high-energy pulsed CO2 laser. Br J Plast Surg 1998;51:5701 .

15. Michel J-L, Laborde-Milaa Roux V, Chavrier Y, et al. Curetage néonatal des naevus congénitaux géants. Ant Dermatol Vencreol 2000; 127:238. 


\section{Congenital naevi treated with erbium: YAG laser (Derma-K) resurfacing in neonates: clinical results and review of literature.}

JUDITH U. OSTERTAG, PATRICIA J.F. QUAEDVI.IEG, FREDERIQUE E.M.J. KERCKHOFFS, ANTON H.M. VERMEULEN, MARTINA J.O.E. BERTLEFF, A.WIM VENEMA, SIMONE. VAN DER GEER, GERTRUUD A.M. KREKELS

BACKGROUND.Giant congenital melanocytic naevi (CMN) are often disfiguring, potentially malignant pigmented lesions present at birth. Their management is based on two main considerations: attempt to minimize the risk of malignancy and to obtain an acceptable cosmetic result. In the past various approaches have been used to treat these naevi. OBJECTIVES. To describe clinical and histopathological results after treatment of CMN in neonates with erbium:YAG (Er:YAG) laser resurfacing. METHODS. 10 Children with CMN were treated with the Er:YAG laser resurfacing in the first weeks of life. RESULTS. Laser ablation is well tolerated by all children and immediate results are good. At a total follow-up ranging from 3 months to 36 months we saw good results, with no or minimal repigmentation, in 8 of 10 patients. Patients experienced minimal side-effects such as postoperative pain, bleeding and scar formation. Postoperative histopathology showed disappearance of heavily pigmented cells in the upper part of the dermis. CONCLUSION. Er:YAG laser resurfacing is an effective method of ablating CMN, with minimal scarring and postoperative complications. KEYWORDS. Congenital naevi, Erbium-YAG laser treatment, Neonates.

\section{Introduction}

Congenital melanocytic naevi (CMN) are often disfiguring and potentially malignant lesions that are present at birth. CMN are present in $1 \%$ of all Caucasian newborns. ${ }^{1,2}$ They can be classified according to their largest diameter. The most common classification is based on the predicted adult size of the naevus ${ }^{1,3}$ Other classifications are based on the percentage body surface area affected or whether or not the lesion is operable. ${ }^{4}$ The treatment of these lesions is based on two principles: limiting the risk of malignant change and obtaining an acceptable cosmetic result. Especially in the giant CMN (GCMN), the cosmetic result is of importance to decrease the potential psychosocial problems. Various therapeutic approaches such as surgical excision, dermabrasion ${ }^{5,6,7}$, curettage $8,9,10,11,12$, cryosurgery, chemical peeling ${ }^{3}$ and $\mathrm{CO}_{2}$-laser dermabrasion $13,14,15,16$ have been used in the past in treating $\mathrm{CMN}$. Nevertheless the best way to treat a CMN still remains an issue. We have previously reported the successful use of the erbium:YAG (Er:YAG) laser (Derma $K$, Lumenis ${ }^{T . M}$ Ltd) in the treatment of a GCMN on the scalp in a 9-day-old girl. ${ }^{7}$ We have since then treated 10 neonates with CMN with the Er:YAG laser. The immediate results and follow-up are presented. Our results show that this method provides good to excellent cosmetic results for any size of CMN with minimal-side effects such as scarring, pain and bleeding. 


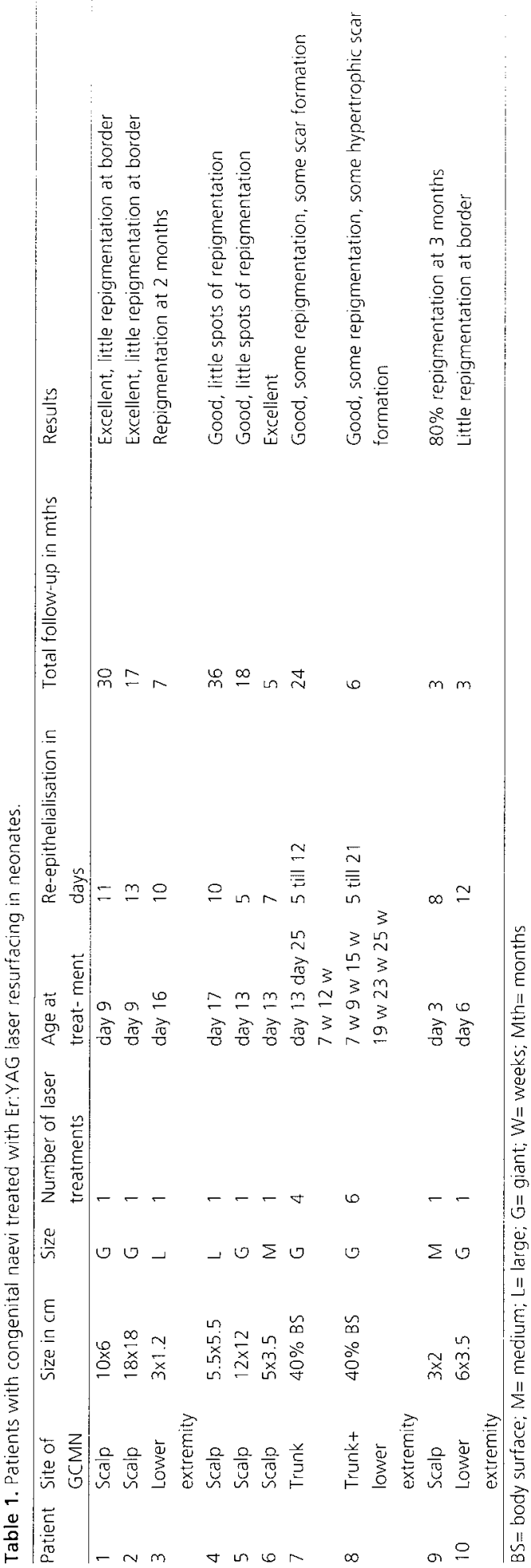

\section{Patients and methods}

We treated 10 neonates (six girls and four boys) with the Er:YAC; laser (Derma K, Lumenis $\left.{ }^{M} L+d\right)$. The C.MN were located on the scalp, trunk and extremities and according to Kopf et al ${ }^{1}$ they were classified as two medium, two large and six giant nevi (Table 1). In six patients the CMN were located on the scalp, two patients had CMN on the lower extremity. Patients 7 and 8 had GCMN on the trunk, buttocks and genital region that accounted for more than 40 percent of body-surface.

Treatment was performed after parents gave informed consent about the Er:YAG laser treatment. The first patients were admitted to a medium care unit postoperatively, later patients were treated in the outpatient clinic. In the patients with the GCMN on the scalp and lower extremities one treatment session was performed. Before treatment the hairs were shaved. All patients were treated in the first weeks of life (ranging from day 3 to day 17). Patients 7 and 8 with the GCMN on the trunk were treated in multiple sessions, because of the extent of the lesion. In these children we did several test-spots under local anesthesia with lidocaine/prilocaine cream (Emla ${ }^{\circledR}$; AstaZeneca) to evaluate the effect of therapy on different areas of the body. In each treatment session the wound surface did not exceed 10 percent of body-surface, which we regarded safe considering the possible complications of large wound surface in neonates. Patient 7 was therefore treated in four sessions at day 13, day 25,7 weeks and 12 weeks of age. Patient 8 was born premature at 29 weeks. She had her first treatment 7 weeks after birth. The other treatment sessions followed at 9 weeks, 15 weeks, 19 weeks, 23 weeks and 25 weeks of age. Depending on the extent and location of the lesion the procedure was performed with general anesthesia in six children, with spinal anesthesia in one child and with local 

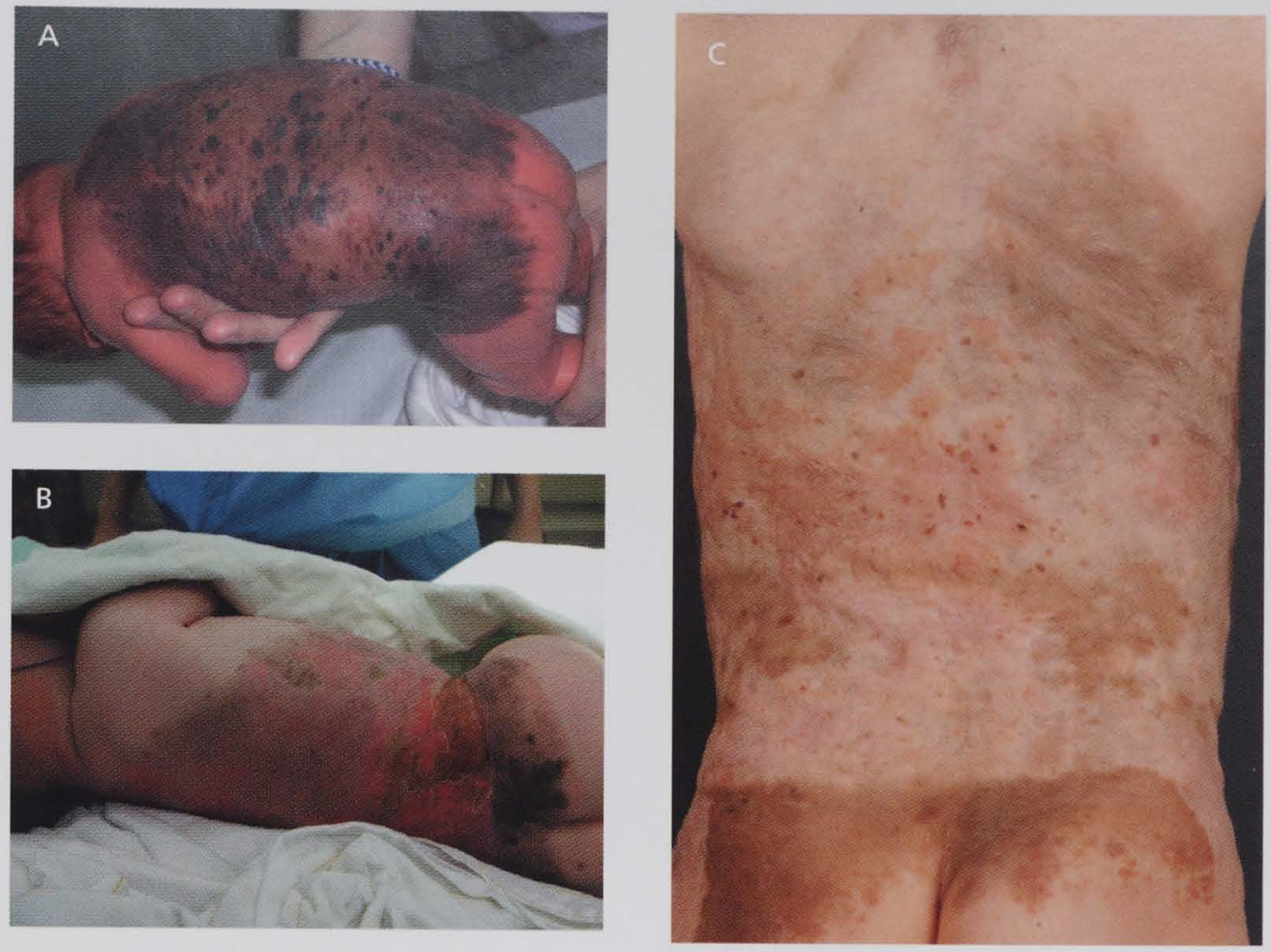

Figure 1A: Patient nr 7 with GCMN on the back pre-operatively.

Figure 1B: Patient $\mathrm{nr} 7$ with GCMN on the back 3 months postoperatively during additional treatment session. Figure 1C: Patient nr 7 with GCMN on the back 26 months postoperatively. Buttocks have not been treated.

anesthesia with lidocaïne/prilocaïne (Emla ${ }^{\circledR}$ cream) in three children. All children were treated with the same type of Er:YAG laser (Derma K, Lumenis ${ }^{\mathrm{TM}}$ Ltd). The fluence varied from 7 to $20 \mathrm{~J} / \mathrm{cm}^{2}$, in the pure Erbium mode, with a pulse rate varying from 8 to 12 pulse per second and spotsize 3 or $6 \mathrm{~mm}$. The laser settings depended on localisation of the lesion, thickness of the $\mathrm{CMN}$ and speed of working. Most CMN were treated in several passes with overlap. Ablation was performed until the visible pigmented part was removed down into the papillary dermis, so that an even wound surface was created. Pigment that remained around the follicles was treated separately with lower fluences. After laser treatment, silver sulfadiazine (Flamazine ${ }^{\circledR}$; Smith \&
Nephew Healthcare) was applied and the wound was dressed with an absorbent dressing either hydrocellular polyurethane (Allevyn ${ }^{\circledR}$; Smith \& Nephew Healthcare) or silicone (Mepilex ${ }^{\circledR}$; Mölnlycke). These dressings were changed once daily until total re-epithelialization was completed.

Seven of the ten children had one or several biopsies analyzed. In five patients biopsies were taken before laser treatment, in two patients during treatment immediately after laser ablation and in four patients postoperative during follow-up. 


\section{Results}

The intervention was well tolerated by all children and no major complications occurred after laser resurfacing. Ablation was easy to perform during all treatment sessions. There was none or minimal bleeding during and after treatment. Patients scemed to experience hardly any postoperative pain, noticed by physicians and parents. No post op analgesia was required except in some cases paracetamol was administered during change of bandage. In patient 7 wound healing was disturbed by a varicellazoster infection that was treated with aciclovir. Two other patients had a Staphylococcus aureus skin infection that was left untreated in patient 1 without consequence and in patient 8 was treated topically with fusidic acid (Fucidin ${ }^{\circledR}$; Leo) with good results. Re-epithelialization was complete within 5-13 days (median 9) in nine patients. Patient 8, who was born premature, had a prolonged wound healing of 21 days after the first treatment session. How ever, after the following treatment sessions wound healing was normal in this patient.

All children showed good to excellent results a few weeks after laser treatment was performed. Patients showed some erythema, hut no repigmentation and no scarring (Figure. 1-31. The total follow-up period ranged from 3 months to 36 months. Patients 3 and 9 showed repigmentation of the naevus $?$ and 3 months after treatment. In all other patients good results were observed during follow-up. In two patients there were no signs of repigmentation at all and in six patients there were spots of repigmentation or minimal repigmentation at the border of the lesion. Two patients ( 7 and 8 ) with large GCMN on the trunk developed hypertrophic scars and skin atrophy. Hair growth was not influenced by our treatment; in particular, alopecia did not occur on the scalp.

In Five patients histopathologic analysis was performed before treatment (Table 2). l'igmented nacvus cells, predominanty in nests, occupied the upper dermis and the lower dermis contaned a less dense diffuse infiltration of non-pigmented naevus cells (Figure 4). Depth of pigment varied from 0.14 to $0.70 \mathrm{~mm}$ measured in the MassonFontana staining. The pigment was seen both in naevus cells and in macrophages. Additional staining was performed with Melan-A, \$100 and HMB-45. Biopsies before laser treatment showed already deep dermal melanocytic involvement even into the subcutaneous fat in neonatal period.

Serial biopsies during follow up in patients 7 and 8 showed no difference in depth of naevus cells with time. The epidermis and heavily pigmented nevus cells were absent in biopsies taken directly after laser treatment (Figure 5). The Masson-Fontana staining showed only sporadic pigmentation in the residual papillary dermis and superficial reticular dermis. Postoperative biopsies during follow-up of patient 7 and 8 showed an upper dermis composed of a dense connective tissue with minimal fibrosis. Heavily pigmented naevus cells were no longer seen in the upper dermis, but the lower dermis still showed a diffuse infiltration of non-pigmented nevus cells. In the two patients ( 3 and 9) with clinical recurrence of pigmentation, biopsies showed some fibrosis and pigment in naerus cells and macrophages, mainly in the papillary dermis and superficial reticular dermis (Masson -Fontana staining). These naevus cells were melan A, S100 and H.MB-45 positive and infiltrated deep in the reticular dermis.

\section{Discussion}

The management of GCMN is still a difficult issue. The general attempt is to minimize the disfiguring appcarance of these lesions and to minimize the risk of malignancy. The latest published results from large prospective and retrospective studies report estimated risks of malignant transfor- 
Table 2. Data of histologic analysis before laser treatment.

\begin{tabular}{|c|c|c|c|c|c|}
\hline Patient & Biopsy site & $\begin{array}{l}\text { Depth nevus cells, } \\
\text { melan A }\end{array}$ & $\begin{array}{l}\text { Depth pigment in } \mathrm{mm} \text {, } \\
\text { masson fontana }\end{array}$ & $\operatorname{HMB} 45$ & Depth nevus cells, $\$ 100$ \\
\hline 4 & Scalp & ST & 0.21 & + & ST \\
\hline 5 & Scalp & ST & 0.48 & + & ST \\
\hline \multirow[t]{2}{*}{7} & Trunk & $S T$ & 0.34 & + & ST \\
\hline & Lower extremity & $S T$ & 0.52 & + & ST \\
\hline \multirow[t]{2}{*}{8} & Lower extremity & ST & 0.7 & + & $S T$ \\
\hline & Trunk & ST & 0.14 & + & ST \\
\hline 10 & Lower extremity & ST & 0.43 & + & ST \\
\hline
\end{tabular}

$\mathrm{ST}=$ subcutaneous tissue

mation of 0.05 to $2.8 \% .18,19,20,21$ Even after complete excision however, the malignancy risk is not completely eradicated as naevus cells can extend deep into the subcutaneous fat, fascia and underlying tissue and malignant melanoma can still occur at extracutaneous sites. 22,23 Complete removal of CMN and especially GCMN by surgical excision is usually difficult and often impossible without functional or cosmetic mutilation. Various other therapeutic modalities besides surgical excision are being used in treating (G)CMN, such as dermabrasion $5,6,7$, curettage $8,9,10,11,12$, cryosurgery, chemical peeling. ${ }^{3}$ and $\mathrm{CO}_{2}$ laser dermabrasion $13,14,15,16$.

In the literature there is little information about CMN and the Er:YAG laser. This $2940 \mathrm{~nm}$ tissue ablation laser with a higher absorption coefficient for water and a lower optical penetration depth than the $\mathrm{CO}_{2}$ laser. The depth of vaporization is $20-40 \mu \mathrm{m}$ per laser pass, so very superficial peels can be achieved. It is possible to perform accurate ablation of the epidermis into the papillary dermis layer by layer, without mechanical force. The thermal injury with the Er:YAG is significantly less deep than with the $\mathrm{CO}_{2}$ laser. Compared with the $\mathrm{CO}_{2}$ laser, treatment with the Er:YAG laser gives a shorter re-epithelialization time and a shorter duration of erythema, for the same depth of injury. ${ }^{24,25}$ Another advantage is that patients experience less pain after Er:YAG laser treatment compared with other treatment modalities. A disadvantage of the Er:YAG laser is that it has a smaller coagulation effect on the blood vessels than the $\mathrm{CO}_{2}$ laser, so treated areas are more likely to bleed a little.

In our study of 10 patients, however, we found none or minimal bleeding during and after ablation. Re-epithelialization was completed within 5-13 days (median 9); in two patients wound infection occurred which was treated topically with good results. Wound healing time after Er:YAG laser ablation is shorter than after dermabrasion and curettage. In these treatments re-epithelialization occurred after 10 14 days. ${ }^{7,11}$ Postoperatively, children needed infusion of fluid and electrolytes after dermabrasion and $2.8 \%$ even needed blood transfusion. Other complications are fever in $10 \%$ and wound infection in $6 \% .^{7}$ In curettage, complications are wound infection in 10-12.5\% 8,12 and hypertrophic scars/cicatricial alopecia in $18.8-28.6 \% .8,9$ In our patients fever did not occur and there was no need of infusion or blood transfusion. We noticed no alopecia in the patients treated on the scalp. De Raeve and Roseeuw $^{8}$ mentioned the need of an intensive care unit postoperatively. Based on the postoperative care after curettage and dermabrasion, our first patients were admitted to a medium care unit; we noticed, however, that patients were experiencing less pain and their overall condition was very good postoperatively. Therefore, the follow- 

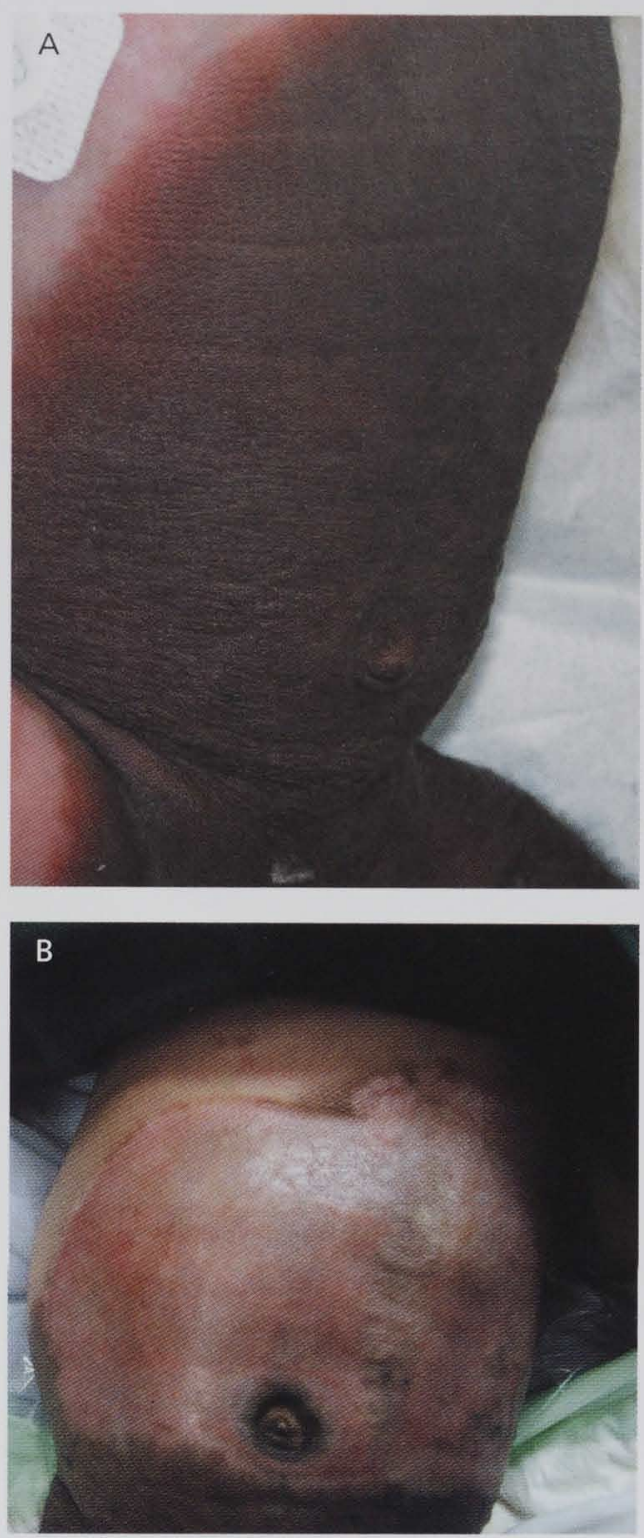

Figure 2A: Patient nr 8 with GCMN on the trunk preoperatively.

Figure 2B: Patient nr 8 with GCMN on the trunk, 2 months postoperatively.
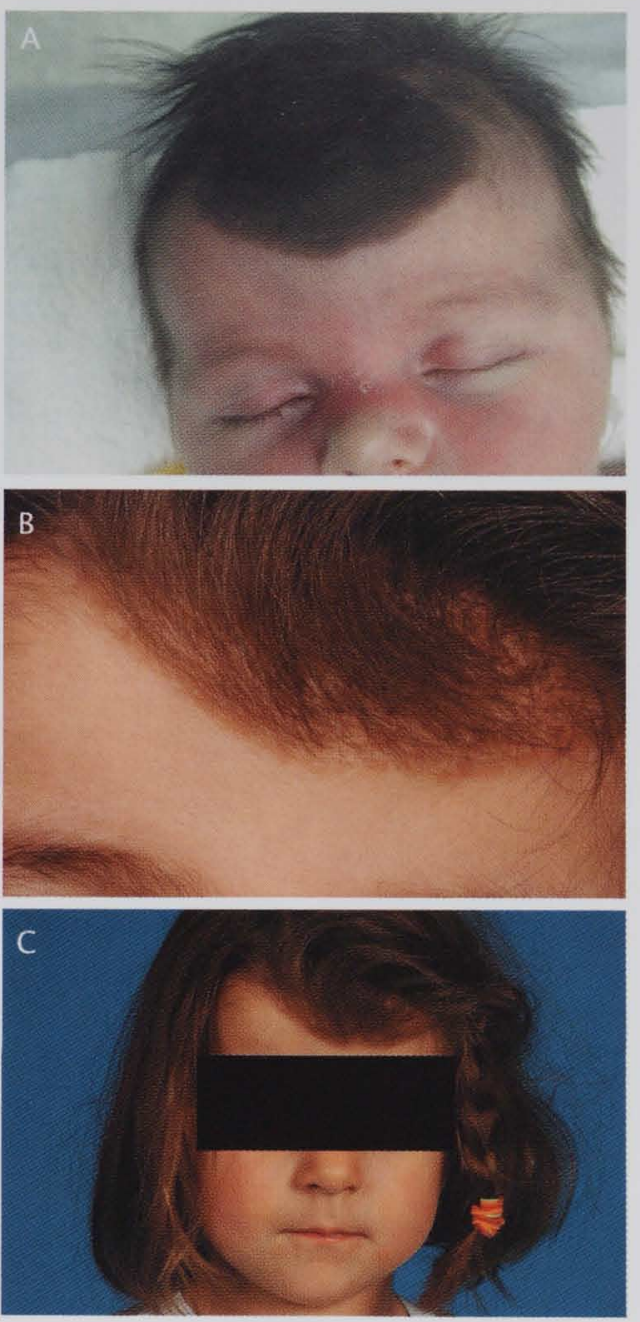

Figure 3A: Patient nr 4 with CMN on the scalp, preoperatively.

Figure $3 \mathrm{~B}$ and $3 \mathrm{C}$ : Patient $\mathrm{nr} 4$ with $\mathrm{CMN}$ on the scalp, 36 months postoperatively. 


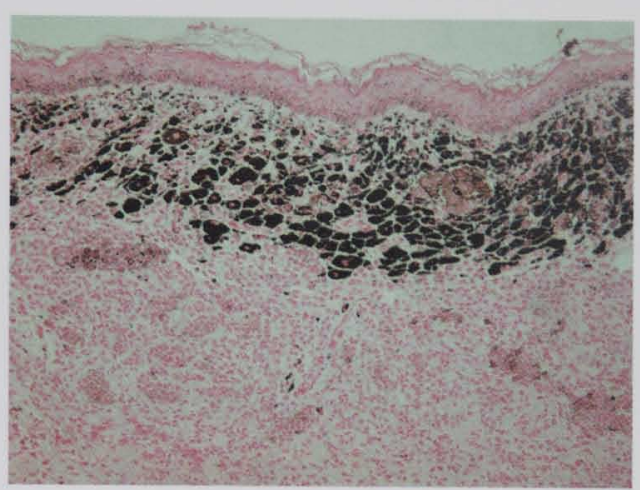

Figure 4: Pre-operative heavily pigmented naevus cells in upper part of the dermis (Masson-Fontana staining), patient $\mathrm{nr} 7$.

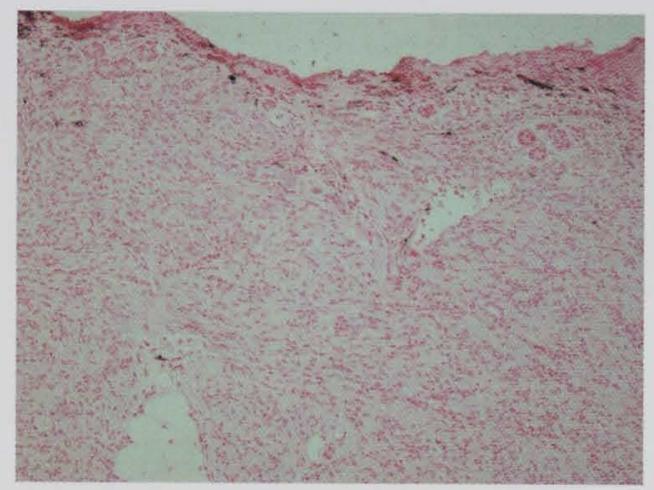

Figure 5: Immediately after ablation. Epidermis and upper part of the dermis removed resulting in absence of pigmented part of the naevus. Lower dermis still shows a diffuse infiltration of nonpigmented naevus cells. (MF staining). Patient $\mathrm{nr} 7$.

ing patients were treated in the outpatient clinic. Our cosmetic results were good to excellent. Two Patients had no signs of repigmentation at all and six patients had minimal spots of repigmentation or little repigmentation at the border of the lesion. Patients 3 and 9 with small nevi on scalp and lower extremity, showed repigmentation 2 and 3 months after treatment.

Bohn et al. reported the need for surgical reconstruction after dermabrasion to improve aesthetic results in $50 \%$ of their patients 26 Repigmentation of $80-100 \%$ was seen in $37 \%$ of the patients in the study of Rompel et al., best results were seen in large and giant naevi. 7 Small naevi, on the other hand showed, more repigmentation, Moss drew the same conclusions. ${ }^{12}$.After curettage, poor, unsatisfactory results were reported in 22-30\%. 10,12 De Raeve and Roseeuw saw a slight repigmentation in all cases after 1 year. ${ }^{8}$

There is a wide variation in the reported histological appearances of congenital naevi, and there may also be differences between small and large naevi in histology. 7,12,27 In GCMN naevus cells can be present throughout the dermis, in adnexal structures, and penetrate into fascia or even into muscle. Small congenital naevi, however, often show a very superficial or predominantly junctional location of naevus cells without deeper infiltration. ${ }^{28}$ In our cases in which biopsies were taken before laser ablation the maximum depth of pigment was measured, we found no correlation between size of naevus and depth of the pigmented part. It is interesting that in that naevus cells were already located deep in the dermis and in even into the subcutaneous fat in neonatal period. Some authors claim that in the first few months of life naevus cells in GCMN are mainly present in the upper dermis but later penetrate into the skin, as was first hypothesized by Miller and Becker. ${ }^{6}$ In some studies it is therefore noted that removal of the upper dermis can only give significant cosmetic improvement if performed before a certain age. We found no changes in depth of naevus cells with time in serial biopsies of two patients. This is not in agreement with the theory of migration. There is no histological supportive evidence that naevus cells do migrate deeply with increasing age. ${ }^{29,30}$ Fenton et al. found that many large $\mathrm{CMN}$ demonstrate deep dermal involvement in the neonatal period, which does not change with age. ${ }^{31}$ RuizMaldonado et al. also described deep der- 
mal involvement in GCMN in the noonatal period, contradicting the hypothesis that naevus cells migrate into the dermis during infancy and naevus cell depth is modified with age. 22

Our results of histopathological analysis showed that before treatment the upper dermis of GCMN was entirely occupied by pigmented naevus cells predominantly in nests and the lower dermis contained a less dense diffuse infiltration of non-pigmented naevus cells. De Raeve and Roseeuw suggested that the curetted superficial naevus cells might be biologically different from the retained deeper cells because superficial naevus cells stained positive for the melanocyte marker HMB-45 whereas deeper naevus cells did not. ${ }^{8}$ We could not confirm this statement. In our patients all naevus cells stained HMB-45 positive. Nevertheless, there was a tendency for the stained naevus cells in the papillary dermis and superficial reticular dermis to have more intense colour than the deeper cells. After treatment the entire upper dermis was composed of dense connective tissue with some degree of sclerosis, but heavily pigmented naevus cells were no longer seen. This is an indication that treatment was successful and had been performed at the correct depth. The deeper dermis still contained a diffuse infiltration of nonpigmented naevus cells.

Although in our study clinical outcome was not influenced by age at time of treatment, other studies have shown that best results were achieved if treatment was performed in the first weeks of life. In contrast with previous assumptions, this seems not to be due to migration of melanocytes, but another factor might be involved. It is unclear until what age Er:YAG laser may still give satisfying results. Additional treatment with a different laser might be necessary to remove the residual hairs. Although Er:YAG laser treatment reduces the number of heavily pigmented naevus cells, follow-up is too short to draw any conclusions about the pessibility of reducing the risk of malis nancy. One should kecp in mind that decper naevus cells remain, as well as nacvus cells outside the skin. Although this type of management improves the aesthetic appearance of CMN, it does not influence the potential risk of malignant transformation due to remaining naevus cells. $32,3.3$ As patients with large CMN are at risk for the development of malignant melanoma, they should be kept under regular clinical surveillance for the development of cutaneous as well as noncutaneous primary malignant melanoma. ${ }^{34}$

\section{Conclusion}

In comparison with other treatment modalities such as curettage, surgery and dermabrasion, Er:YAG laser resurfacing is an effective method of ablating CMN with minimal risk of scarring and complications. A major advantage of Er:YAG laser treatment is that we did not see alopecia on the scalp, and patients experienced less pain postoperatively in comparison with other treatment options.

In the past, early treatment was claimed to be necessary, but this claim now seems to be controversial. Our histological findings do not support this assertation. Our treatment outcome doe not exclude the risk of malignant transformation and regular follow-up for malignant development remains necessary.

\section{References}

1. Kopf AW, Bart RS, Hennessy P. Congenital nevocytic nevi and malignant melanomas. I Am Acad Dermatol. 1979;1:123-130.

2. Rhodes AR. Benign neoplasias and hyperplasias of melanocytes. In Fitzpatrick TB ed. Dermatology in General Medicine, 5th ed. New York: Mc Graw-Hill, 1999:1018-51. 
3. Hopkins JD, Smith AW, Jackson IT. Adjunctive tratment of congenital pignented nevi with phenol chemical peel. Plast Reconstr Surg 2000;105:1-11.

4. Zaal I.I, Mooi WJ, Sillevis Smitt JH, van der Horst CMAM. Classification of congenital melanocytic naevi and malignant transformation: a review of the literature. $\mathrm{Br}$ J Plast Surg 2004; 57: 707-719.

5. Johnson HA. Permanent removal of pigmentation from giant hairy naevi by dermabrasion in early life. Br J Plast Surg 1977;30:321-3.

6. Miller CJ, Becker DW. Renoving pigmentation by dermabrading naevi in infancy. Br J Plast Surg 1979;32:124-6.

7. Rompel R, Möser M, Petres J. Dermabrasion of congenital nevocellular nevi: experience in 215 patients. Dermatology 1997:194:261-7.

8. De Raeve LE, Rosecuw DI. Curettage of giant congenital melanocytic nevi in neonates: A decade later. Arch Dermatol 2002;138:943-8.

9. Michel JL, Laborde-Milaa Roux V, Chavrier Y et al. Neonatal curettage of giant congenital nevi. Ann Dermatol Venereol 2000;127(1):238.

10. Casanova D, Bardot J, Andrac-Meyer I, Magalon G. Early curettage of giant congenital naevi in children. Br J Dermatol 1998;138:3415.

11. De Raeve LE, De Coninck AL, Dierickx PR, Roseeuw DI. Neonatal curettage of giant congenital melanocytic nevi. Arch Dermatol 1996; 132:20-2.

12. Moss AL.H. Congenital giant naevus: a preliminary report of a new surgical approach. $\mathrm{Br} J$ Plast Surg 1987;40:410-9.

13. Reynolds N, Kenealy J, Mercer N. Carbon dioxide laser dermabrasion for giant congenital melanocytic nevi. Plast Reconstr Surg 2003;111:2209-14.

14. Michel JL. Lasertherapy of giant congenital melanocytic nevi. Eur J Dermatol 2003;13:5764.

15. Kay AR, Kencaly J, Mcrcer NS. Successful treatment of giant congenital melanocytic nevus with the high energy pulsed $\mathrm{CO}_{2}$-laser. Br J Plast Surg 1998;51:22-4.

16. Michel JI., Caillet-ChomeI I. Traitement par laser $\mathrm{CO}$ ? superpulsé des nevus congénitaux géants. Arch Pediatr. 2001;8:1185-94.
17. Lapierek, Ostertag JU, Van der Kar 'T, Krekels (i. A neonate with a giant congenital nevus: new treatment option with the frbium: YACi lascr. Br J Plast Surg. 2002;5.5(5):440-2.

18. Berg P, Lindelof $B$. Congenital melanocytic nacvi and cutaneous mclanoma. Melanom Res $2003 ; 13(5): 441-445$.

19. Bittencourt FV, Marghoob AA, Kopf AW, Koenig Kl, Bart RS. Large congenital melanocytic nevi and the risk for development of malignant melanoma and neurocutanerus melanocytosis. Pediatrics 2000); 106(4):736741.

20. Watt AJ, Kotsis SV, Chung KC. Risk of melanoma arising in large congenital melanocytic nevi: a systematic review. Plast Reconstr Surg 2004; 113(7):1968-73.

21. Ka VSK, Dusza SW, I Ialpern AC, Marghoob AA. The association between large congenital melanocytic naevi and cutaneous melanoma: preliminary findings from an interner based registry of 379 patients. Melanoma Res 2005; 1.5(1):61-67.

22. Ruiz-Maldonado R, Tamayo L, Laterza AM, Duran C. Giant pigmented nevi: Clinical, histopathologic and therapeutic considerations. J Pediatr 1992;120:906-11.

23. Rhodes AR. Congenital nevomelanocytic nevi: Histologic patterns in the first year of life and evolution during childhood. Arch Dermatol 1986;122:1257-62.

24. Acland KM, Barlow RJ. Iasers for the dermatologist. Br J Dermatol 2000;143:244-55.

25. Ratner D, Tse Y, Marchell N, Goldman MP et al. Cutaneous laser resurfacing. J Am Acad Dernatol 1999;41:365-89.

26. Bohn J, Svensson H, Alberg M. Demabrasion of large congenital melanocytic naevi in neonates. Scand J Plast Reconstr Surg Hand Surg 2000; 34(4):321-6.

27. Zitelli JA, Grant G, Abel F, Boyd JB. Iistologic pattern of congenital nevocytic nevi and implications for treatment. J Am Acad Dermatol 1984;11:402-9.

28. Walton RG, Jacobs AH, Cox AJ. Pigmented lesions in newborn infants. $\mathrm{Br} \mathrm{J}$ Dermatol 1976;95:389-96.

29. Nickoloff BJ, Walton R, Pregerson-Rodan K et al. Inmunohistologic patterns of congenital nevocellular nevi. Arch Dermato! 1986;122:1263-8. 
30. Lawrence CM. Treatment options for giant congenital nevi. Clin exp dermatol 2000;25:711.

31. Fenton DA, Mayou B, Atherto D et al. Histopathology of giant congenital melanocytic nevi: Implications for treatment (Abstract) $\mathrm{Br}$.J Dermatol 1987;117 (Suppl.32):40.

32. Kopera D, Hohenleutner U, Stolz W et al. Ex viv quality-switched ruby laser irradiation of cutaneous melanocytic lesions: persistence of S-100, HMB-45 and Masson-positive cells. Dermatology 1997;194(4):344-50.
33. Zalaudek I, fom M, Richtig li et al. Inual recurrence in melanoma in situ: inflerence of sex, age, site of involvement and therapentic modalities. Br J Dermatol 200.3; 148: 70)3-8.

34. Zutt M, Kretschmer I., Enmert $S$, et al. Multicentric malignant melanoma in a giant melanocytic congenital nevus 20 years after dermabrasion in adulthood. Dermatol Surg 2003;29:99-101. 


\section{CHAPTER 4}

\section{Complications of laser resurfacing}

Ostertag JU, Theunissen CC, Neuman HA.

Hypertrophic scars after therapy with $\mathrm{CO}_{2}$ laser for treatment of multiple cutaneous neurofibromas.

Dermatol Surg 2002 Mar;28(3):296-8.

Quaedvlieg PJ, Ostertag JU, Krekels GA, Neumann HA.

Delayed wound healing after three different treatments for widespread actinic keratosis on the atrophic bald scalp.

Dermatol Surg 2003 Oct;29(10):1052-6. 
84 CHAPTER 4 


\title{
Hypertrophic scars after therapy with $\mathrm{CO}_{2}$ laser for treatment of multiple cutaneous neurofibromas
}

\author{
JUDITH U OSTERTAG, CHANTAL C.W. THEUNISSEN, H.A.MARTINO, NEUMANN
}

BACKCiROUND. $\mathrm{CO}_{2}$ laser surgery is a treatment modality for cutaneous neurofibromas. OBJECTIVE. Hypertrophic and atrophic scars can result from treatment with $\mathrm{CO}_{2}$ laser surgery. We present a case of cutaneous neurofibromatosis that developed hypertrophic scars postoperatively. METHODS. Continuous wave $\mathrm{CO}_{2}$ laser surgery therapy was applied to the patient. RESULT. Hypertrophic scars developed 2 months after therapy. CONCIUSION. With a preliminary test treatment the patient is able to see the expected result.

VON RLCKLINGI IAUSEN neurofibromatosis also known as neurofibromatosis 1 ( McK $162200)$, is a disease with skin tumors derived from peripheral nerves. Von Recklinghausen neurofibromatosis is an inherited neuroectodermal abnormality characterized by the presence of multiple neurofibromas, six or more café-au-lait macules (larger than $15 \mathrm{~mm}$ postpuberty), axillary freckles, hypertrophic and cystic bone lesions, and Lisch nodules in the iris. The mode of inheritance is autosomal dominant on gene $17 q 11.2$. This gene is responsible for the production of the tumor suppressor neurofibromin. With a prevalence of one in 2500 births, it is one of the most prevalent genetic defects. ${ }^{1}$

Because of the psychological impact of the disease, treatment to remove the neurofibromas which stigmatize the patient is often requested. $2,3 \mathrm{CO}_{2}$ laser vaporization is a simple procedure that quickly removes the tumor with minimal postoperative discomfort and acceptable cosmetic results. ${ }^{3,4}$

\section{Case Report}

A 54-years old woman with neurofibromatosis 1 presented with multiple caféau-lait macules and many fibromas. Some of the other clinical symptoms of Von Recklinghausen neurofibromatosis were also present: axillary freckles and Lisch nodules in the iris. She had no health problems or neurological abnormalities at that moment. Several excisions of fibromas were already performed under local anesthesia. This time she was seen at our department for $\mathrm{CO}_{2}$ treatment of newly developed neurofibromas.

The neurofibromas were treated with with continuous wave $\mathrm{CO}_{2}$ laser, $20 \mathrm{~W}$ on defocused mode for sessile form and $10 \mathrm{~W}$ when excising the pendunculated form. Under general anesthesia about 100 lesions were treated on face, arms, neck and collar. After the laser therapy, chlorohexidine $1 \%$ creme was applied to the skin and instructions were given to avoid sunlight.

The wounds healed by second intention wound healing in 3 weeks time. Two months later the face, neck and collar were recovered well. However, several hypertrophic and atrophic scars persisted on the arm, mostly on the hand (Figure 1)

A $3 \mathrm{~mm}$ biopsy was performed on the left hand. Histopathology showed an epidermis of normal thickness. In the dermis, scar tissue formation was visible, characterized by parallel lying fibroblasts and colla- 


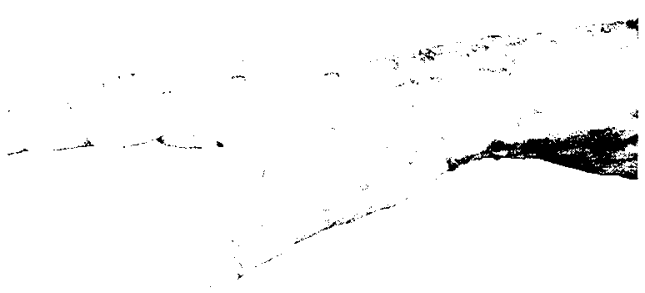

Figure 1: Hyperthropic scars 2 months after laser therapy.

gen. In the depth, a remainder of the neurofibroma was still present.

The patient was treated with 13-cisretinoid $80 \mathrm{mg} / \mathrm{day}$. After 4 months of therapy an improvement of the scars occurred. There was almost no crythema left and the scars where flattened. Smooth depigmented scars remained.

\section{Discussion}

The classic pattern of anatomic distribution of neurofibromas is predominance on the trunk, as well as head and neck involvement, with decreasing incidence of lesions as one proceeds peripherally. The involvement of the hand, especially the palm, is quite uncommon. Traditional surgical procedures are as variable as the modes of presentation of the disease. Most commonly, repeated excisions of tumor involving the orbit, eyclids, cheeks, ears, lips, nose, and mouth are done, followed by appropriate reconstruction such as skin graft, rytidectomy, blepharoplasty, tarsorrhaphy, or fascia sling. Frequently a secondary reconstruction is necessary. 5

Very small fibromas cannot be treated by conventional surgery, as they usually present in large numbers: the enormous amount of time required makes it impossible to treat all tumors. By contrast, laser can perform this task quickly and without blecding, since the coagulating capability of the laser light beam seals blood vessels up to about $0.5 \mathrm{~mm}$ in sime immediately. For this reason $\mathrm{CO}_{2}$ laser has been developed during the last 10-15 years and has become a standard treatment for neurofibromas of the skin. 2 Its advantages include high patient satisfaction with the rapid, staged removal of thousands of neurofibromas, minimal morbidity, and enhanced appearance. Healing is complete in 6 wecks or less. ${ }^{4}$

Our patient was in good health and had not reported any previous abnormal scarring or keloid formation even after carlier excision. In port-wine stains, hypertrophic scars are described after treatment with $\mathrm{CO}_{2}$ laser, argon laser and even so with flashlamp-pumped pulsed dyc laser surgery, although treatment is effective in most instances. $6,7,8$

Hyperthropic scar formation occurring during the first 3-4 months after $\mathrm{CO}_{2}$ laser therapy of neurofibromas has been mentioned in literature. ${ }^{2}$ It remains an uncommon complication after $\mathrm{CO}_{2}$ laser therapy. In neurofibromas, depigmented, flat, circular, and depressed scars are seen. ${ }^{2,4}$ Instead of a complication of treatment, $\mathrm{CO}_{2}$ laser therapy is frequently suggested as an effective treatment for hypertrophic scars.

Suggested causes for scar formation after treatment are localized infection, trauma within 24 hours, overlap of adjacent test pulses, the location, and higher pulse level. $6,7,10$

In our case the scars were only present on the underarm and hand. Thermal trauma could be an explanation. 1 Another explanation could be the characteristics of the neurofibroma itself. Ncurofibromas are complex mixtures of Schwann cells, fibroblasts, perineural cells, vascular endothelium and mast cells ${ }^{12}$ Interactions of these cells during trauma and wound healing might produce scars. In our patient the anatomic site, in combination with the wound depth, was probably the cause of 
hypertrophic scarring, as she had no problems on the face, neck and collar after the same treatment. Extremities heal significantly longer as compared to the face and there is a greater risk of hypertrophic scar formation. ${ }^{1.3}$

Isotretinoin, a synthetic isomer of tretinoin (vitamin A acid,) has an anti inflammatory and antineoplastic activity. Tretinoin can induce hypertropic scar formation. Nonetheless, it seems to work in many cases, an apparent contradiction. In literature there are indications that retinoids can produce reduction of fibroblast proliferation and collagen synthesis. Also topical vitamin $\mathrm{A}$ has shown effective in treatment of hypertrophic scars. ${ }^{10,14}$ Although there is no evidence, we believed that treatmont with 13-cis-retinoid might reduce or inhibit further fibroblast proliferation. Our paticnt responded to the treatment, but it is doubtful whether the effect is due to the drug or to spontaneous resolution of the hypertropic scar.

The cosmetic disfigurement is the most important issue in the decision to treat cutaneous symptoms of neurofibromatosis. Treating patients with extensive neurofibromas with $\mathrm{CO}_{2}$ laser is still the best choice. However, it is strongly advised to perform a test treatment be performed to judge the effectiveness of the procedure and whether the developed scar is an acceptable trade-off.

\section{References}

1. Riccardi VM. Neurofibromatosis: phenotype, natural history, and pathogenesis. 2nd ed. Baltimore, John Hopkins University Press, 1992

2. Katalinic D. Laser surgery of neurofibromatosis 1. J Clin Laser Med. Surg. 1992 Jun; 10(3): 18.592

3. Roenigk Rk, Ratz JL. $\mathrm{CO}_{2}$ laser treatment of cutaneous neurofibromas. J Dermatol Surg Oncol 1987 feb; 13 (2): $187-90$

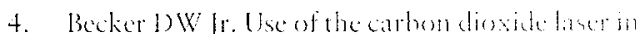
freating multiplecutancous neurofibromas ann Plast Sure 1991 Jun; 26(6): 582-6

5. Bromley (iS, Sherman Ji: (ionlian $D$ fr. Neurofibromatosis- distribution of lesions and surgical treatment. Ann Plast surg, 1982 Apr; 8 (4): 272-6.

6. Tan OT, Carney JM, Margolis R, et al. The histologic responses of port-ivine stains treated by argon, carbondioxide, and tumable dye laser. Arch Dermatol 1986;122:1016-22

7. James M. swinehart, MD. Iypertrophic scarring resulting from flashlamp-pumped pulsed dye laser surgery. I An Acad Dermatol. 1991 Nov: 2.5:84.5-6

8. David A. (aston, MD, David P. (lark, MI). Facial Hypertrophic Sarring from Pulsed Dye Laser. Dermatol Surg 1998; 24:52.3-52.5

9. Kenneth C. Nowak MD, Matthew MeCormack BBA, R James Koch MD MS. The effect of supperpulsed carbon dioxide laser energy on keloid and normal dermal fibroblast secretion of growth factors: a serumfree study. Plast Reconstr Surg. 2000 May; 105(6): 1973-8

10. Sandy S. Urioste, Kenneth A. Arndt, and Jeffrey S. Dover. Keloids and Hypertrophic Scars: Review and Treatment Strategies. Seminars in Cutaneous medicine and Surgery, 18;2 (june), 1999: 159-171

11. Marta I. Rendon-Pellerano, MD, Jerome Lentini, MD, William E. Eaglstein, MD, Robert S. Kirsner, MD, Kendall Ianft, MD, and Rube J. Pardo, MD. Laser Resurfacing: Usual and Unusual Complications. Dermatol Surg 1999; 25:360-367

12. Riccardi VM. Of mass and men: neurofibromas and histogenesis. Arch Dermatol. 2000 Oct; 136(10): $1257-8$

13. Gloria Jimenez, $M D$ and James $M$. Spencer, MD, MS. Erbium: YAG Laser Resurfacing of the Hands, Arms, and Neck. Dermatol Surg $1999 ; 2.5: 831-835$

14. Albert M. Klingman, MD PhD. the growing importance of topical retinoids in clinical dermatology: a retrospective and prospective analysis. J Am Acad Dermatol 1998; 39:52-7 
88 CHAPTER 4 


\section{Delayed wound healing after three different treatments for widespread actinic keratosis on the atrophic bald scalp}

PATRICIA J.F.QUAEDVLIEG, JUDITH U. OSTERTAG, GERTRUUD A.M. KREKELS, H.A. MARTINO NEUMANN

BACKGROUND. Actinic keratosis is an excedingly common premalignant lesion that can develop into squamous cell carcinoma. There is an increasing prevalence of actinic keratosis with increasing age. Numerous treatment options are available for the treatment of actinic keratosis on the scalp. Although we know that atrofic skin heals slowly one should be careful but should not hesitate to treat. OBJECTIVE. We present three parients with widespread actinic keratotic lesions on the atrophic bald scalp who received different treatments. Ml:Tlolos. Patient 1 was treated with mediumdepth chemical peel, patient 2 with cryopeel, and paticnt 3 with $\mathrm{CO}_{2}$ laser resurfacing. In all patients, the entire surface area was treated. RESULTS. Despite of the different treatment methods used, all three patients had severely delayed wound healing as a complication. Remarkably, all patients had a prolonged period of re-epithelialization. CONCLUSION. Care has to be taken in patients with widespread actinic keratosis on the atrophic bald scalp when treating the entire surface arcas regardless the treatment modality.

ACTINIC KERATOSES (or solar keratoses) are cutancous neoplasms that occur primarily on sun-exposed skin surfaces. These premalignant lesions usually are a conscquence of long-term solar radiation but may also be caused by UV light exposure from artificial sources or exposure to polycyclic aromatic hydrocarbons. Persons with skin type Fitzpatrick I and II are more susceptible to the development of actinic keratoses. The sites of predilection for actinic keratoses are the face (especially the forehead) and the dorsal hands. 1,2 Although it is usually possible to diagnose actinic keratoses on the basis of the clinical appearance of a lesion, it is advisable to takc a biopsy to confirm the clinical diagnoses histologically and more important, to distinguish one from a squamous cell carcinoma of the skin and other pathologic esions. Once the diagnosis is confirmed, lifetime follow-up might be necessary.

There is an increasing prevalence of actinic keratosis with increasing age. In the 3 rd decade of life, the prevalence is less than $10 \%$. This rises to more than $80 \%$ in faircomplexioned persons who are of 60-69 years old. Men are more affected than women. ${ }^{3}$

Estiates of malignant conversion have varied in literature from $0.25 \%$ up to $20 \%$ for an individual lesion during a 1 -ycar time course [4]. The risk of malignant transformation for an average patient with actinic keratoses followed up for 10 years would be $6.1 \%$ or $10.2 \%$, depending on the study analyzed. 5

Numerous treatment options are available for the treatment of actinic keratoses. Laser resurfacing, chemical peel, cryopecl, and dermabrasion are different options to 
treat whole surface areas. Although there are diverse treatment options for actinic keratoses, literature is lacking prospective randomized studies comparing these treatments.

We report three cases of diffuse widespread actinic keratoses on the atrophic bald scalp in which three different treatment modalities were used to treat entire surface areas: medium- depth chemical peel, cryopeel, and laser resurfacing. All three patients showed complication in wound healing.

\section{Case 1}

A 60 year-old man presented with a history of multiple scaly erythematous hyperkeratotic lesions on the scalp for several years. Histopathology confirmed the clinical diagnosis actinic keratoses. He had Fitzpatrick skin type II, no excessive sun exposure, and an atrophic bald scalp for more than 20 years. He was treated 1 year ago by excision with negative tumor margins for an atypical fibroxanthoma on the scalp. The wound healed by secondary intention without any problem. Medical history showed asthma for which he uses corticosteroid inhalers.

After informed consent, pretreatment with topical tretinoin $0.05 \%$ and prophylactic antiviral (valaciclovir) and antibacterial (flucloxacilline) medication, his scalp and forehead were treated with a mediumdepth chemical peel; Jessner's solution and trichloroaceticacid 35\%. Postoperatively, he was treated with acetic acid gauze compresses three times a day and Fucidine ${ }^{(1)}$ creme. The patient was seen 2 times a week. In the direct postoperative period, there was only crust formation and some erosions. After 1 month, the scalp was almost healed completely, but there some erosive lesions still remained. The skin appeared atrophic and did not recover normally. After 6 months, therc were still superficial erosions with or without yollowish crusts and pustules.

Several wound cultures were taken in which twice regular skin flora was seen, twice Staphylococcus aureus and once Candida Albicans. The patient was treated scveral times with oral antibiotics and antimycotics, depending on wound cultures and clinical appearance (Azitromycine, Itraconazol, and Fluconazol). Topical treatment consisted of intermittent Fucidine ${ }^{(}$, Triamcinolone, Chlorohexidine, Liquor carbonens detergents and Miconazol.

Despite meticulous postpeel follow-up, multiple wound cultures, and topical and oral cxtensive treatment, no normal healing appeared. At this time, 16 months after the peel, the skin is nearly healed with obvious atrophy. Minimal erosions, and some crusts and some pustules still occur intermittently. No recurrence of actinic keratoses has been noticed so far.

\section{Case 2}

An 85-year old man with multiple scaly hyperkeratotic lesions on the scalp since 10 years. He had Fitzpatrick skin type II. There was no excessive sun exposure, and he had a bald scalp for 45 years. Multiple biopsies had been taken that all showed actinic keratoses. In the past, he was treated repeatedly with cryotherapy (liquid N2) and topical 5-fluorouracil. The patient had been treated previously for a basal cell carcinoma on the right temple with excision (tumor margins negative) and a squamous cell carcinoma on the left forehead, which was excised completely. Medical history showed atrial fibrillation. As medication he uses carbasalatecalcium 38, bumetanide, sotalol, digoxine and isorbidedinitrate. Eight years ago, he also had an adenocarcinoma of the sigmoid, followed by chemotherapy consisting of 5-fluorouracil and levamisol.

After informed consent, the entire scalp was treated with cryopeel, which was per- 
formed under tumescent anesthesia. Before the peel, multiple tangential excisions of keratotic lesions were made with a carbon steel razor blade. The scalp was divided into 4 sections, which were treated with the liquid nitrogen device (Frigitronics cryo). An open-spray method was used; the entire marked region was sprayed evenly by moving the tip up and down and left to right. On the actinic keratoses, the tip was brought closer to get a deeper peel. Postoperatively, the patient was treated with Vaseline gauzes. After the cryopeel, the paticnt was seen twice a week. During the first days, he developed blisters and wounds that covered the cntire scalp. Within 2 weeks, he had necroses of the skin on the scalp, and a necrotomy was performed. After 2 months, a slow re-epithelialization occurred, but multiple erosion with exsudate remained. Wound cultures were taken; two showed a Staphylococcus aureus and only normal skin flora was seen the other three times. The patient was treated systemically with Azitromycine and topical with Chlorohexidine and Fucidine.

Despite regular follow-up, multiple wound cultures, and topical and oral treatment, the skin remained atrophic, and there was no normal healing. Currently (10 months postoperative), some erosive lesions on a very atrophic skin still remain, and there is an intermittent formation of yellow crusts. (figure 1)

\section{Case 3}

A 77-year-old man with actinic keratoses on the scalp, forehead and cheeks for several years. The patient had Fitzpatrick skin type I, no excessive sun exposure, and a bald scalp for more than 20 years. Histopathology confirmed the clinical diagnosis of actinic keratoses. He had previously had several treatments with topical 5fluorouracil and cryotherapy. Nevertheless, he developed a squanous cell carcinoma on the left side of the forchead that was excised completely. The patient was also known with chronic venous insufficiency, arrhythmia and hypercholesterolaemia for which he uses atorvastatine and acetylsalicylic acid.

After informed consent and prophylactic valaciclovir and ciprofloxacine, the forehead and scalp were treated with $\mathrm{CO}_{2}$ laser. The following settings were used: Sharplan, Silk Touch, 260 hand picce, spot size 12 $\mathrm{mm}, 34$ Watt, 2 passes on the forehead and scalp. The actinic keratoses were treated with an extra pass with a $5 \mathrm{~mm}$ spot size. Postoperatively, Silon TSR was applied for 4 days. After 4 days, acetic acid gauze compresses and Fucidine creme were applied. After this treatment, the patient was secn twice a week. After 2 weeks, the patient noticed a burning sensation of the scalp. Clinically, there were erosions, erythema, and crusts all over the scalp. Fucidine was stopped on suspicion of contact allergy. Epicutancous allergic investigation excluded an allergic reaction. After 27 days, re-epithelialization started, and the healing progressed. Unfortunately, on day 41 , therc were superficial erosions all over the scalp. The patient had to be admitted to the hospital for further trcatment. Wound cultures were taken several times, that showed a Candida Glabrata, a Staphylococcus aureus, and six times normal skin flora was seen. Hc was treated several times with Itraconazol, Erytromycine, Ketoconazol, Fucidine, and Mupirocine depending to the culture results. At 6 month after the $\mathrm{CO}_{2}$ treatment, the scalp was healed completely. Atrophic and casy bruising skin remained.

Despite regular follow-up, 10 months after $\mathrm{CO}_{2}$ laser treatment, he had another 8 months period in which he regularly developed erosions, crusts and bacterial infections on the vertex (Figure 2). Now, almost three years later, atrophic scarring with depigmentation and teleangiectasia on the scalp remains. 


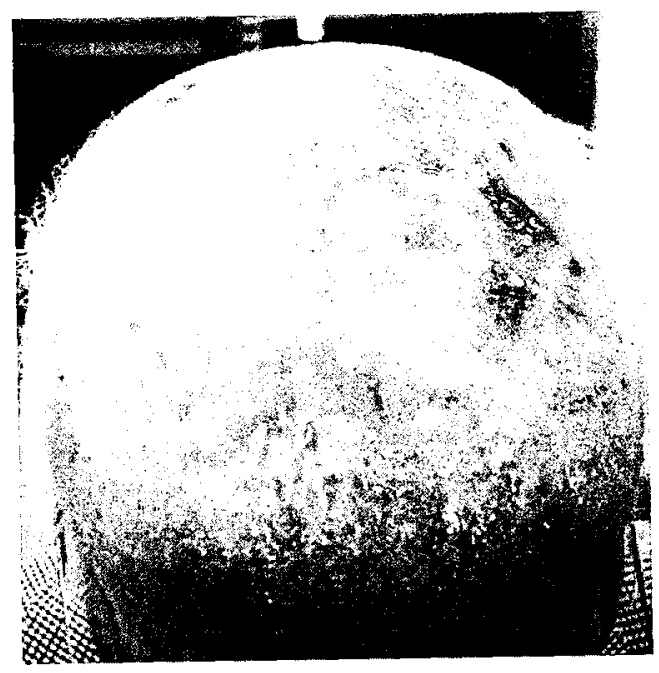

Figure 1: 10 months postoperative; some erosive lesions on a very atrofic skin.

\section{Discussion}

Because of the high incidence of actinic keratoses and the risk of malignant development, it is incumbent on all practitioners to provide efficacious therapy. The primary rreatment goal is destruction of the abnormally differentiated epithelium. Through destruction of the premalignant epithelial cells, a wound is created, and re-epithelialization usually from the hair follicles occurs. The new epithelium shows no premalignant features. ${ }^{6}$ This can be accomplished by a variety of means, including desiccation, curettage, cryotherapy, and cxcision. Dermabrasion, chemical peels, laser treatments, and photodynamic therapy can also be used to destroy the lesions. ${ }^{7,8}$ Topical 5 -

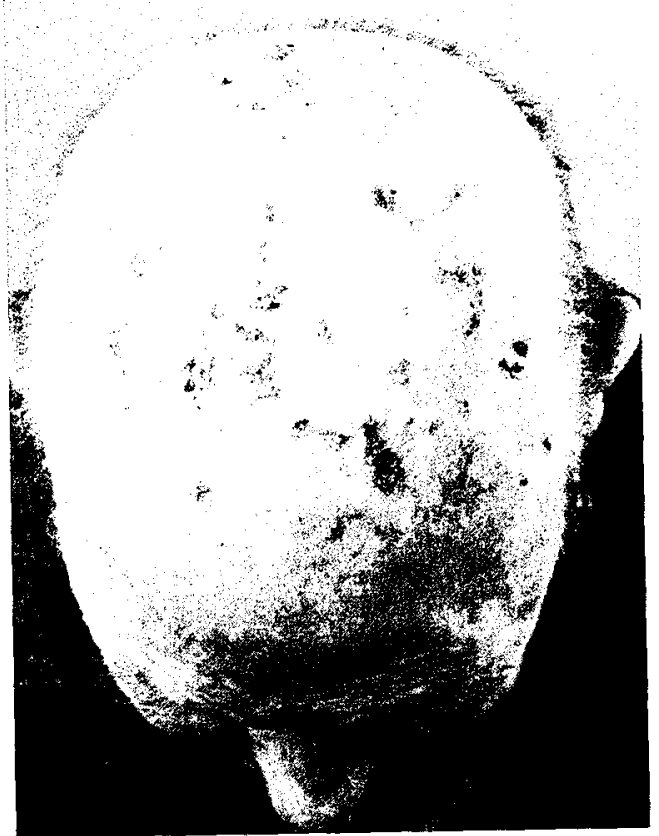

Figure 2: 18 months postoperative; erosions and yellowisch crusts on a atrofic skin

fluorouracil is a standard therapy for multiple actinic keratoses. ${ }^{9}$

Diffuse widespread actinic keratoses need special approach. The method selected depends on variables that may include but are not limited to the medical status of the patient; lesions characteristics such as size, location, duration, and change in growth pattern; previous treatment; the skin condition (atrofic or not) and certain anatomic locations such as ear and scalp. Dermabrasion, chemical peel, laser resurfacing, and cryopeel are all therapy modalities that give destruction of the actinic keratoses and the surrounding skin. ${ }^{10-1.3}$ The benefit of these surface therapies is that the clinically normal-appearing skin, which is histopathologic atypical, is also removed. Depending on the therapy given, there are 
different types of destruction: mechanical (dermabrasion), chemical (chemical peel) and physical (laser and cryopeel).

Despite the different mechanism of chemical and physical destruction, all of these defects heal by re-epithelialization from residual adnexal epithelium and epithelium derived from adjacent uninjured skin. After all three treatments (chemical peel, laser and cryotherapy) the four stages of wound healing are apparent. They include hemostasis, inflammation, granulation, and tissue remodeling. Many complications can be recognized during the healing stages. Viral, bacterial, or fungal infection and contact irritants (local therapy agents) can interfere with wound healing. Other systemic factors might disturb wound healing, such as diabetes mellitus, immune status, smoking habit. Factors such as localization, depth of penetration, and amount of tissue necrosis also play an important role in wound healing. ${ }^{18,19}$ Delayed wound healing after $\mathrm{CO}_{2}$ laser resurfacing has the same causistic factor as in other treatment modalities. If the thermal injury plays an extra role, still has to be discovered. 20

Localization of the lesion seems to play also an important role. Anatomically, the skin of the scalp differs from the skin of the face, hands and eyelids. The most important factor is the presence of adnexes. An actinically damaged scalp may reflect the atrophic process of age more than the face does. Atrophy in this area may be more clinically and histologically obvious and plays an important role. With aging, the dermis may be significantly attenuated, and wounding agents may be more destructive because they are metabolized less rapidly. Fewer adnexal structures exist to promote re-cpithelialization. All our patients had multiple actinic keratoses on the bald scalp. In all three cases presented, we observed a great similarity in delayed wound healing. Finally, in all three the cases, the scalps reepithelialized for $90 \%$ despite erosions and obvious skin atrophy. Patients previous treatments did not seem to have an influence. It was remarkable that especially the re-epithelialization phase of wound healing was prolonged in all three of the cases. All patients had a bacterial or fungal infection, which might have delayed wound healing. On the other hand, they were treated with adequate systemic or topical medication. The patients had received different topical agents, which might have given an irritant factor. Although clinically there were no signs of contact irritant or contact allergy, none of the patients had systemic factors. All treatments were performed with standard procedures. Even the depth of injury after these three different treatment options does not seem to be the cause of the delayed wound healing. Localization might play an important role. Despite of the great amounts of variable causes within our patients to delay wound healing, this doesn't seem to be the cause. We have treated many patients with these variables without any complication. The most reasonable cause of delayed wound healing in our three patients seems to be the atrophic bald scalp. All of the patients had a bald scalp for more than 20 years. Possible factors of disturbed wound healing could be the destruction of hair follicles and or the absence of hair follicles before treatment. There might be a possibility that the actinically damaged skin itself plays a role in disturbed wound healing, although we could not find confirmations in literature for this statement.

\section{Conclusion}

Despite the different possible treatment modalities for widespread actinic keratoses, it is important to consider the localization and the condition of the actinically damaged skin and the depth of penetration caused by the treatment. In the presented cases, the primary process of wound healing started off well, but there was a disturbance in sec- 
ondary wound healing. Several factors might play a role, such as the lack of adnexes on the bald scalp, the actinically damaged skin itself, or other yet unknown individual factors. Although we know that wound healing in atrofic skin is mostly prolonged, we should not hesitate to treat these patients with actinic keratosis. The benifit of preventing skin cancer or to treat premalignant lesions is far more important, but care has to be taken for the risk of the delayed woundhealing. Independent of what therapy we use, the patient-factor plays a major role in the wound healing.

\section{References}

1. Schwartz RA. Actinic Keratoses. Skin cancer recognition and mangement. New York Springer Verlag 1988; 4-10.

2. Callen J.P, Bickers DR and Moy RA. Actinic keratoses. J Am Acad Dermatol 1997;36 (4):650-3.

3. Schwartz RA. The actinic keratosis. A perspective and update. Dermatol Surg 1997; 23(11): 1009-19; quiz 1020-1.

4. Marks R, and R. G. Malignant transformation of solar keratoses to squamous cell carcinoma. Lancet 1988; 1: 296-7.

5. Dodson JM., et al., Malignant potential of actinic keratoses and the controversy over treatment. A patient-oriented perspective. Arch Dermatol 1991; 127(7): 1029-31.

6. Feldman SR. et al. Destructive procedures are the standard of care for treatment of actinic keratoses. J Am Acad. Dermatol 1999; 40(1): 43-7.

7. Drake LA. Guidelines of care for actinic keratoses. J of Am Acad of Dermatol 1995; 32(1): 95-98.

8. Schwartz RA. Premalignant keratinocytic neoplasms. J of the Am Acad of Dermatol 1996; 35: 223-42.

9. Jansen GT. Topical chemotherapy. Clin Dermatol $1992 ; 10(3)$ : 305-7.
10. Coleman WP. 3rd, Yarborough YM. and Mandy SH. Dermabrasion for prophylaxis and treatment of actinic keratoses. Dematol Surg 1996:22(1):17-21.

11. Witheiler 1)D. et al. Iong-term efficacy and safety of Jessner's solution and $3.5 \%$ trichloroacetic acid vs $5 \%$ fluorouracil in the treatment of widespread facial actinic keratoses. Dermatol Surg 1997; 23(3): $191-6$.

12. Trimas SJ, Ellis DAF, and Metz. RD. The carbon dioxide laser. An alternative treatment of actinically damaged skin. Dermatologic Surgery 1997; 23: 885-9.

13. Chiarello SE. Cryopeeling (extensive cryosurgery) for treatment of actinic keratoses: an update and comparison. Dermatol Surg $2000 ; 26(8): 728-32$.

14. Monheit GD. Medium Depth Chemical Peel, in Skin Resurfacing, William.P.Coleman and N. Lawrence, Editors 1998; 69 Chapter 7

15. Brody, H.J., Skin Response to Chemical peeling, in Skin Resurfacing, W.P. Coleman and N. Lawrence, Edirors 1998; 37-44 Chapter 4

16. Zacharian SA. The cryolesion and the pathogenesis of cryonecrosis, in Cryosurgery for skin cancer and cutaneous disorders. S.A.Zacharian Editor 1985; 1-30 Chapter 1

17. Mc Burney E, William P.Coleman and Lawrence $N$. Physics of resurfacing lasers, in Skin resurfacing Editors 1998; 155-160 Chapter 14

18. Rook, Wilkinson, and Ebling, Textbook of Dermatology ed. R.H. Champion 1992; oxford: Blackwell scientific Publications.

19. Cho $Y$, and Lo JS. Dressing the part. Dermatologic Clinics 1998; 16: 25-47.

20. Molgat YM. et al., Comparative study of wound healing in porcine skin with $\mathrm{CO}_{2}$ laser and other surgical modalities: preliminary findings. Int $\mathrm{J}$ Dermatol 1995; 34(1): 42-7. 
CHAPTER 5

General discussion and recommendations 
96 CHAPTER 5 


\section{General discussion}

Resurfacing of the facial skin has been used in the past to improve cosmetic appearance of the skin. For this purpose ablative techniques such as chemical peels and dermabrasion were used for decades.' Lasers were introduced as an alternative in the last part of the twentieth century. Ablative lasers in dermatology, e.g. carbon dioxide $\left(\mathrm{CO}_{2}\right)$ and erbium:yttrium-aluminiumgarnet (Er:YAG), have been proved to be an effective and refined method for resurfacing the skin. The precise technique of laser ablation provides an advantage compared to dermabrasion and chemical pecling. The physician-consultant furthermore has the clear benefit of being able to directly evaluate the effects of the treatment. The additional haemostatic cffect (in particular in the use of $\mathrm{CO}_{2}$ laser or Er:YAG combined with $\left.\mathrm{CO}_{2}\right)$ is also an important benefit compared with diffuse and sometimes heavy bleeding during dermabrasion procedure. At least equal but often superior cosmetic results are described by using laser resurfacing. ${ }^{2-6}$

In the literature it was shown that $\mathrm{CO}_{2}$ and Er:YAG laser resurfacing is an effective treatment for rhytides and acne scars. Method of treatment, cosmetic outcome, short and long term side effects, and complications have been documented well in the literature as shown in this thesis. However there are few randomized controlled trials (RCT) with often small number of patients.

Since the early 90's from last century until now, these lasers have been used almost exclusive for cosmetic purposes. However besides to achieve cosmetic rejuvenation this technique is suitable for treatment of several skin diseases. Espccially those diseases that require an area to be treated (so called ficld therapy) like widespread actinic keratoses (AK) and large or giant congenital melanocytic nevi (GCMN) do benefit as well from these treatments that have their target on removing superficial layers of the skin. The technique can be applied to any skin disorder in which superficial treatment would be successful. The list of medical applications given in chapter 2 is certainly not complete. Reports of laser resurfacing as treatment for recalcitrant psoriasis have also been mentioned. ${ }^{7-9}$ In the future we expect even more clinical applications for laser resurfacing as treatment, or additional treatment for skin disorders.

As shown in this thesis, evidence in the literature about ablative laser treatment for medical indication is limited. This might be due to the fact that lasers were originally used in cosmetic practice, while in general dermatological practice these lasers were introduced on a small base by a limited number of dermatologists. High costs of the equipment and reimbursement problems might have played a part. Another aspect is the learning curve of applying laser resurfacing. This invasive surgical laser procedure is certainly not an easy treatment. It is more than simply "press the buttons on the device". Knowledge about the skin type, indications for laser resurfacing, pre-, perand postoperative procedures is required. The correct laser setting for each indication is important. Additionally, a too superficial treatment will result in too less effect, and if treatment is performed to deep, undesired side effects or scarring occur. Furthermore knowledge of wound healing, recognizing and treating side effects and complications is mandatory. ${ }^{10,11}$

Nowadays, numerous treatment options exist for AK with variable clinical cure rates. Some treatments are basically used for individual AKs and others for large treatment areas of so called field treatments. ${ }^{12-14}$ Although many different treatments arc used for AK, we found only three comparative studies, which compared two different therapies for AK in a randomised way. 15-17 
Of the three longstanding treatment options, like 5-FU, cryotherapy and curettage, 5-FU is the therapy which has been investigated most and a good efficacy is described. Reductions in number of $\mathrm{AK}$ from $47.5 \%$ to $91.7 \%$ are described and total clearance rates varying from $1.5 \%$ to $57.8 \%$. A general trend in the treatment of $A K$ is seen with new therapies like PDT and a topical immune response modifier imiquimod.

Actinic keratoses is nowadays considered to be a "keratinocytic intraepidermal neoplasia", with a proven risk for transformation into squamous cell carcinoma (SCC), so treatment in our opinion is mandatory and preventive of the development of SCC. ${ }^{18,19}$ Furthermore field treatment of not only visible but also sub clinical AK might result in a further prophylactic effect.

Regarding laser resurfacing as treatment for a medical indication like AK, evidence is not available in the literature. Randomized controlled trials on laser ablation treatment for AK treatment are lacking. Only casereports and small studies describing the clinical effects with overall short follow-up can be found. ${ }^{20-26}$ In our experience we had good clinical results after laser resurfacing in patients with therapy resistant widespread $A K$ in the face. We retrospectively analysed the results of a group of patients. Compared to other authors, we describe a much longer follow-up time. Only Iyer et al, who described retrospectively 24 patients with laser resurfacing for facial AKs, had a similar follow-up time, with similar recurrence rates. ${ }^{26}$ In this thesis we show that laser resurfacing as treatment for AK, shows long times of recurrence free intervals. Besides the good clinical results we had a considerable amount of side effects: especially the long-term side effects of hypopigmentation, itching, and atrophic skin. This might be due to the fact that $68 \%$ of the patients were treated on the forehead and/or the scalp region, areas which are more susceptible to side effects, especially in older patients with already precexistent atrophic skin. Another explanation might be that the $\mathrm{CO}_{2}$ laser was used in two third of the patients. The results of our prospective study show that laser therapy is more effective than the standard therapy with 5-FU in treatment of widespread $A K$. The recurrence rate within one year is slightly higher than in our retrospective study. Compared to laser resurfacing, the disadvantages of $5-\mathrm{FU}$ include the length of treatment, significant inflammatory reactions, and the painful and cosmetically disturbing treatment area, which has a negative effect on patients compliance. ${ }^{27}$ However, in our study, more side effects occurred after lascr surgery especially erythema and hypopigmentation. These are well known side effects after laser resurfacing as well as after 5-FU. 27-30 Again one could explain this high amount of side effects by the fact that the majority of the patients had been treated on he scalp region which is more susceptible to adverse effects.

None of the patients had delayed wound healing and only onc developed scar formation, complications as described in chapter 4 of this thesis. These complications can occur especially on non-facial areas. We report 3 cases of diffuse widespread actinic keratoses on the atrophic (male) bald scalp in which 3 different treatment modalities were used to treat whole surface arcas: medium depth chemical peel, cryopecl and ablative laser resurfacing. These 3 different trcatment options were all complicated by delayed wound healing. Remarkable was that all patients had a prolonged period of reepithelialization. We believe that delayed wound healing after $\mathrm{CO}_{2}$ laser resurfacing has the same causistic factor as in other treatment modalities. If the thermal injury plays an extra role still has to be discovered. Delayed wound healing after laser resurfacing for AK has been described before ${ }^{31}$ Ramsdell ${ }^{32}$ and Laffitte $e^{3.3}$ proposed that our 
3 patients suffered from erosive pustular dematosis of the scalp as a result of the treatments. The pathophysiologic mechanism of this inflammatory process on the scalp is unknown. ${ }^{34}$ It is described after laser resurfacing procedure of the scalp, 3.5 and after other therapies on the scalp for actinic keratoses. 36,37

This thesis does not provide evidence that laser resurfacing has a prophylactic effect on the development of NMSC. The follow up is too short and groups are too small. We even found malignant lesions after laser treatment. This has been described in literature before. ${ }^{22,25}$ We assume that these malignant cells must have been in the skin before treatment, but that they where not clinically obvious, since theoretically, all epithelial tumours should be removed after laser resurfacing. The malignant lesions probably originate from follicular cells that were not damaged during the resurfacing.

On the other hand, we strongly believe that $\mathrm{CO}_{2}$ or Er:YAG laser resurfacing has a prophylactic effect. Actinic keratosis has to be considered as a SCC in situ at their earliest stages. If left untreated, malignant progression of $\mathrm{AK}$ will be a continuum process possibly resulting in metastasis and/or mortality. Laser resurfacing as field treatment, which removes clinical and subclinical lesions, is therefore preventive of development of SCC. Supportive to the hypothesis that laser resurfacing is preventive for development of SCC, is the fact that submitted data show significant less p53 expression immunostaining after laser resurfacing compared to 5 -FU in our prospective study. ${ }^{38}$

Besides the known risk factors, such as skin type, immunosuppression etc, there are clinical parameters indicating those $\mathrm{AK}$ with increased risk of malignancy; induration, diameter, rapid enlargement, bleeding, erythema / inflammation and ulceration. 39

On determining the different possible treatment modalities for widespread actinic keratoses it is important to comsider the localization, the condition of the actinicalls damaged skin, and the depth of penetration caused by the treatment. Care has to be taken in patients with widespread actinic kcratosis on the atrophic bald scalp when treating the whole surface arcas regardless the treatment modality.

The management of large or giant congenital melanocytic nevi (CMN or (GCMN) is based on two main considerations: attempt to minimize the risk of malignancy and to obtain an acceptable cosmetic result. ${ }^{40,41}$ Evidence about Er:YAG laser in the treatment of CMN was absent.

In this thesis, we describe Er:YAG laser resurfacing as new treatment option for a giant congenital naevus in a neonate. As we experienced that $\mathrm{Er}: Y A G$ laser resurfacing is an excellent method for removing the superficial part of the GCMN, we further investigated this treatment modality in more patients. Besides good clinical results, histopathologic examination before and after laser therapy showed that laser ablation effectively removes superficial layers of CMN, which locates the majority of pigmented cells. However, the nevoid cells in more profound layers as well as pigmentation in deeper layers is not affected. Another remarkable finding was that biopsies before laser treatment showed already deep dermal melanocytic involvement even down into the subcutaneous fat in neonatal period. Serial biopsies during follow showed no difference in depth of naevus cells at later moments. In the available literature, early treatment in the first few weeks after birth is recommended because of the so called migration theory. Serial biopsies failed to underscribe this theory that nevoid cells and pigmentation migrate to decper layers after the first few weeks after birth. So in this thesis early treatment is questioned, and to our opinion not mandatory. However in literature there are reports that early treatment in 


\section{Recommendations}

- Ablative lasers are excellent tools for resurfacing the skin. Prospective studies regarding all indications for ablative laser resurfacing should be performed.

- Laser resurfacing is effective as treatment modality in patients with widespread actinic keratoses and superior with regard to efficacy, compared to standard treatment with 5 -fluorouracil.

- Laser resurfacing is suitable for patients with diffuse widespread AK, especially patients with actinic keratoses resistant to other treatment modalities, and for patients with a history of multiple malignant lesions.

- Laser resurfacing should be applied very carefully on non-facial regions regarding the side effects.

- Laser resurfacing is a safe and excellent treatment modality for congenital melanocytic nevi.

- Laser resurfacing should be used by well trained physicians who are specialized in diagnosing and treatment of the skin diseases they want to treat. They should be well trained about all laser resurfacing procedures and be capable of rccognizing and treating side effects and complications.

the first months of life gives a better cosmetic outcome. ${ }^{42}$ Compared to other resurfacing techniques, such as dermabrasion and curettage in our opinion laser resurfacing has the advantage of less postoperative pain and no need for intravenous fluid treatment. Another major advantage of ErbiumYAG laser treatment is that we did not see alopecia on the scalp.

For CMN the process of occurrence of malignant melanoma is not fully understood. Furthermore, the malignant conversion rate in the literature might be overem- phasized. In the recent literature the incidence of melanoma and mortality is mich lower than in carlier reports. ${ }^{43-46} \mathrm{De}$ Racve and Rosectw suggested that the curctted superficial naevus cells might be biologically different from the retained decper cells because superficial nacvus cells stained positive for the melanocyte marker HMB-45 whereas deeper nacvus cells did not. ${ }^{47} \mathrm{Wc}$ could not confirm this statement. In our patients all nacvus cells stained HMB-4.5 positive. In a recent study, more foundation for the climination of the superficial layers of the GCMN is given. The hypothesis that the superficial naevus cells are more biologically active and are at higher risk of malignant transformation is suggested, and supported by genetic and immunohistochemical evaluations. ${ }^{48}$ This recent published study is supporting the advantages of techniques of superficial removal such as curettage or laser resurfacing. Debulking a great number of superficially located naevus cells might reduce the risk of malignancy not only by numerical reduction of potential malignant nacvus cells, but also by removing those nacvus cells with the greatest proliferating activity.

An additional advantage of laser resurfacing might be the easier follow up of possible occurinr malignant transversion in a treated less pigmented skin compared to untreated skin. On the other hand, repigmentation can lead to diagnostic controversics. ${ }^{49-51}$ Malignant melanoma can occur after all treatment modalitics including laser resurfacing, so regular follow up remains mandatory. Differentiation from pseudo melanoma can be difficult in treated arcas. ${ }^{50,52}$

Horner et al. published data on treatment of $\mathrm{CMN}$ with $\mathrm{CO}_{2}$ laser with a considerable amount of hypertrophic scarring, not in favour for the use of $\mathrm{CO}_{2}$ laser as tratment modality. ${ }^{53}$ However, hypertrophio scars occur also after other treatments, such as dermabrasion and curcttage. ${ }^{42,47}$ 
Cultured epithetial autografts that have been used after curettage or Er:YAG ablation of GCMN, presenting a novel option in the postoperative management of GCMN, which seems to accelerate healing, with fewer side effects. ${ }^{54}$ ) However, this study has limitations in the design, so these conclusions should be read with some scepticism.

Combined treatment of ablative $\mathrm{CO}_{2}$ laser surgery and Q-switched ruby laser, Qswitched alexandrite laser, or the NdYAG laser have been reported as successful. 55,56 . In this thesis, we state that compared with other treatment modalitics such as curettage, surgery and dermabrasion, Er:YAG laser resurfacing is an excellent refined method of ablating congenital melanocytic nevi with minimal risk of scarring and complications.

We did no prospective randomized study comparing the two ablative laser systems $\left(\mathrm{CO}_{2}\right.$ vs Er; Yag) regarding efficacy and side effects in the treatment of AK or CMN. Based on our experience we state that especially in risk areas such as the scalp and non facial areas, the Er:YAG laser may be preferablc. In our retrospective study on $\mathrm{AK}$, in which $\mathrm{CO}_{2}$ in almost all patients was used, we saw a considerable amount of long term side effects like hypopigmentation and atrophic skin. In the prospective study on $\mathrm{AK}$, in which all paticnts where treated mainly with Er:YAG (and where the $\mathrm{CO}_{2}$ was used only as additional hemostasis), hypopigmentation occurred also frequently but no atrophy was seen at all. In literature it is known that Er:YAG laser has fewer side effects than $\mathrm{CO}_{2}$ laser. Combination of ablation with minimal side effects, like Er:YAG with additional possible hemostases (like $\mathrm{CO}_{2}$ ) in one device (c.g. Derma-K laser, Lumenis ${ }^{\mathrm{TM}}$ Ltd), has advantages. More research is necessary to distinguish between Er:YAG and $\mathrm{CO}_{2}$ regarding side effects, additional dermal effects and clinical outcome.
When applying ablative laser resurfacing as treatment modality for medical skin disorders there will be almost always a dramatic optical improvement. The therapeutic effects and the cosmetic improvement of laser resurfacing accompany each other, similar to a lot of treatments in general dermatological practice, which is one of the amenities in our profession.

\section{References}

1. Coleman WP, Lawrence N. Skin Resurfacing. 1998 Williams \& Wilkins.

2. Gin I, Chew J, Rau KA, Amos DB, Bridenstine JB. Treatment of upper lip wrinkles: A comparison of the 950hsec divell time carbon dioxide laser to manual tumescent dermabrasion. Dermatologic Surgery 1999;25:468-74.

3. IIolmkvist KA, Rogers CiS. Treatment of perioral rhytides. Archives of Dermatology 2000;136:725-31.

4. Kitzmiller WJ, Visscher M, Page DA, Wicket RR, Kitmiller KW, Singer 1.J. A controlled evaluation of dermabrasion versus $\mathrm{CO}_{2}$ laser resurfacing for the treatment of perioral wrinkles. Plast Reconstr Surg. 2000 Nov; 106 (6):1366-72; discussion 1373-4.

5. Reed JT, Joseph AK, Bridenstine JB. Trearment of periorbital wrinkles. A comparison of the SilkTouch carbon dioxide laser with a mediundepth chemical pecl. Dermatol Surg. 1997 Aug;23(8):643-8.

6. Kauvar AN, Dover JS. Facial skin rejuvenation: laser resurfacing or chemical peel: choose your weapon. Dermatol Surg. 2001 Feb;27(2):20912.

7. Asawanonda P, Anderson RR, Taylor CR. Pendulaser carbon dioxide resurfacing laser versus electrodesiccation with curettage in the treatment of isolated, recalcitrant psoriatic plaques. J Am Acad Dematol. 20000 Apr:42(4):660-6.

8. Alora MB, Anderson RR, Quinn T, Taylor CR. $\mathrm{CO}_{2}$ laser resurfacing of psoriatic placpues: a pilot study. Lasers Surg Med. 1998:22(3):16570. 
9. Boehnke WH, Ochsendort F, Wolter M, Kaufmann R. Ablative techniques in Psoriasis vulgaris resistant to conventional therapies. Dermatol Surg. 1999 Aug;25(8):618-21.

10. Goldman MP. $\mathrm{CO}_{2}$ laser resurfacing of the face and neck. Facial Plast Surg Clin North Am. 2001;9:283-290.

11. Alster TS. Cutaneous resurfacing with $\mathrm{CO}_{2}$ and erbium:YAG lasers: preoperative, intraoperative, and postoperative considerations. Plast Reconstr Surg. 1999;103:619-632.

12. Spencer JM, Hazan C, Hsiung SH, Robins P. Therapeutic decision making in the therapy of actinic keratoses. J Drugs Dermatol. $2005 \mathrm{May}-$ Jun;4(3):296-301.

13. Jorizzo JL, Carney PS, Ko WT, Robins P et al. Treatment options in the management of actinic keratosis. Cutis 2004;74(6 Suppl):9-17.

14. Wheeland $R G$. The pitfalls of treating all actinic keratoses as squamous cell carcinomas. Semin Cutan Med Surg. 2005 Sep;24(3):152-4.

15. Szeimies RM, Karrer $S$, radakovic-Fijan $S$, Tanew A. Photodynamic therapy using topical methyl 5-aminolevulinate compared with cryotherapy for actinic keratosis: A prospective, randomised study. J Am Acad Dermatol. 2002:47:2: 258-262

16. Smith S, Piacquadio D, Morhenn V, Atkin D, Fitzpatrick R. Short incubation PDT versus 5FU in treating actinic keratoses. J Drugs dermatol. $2003 \mathrm{Dec} ; 2$ (6): 629-35

17. Freeman $M$, Vinciullo $C$, Francis D, et all. A comparison of photodynamic therapy using topical methyl aminolevulinate (Metvix) with single cycle cryotherapy in patients with actinic keratosis: a prospective, randomized study. J Dermatol Treat. $2003 ; 14: 99-106$

18. Lebwohl M. Actinic keratosis: epidemiology and progression to squamous cell carcinoma. $\mathrm{Br}$ J Dermatology 2003;149(suppl.66): 31-33.

19. Ortonne JP. From actinic keratosis to squamous cell carcinoma. Br J Dermatol. 2002 Apr;146 Suppl 61:20-3.

20. Trimas S.J., D.A. Ellis, and R.D. Metz. The carbon dioxide laser. An alternative for the treatment of actinically damaged skin. Dermatol Surg 1997;23(10):885-9.
21. Drnoveck-Olup B, Veldlin B. Ise of lir: YAC; lasers for benign skin disorders. I asers Surg Mod 1997;21(1):13-9.

22. Fuloun J.E, Rahimi A.D, Ifcleon P, Dahlbergk, Helly A.G. Disappointing results following resurfacing of facial skin with $\left(\mathrm{CO}_{2}\right.$, lasers for profylaxis of keratoses and cancers. Dermatol Surg 1999 Sept;2S (9):729-32.

23. Massey R.A, Eliezri Y.D. A case report of laser resurfacing as a skin cancer prophylaxis. Dermatol Surg 1999;25:513-516.

24. Jiang S.B., Levine V.J, Nehal K.S et al. Er:YAG laser for the treatment of actinic keratoses. Dermatol Surg 2000;26(5):437-40.

25. Stratigos AJ, Tahan S, Dover JS. Rapid development of nonmelanoma skin cancer after $\mathrm{CO}_{2}$ laser resurfacing. Arch Dermatol 2002;1.38:696-97.

26. Iyer S, Friedli A, Bowes I, et al. Full face laser resurfacing: therapy and prophylaxis for actinic keratoses and non-melanoma skin cancer. Lasers Surg Med 2004;34(2):1 14-9.

27. I abandeira J, Pereiro Jr M, Valdes F, Toribio J. Intermittent Topical 5-fluorouracil is effective without significant irritation in the treatment of actinic keratoses but prolongs treatment duration. Dermatol Surg 2004;30:517-520.

28. Alster TS, Lupton JR. Erbium:Yag cutaneous laser resurfacing. Dermatol Clin 2001; $19(3): 453-466$.

29. Nanni, C.A. and T.S. Alster, Complications of cutaneous laser surgery. A review. Dermatol Surg, 1998;24(2):209-19.

30. Alster, T.S. and J.R. Lupton. Prevention and treatment of side effects and complications of cutaneous laser resurfacing. Plast Reconstr Surg 2002; 109(1):308-18.

31. Thomas WO, I-Iendrix C, Rayburn SI, Luterman A. Laser resurfacing complication. South Med J. 1999 Oct;92(10):999-1001.

32. Ramsdell WM. Three patients with actinic keratoses on atrophic balding scalps who experienced delayed healing after treatment. Dermatol Surg. 20()4 Feb;30(2 Pt 1):237. 
33. Laffitte E, Panizan RG, Saurat JH. Deliyed wound healing on the scalp following trattment of actinic keratoses: Erosive pustular dematosis of the scalp. Dermatol Surg. 2004 Dec;30(12 Pt 2): 1610

34. Mastroianni A, Cota C, Ardigo M, Minutilli E, Berardesca E. Erosive pustular dermatosis of the scalp: a case report and review of the literature. Dermatology. 2005;211(3):273-6

35. Laffitte E, Kaya G, Piguet V, Saurat JH. Erosive pustular dermatosis of the scalp: treatment with topical tacrolimus. Arch Dermatol. 2003 Jun; 139(6):712-4.

36. Rongiotetti F, Delmonte $S$, Rossi ME, Strani CF, Rebora A. Erosive pustular dematosis of the scalp following cryotherapy and topical tretinoin for actinic keratoses. Clin Exp Dermatol. 1999 Nov;24(6):499-500.

37. Trueb RM, Krasovec M. Erosive pustular dermatosis of the scalp following radiation therapy for solar keratoses. Br J Dermatol. 1999 Oct; 141(4):763-5. No abstract available.

38. Quaedvlieg PJ, Creytens D, Pauwels P, Ostertag JU, Niemann FH, Thissen MR, Krekels GA. Immunohistochemical changes of $p .53$ in trated actinic keratosis with Derma $\mathrm{K}$ laser resurfacing. Submitted.

39. Quaedvlieg PJ, Tirsi E, Thissen MR, Krekels K. Actinic keratosis: how to differentiate the good from the bad ones? Submitted.

40. Tannous ZS, Mihm MC, Sober AJ, Duncan LM. Congenital melanocytic nevi: clinical and histopathologic features, risk of melanoma, and clinical management. I Am Acad Dermatol. 2005 Feb;52(2):197-203. Review

41. Lawrence CM. Treatment options for giant congenital naevi. Clin Exp Dermatol. 2000 Jan;25(1):7-11.

42. Rompel R, Möser M, Petres J. Dermabrasion of congenital nevocellular nevi: experience in 215 patients. Dermatology 1997;194:261-7.

43. Berg $P$, Lindelof B. Congenital melanocytic naevi and cutaneous melanoma. Melanom Res 2003; 13(5):441-445.

44. Bittencourt FV, Marghoob AA, Kopf AW, Kocnig KL, Bart RS. Large congenital melanocytic nevi and the risk for development of malignant melanoma and neurocutaneous melanocytosis. Pediatrics 2000; 106(4):736741 .
45. Watt A], Kotsis SV, Chumg KC.. Risk of melanoma arising in large congenital melanecytic nevi: a systematic review. Plast Reconstr Surg $2004 ; 11.3(7): 1968-7.3$.

46. Ka VSK, I)usza SW, Ialpern AC; Marghoob AA. The association between large congental melanocytic naevi and cutaneous melanoma: preliminary findings from an internet based registry of 379 pationts. Mclanoma Res 2005; $15(1): 61-67$.

47. De Raeve L.E, Roseeuw I)I. Curettage of giant congenital melanocytic nevi in neonates: A decade later. Arch Dermatol 2002;138:943-8.

48. De Rateve Lli, Claes A, Ruiter DJ, van Mujen (iN, Rosseuw 1), van Kempen LC. I)istinct phenotypic changes between the superficial and deep component of giant congenital melanocytic naevi: a rationale for curettage. Br J Dermatol. 2006 Mar; $154(3): 485-92$

49. Shipkov CD, Anastassov YK, Yonkov A. The place of laser treatment in the management of congenital melanocytic nevi. Ann Plast Surg. 2006 Feb;56(2):222-4.

50. Boer A, Wolter $M$, Kaufmann R. Pseudomelanoma following laser treatment or laser-treated melanoma? J Dtsch Dematol Ges. 2003 Jan; $1(1): 47-50$.

51. Dummer R, Kempf W, Burg G. Pseudo-melanoma after laser therapy. Dermatology. 1998:197(1):71-3.

52. Woodrow SL, Burrows NP. Malignant melanoma occurring at the periplery of a giant congenital naevus previously treated with laser therapy. Br J Dermatol. 2003 Oct; 149(4):886-8.

53. Horner BM, El-Muttardi NS, Mayou BJ. Treatment of congenital melanocytic nacvi with $\mathrm{CO}_{2}$ laser. Ann Plast Surg. 2005 Sep;55(3):276-80.

54. Wang KK, Kim MJ, Song WK, Cho S. Comparative treatment of giant congenital melanocytic nevi with curetrage or Er;YAG laser ablation alone versus with cultured epithelial autografts. Dermatol Surg. 2005 Dec;31(12): I 660-7.

55. Chong SJ, Jeong E, Park HJ, Lee JY, Cho BK. Treatment of congenital nevomelanocytic nevi with the $\mathrm{CO}_{2}$ and $\mathrm{Q}$-switched alexandrite lasers. Dermatol Surg. 2005 May;31(5):518-21.

56. Dave R, Mahaffey PJ. Combined early treatment of congenital melanocytic nacvus with carbon dioxide and NdYag lasers. Br I Plast Surg. 2004 Dec;57(8):720-4. 
CHAPTER 6

Summary / Samenvatting 


\section{Summary}

Carbon dioxide $\left(\mathrm{CO}_{2}\right)$ and erbium: yttriumaluminium-garnet (Er:YAG) lasers are so called ablative lasers. They are able to perform precise layer by layer ablation of the skin by evaporization. This so called 'laser resurfacing' of the upper layers of the skin is used primarily for cosmetic purposes such as treating the aging skin, rhytides, and acne scars. However this technique is also suitable for treating benign and possible malignant skin disorders. In this thesis, ablative laser resurfacing as treatment modality is evaluated. The aims of this thesis is to define when laser resurfacing might be indicated for premalignant skin diseases, in the context of other available treatments.

In chapter 1 resurfacing with the $\mathrm{CO}_{2}$ laser is first described as an ablative technique for the treatment of skin aging. The procedure, the indications, adverse effects, and complications are mentioned. Second, the evidence found in the literature on $\mathrm{CO}_{2}$ and $\mathrm{Er}: \mathrm{YAG}$ laser resurfacing as treatment modality for rhytides, acne scars, and several skin disorders, is described. In contrast to the many prospective studies on $\mathrm{CO}_{2}$ and Er:YAG lasers that show the effectiveness as resurfacing modality for rhytides and acne scars, for medical benign and premalignant skin diseases the evidence is limited

In chapter 2 first of all a review of the literature on treatment modalities of actinic keratoses ( $\mathrm{AK}$ ) is given. The literature from July 1986 to July 2005 was analysed and divided according to study design, intervention (treatment modality of AK) and the outcome measures; effectiveness, recurrence, and clearance rates, number of patients and lesions, and duration of followup. 1165 Articles were identified. Only 27 studies have investigated treatment options for $A K$ and mentioned effectiveness, clearance and or recurrence rates, number of pationts and/or lesions and duration of $f_{(s)}$ low-up.

Regarding laser resurfacing as treatment for a medical indication like AK, no evidence is available in the above examined literature.

We first studied laser resurfacing as treatment for diffuse widespread actinic keratoses on the face and scalp. Twenty-five patients werc analysed regarding recurrence rates, adverse effects, and improvement. We conclude that Laser resurfacing is an effective treatment modality for diffuse widespread actinic keratoses which long-term recurrence frec intervals.

Secondly, in this thesis, we describe the fist prospective randomized study on laser ablation for AK. We prospectively investigated the effect of Er:YAG laser resurfacing as treatment modality for widespread $A K$, in comparison with the standard treatment with topical 5-fluorouracil (5-FU). Fifty-five patients with multiple $A K$ on the scalp and or the face were included and prospective analyzed clinically and histopatologically. The results show that laser resurfacing is more effective than the standard therapy with $5 \mathrm{FU}$, however, more side effects occurred after laser surgery especially erythema and hypopigmentation. This study provides evidence that $\mathrm{Er}: \mathrm{YAG}$ laser resurfacing is an effective treatment modality for widespread $\mathrm{AK}$.

In chapter 3 laser resurfacing as treatment modality in another premalignant skin disorder is evaluated: (giant) congenital melanocytic nevi (CMN). Various therapeutic approaches such as surgical excision, dermabrasion, curettage, cryosurgery, chemical peeling, and $\mathrm{CO}_{2}$-laser resurfacing, have been used in the past in treating (giant) CMN, the outcome results vary widely.

For the first time in literature, we describe Er:YAG laser resurfacing as new and safe treatment option for GCMN in a 
neonate. We show that Er:YAG laser resurfacing is an excellent method of removing the superficial pigmented part of the GCMN.

Furthermore we prospectively investigated the clinical and histopathological results after treatment of medium, large, or giant CMN with Er:YAG laser resurfacing in the first weeks of life in 10 children. Er:YAG laser ablation is well tolerated by all children and immediate results are good. The epidermis and heavily pigmented naevus cells were absent in biopsies taken directly after laser treatment. Postoperative biopsies during follow up showed absence of heavily pigmented cells in the upper part of the dermis. Serial biopsies could not support the theory of migration of naevus cells. Er:YAG laser resurfacing is an excellent refined method of ablating CMN with minimal risk of scarring and complications.

In chapter 4 complications that can occur after laser resurfacing are described. We present a case of cutaneous neuro- fibromatosis that developed hypertroplic scars postoperative.

Furthermore we report three cases of diffuse widespread actinic keratoses on the atrophic bald scalp in which threc different treatment modalities were used to treat entire surface areas: medium-depth chemical peel, cryopecl, and ablative laser resurfacing. Despite of the different treatmentmethods used, all three patients had a severe delayed wound healing as complication.

In chapter 5 the results of the investigations presented in the previous chapters are discussed and recommendations are given.

$\mathrm{CO}_{2}$ and Er:YAG lasers, have been proved to be an effective and refined method of resurfacing the skin. However besides to achieve cosmetic rejuvenation this technique is suitable for treatment of skin disorders, especially those diseases that require field therapy like widespread $\mathrm{AK}$ and large or giant CMN. 


\section{Samenvatting}

$\mathrm{CO}_{2}$ en Er:YAG lasers zijn verdampende lasers die het mogelijk maken zeer nauwkeurig laag voor laag de huid te abladeren door middel van vaporizatic.

Deze zogenaamde "laser resurfacing" van de bovenste lagen van de huid, wordt met name gebruikt voor cosmetische doeleinden zoals de behandeling van huidverouderingsverschijnselen, onder andere rimpels, en de behandeling van acne littekens.

Echter, deze techniek is tevens geschikt voor de behandeling van benigne en potenticel maligne huidaandoeningen. In dit proefschrift wordt ablatieve laser resurfacing als behandeltechnick geëvalueerd. De doelstelling van dit proefschrift is de plaatsbepaling van laser resurfacing in de behandeling van premaligne huidaandoeningen, in de context van andere mogelijke therapieën.

In boofdstuk 1 wordt allereerst ablatic van de huid door middel van $\mathrm{CO}_{2}$ laser resurfacing beschreven als behandelingstechniek voor huidveroudering. De behandelingsprocedure, de indicatiestelling, de bijwerkingen en complicaties worden vermeld. Vervolgens wordt de bewijskracht, oftewel de evidence, die is gevonden in de literatuur met betrekking tot laser resurfacing bij de behandeling van rimpels, acne littekens en andere huidaandoeningen beschreven.

Er bestaan vele prospecticve studies die de effectiviteit van $\mathrm{CO}_{2}$ en Er:YAG laser resurfacing aantonen voor de behandeling van rimpels en acne littekens. Voor de behandeling van medisch benigne en premaligne huidafwijkingen met ablatieve lasers is de cvidence echter zeer bepcrkt.

In hoofdstuk 2 wordt cen systematisch overzicht van de literatuur gegeven betreffende de behandelingsmogelijkheden voor actinische keratosen (AK). De literatuur van juli 1986 tot juli 2005 werd geanalyseerd en onderverdeeld op basis van studieopzet, interventie en eindpunten; effectiviteit, recidief, complete remissie, het aantal lacsies, het aantal patienten en de follow-up. Iir werden 1165 artikelen gevonden. Slechts 27 studies onderzochten de therapięn voor AK en vermeldeten de bovengenoemde cindpunten. In de gevonden literatuur werd geen evidence aangetroffen voor laser resurfacing als behandeling voor ecn medische indicatic, zoals AK.

Vervolgens bestudecrden wij ten cerste laser resurfacing als behandeling voor diffuse AK in het gelaat en op de schedel. Recidief cijfers, bijwerkingen en verbeteringen van aktinische schade werden geanalyseerd voor 25 patiënten. Wij concludeerden dat laser resurfacing een effecticve behandelmethode is voor diffuse $A K$ met lange recidiefvrije intervallen.

Vervolgens wordt in dit proefschrift de cerste prospectief gerandomisecrde studie naar laser resurfacing als behandeling voor AK beschreven. Wij onderzochten prospectief het effect van Er:YAG laser resurfacing en vergeleken dit met de standaardtherapie, lokale 5-fluorouracil crème (5-FU). 55 Patiënten met multipele AK op de schedel en/ of in het gelaat werden geincludeerd. Zowel klinische als histopathologische analyse vond plaats. Uit de resultaten blijkt dat laser resurfacing effecticver is dan de standaardtherapie 5-FU. Er ontstaan echter wel mecr bijwerkingen na laser behandeling, vooral crytheem en hypopigmentatic. Onze studie lat zien dat Er:YAG laser resurfacing effectief is als behandeling van diffuse AK.

In hoofdstuk 3 wordt laser resurfacing geëvalueerd als behandeling voor een andere pre-maligne huidaandocning; (giant) congenitale melanocytaire nacvi (CMN), oftewel (reuze) aangeboren moedervlek.

In het verleden zijn verscheidene therapicën toegepast ter behandeling van CMN; chirurgische excisie, dermabrasic, curettage, 
cryochirurgie, chemische peeling en $\mathrm{CO}_{2}-$ laser resurfacing. De resultaten hicrvan zijn zeer wisselend.

Wij beschrijven als cersten in de literatuur Er:YAG laser resurfacing als ecn nieuwe en veilige behandelmethode voor giant CMN bij een neonaat. Wij tonen aan dat het een uitstekende methode is om het oppervlakkige gepigmenteerde deel van de giant CMN te verwijderen.

Tevens onderzochten wij prospectief de klinische en histopathologische resultaten van medium, large en giant CMN na de behandeling met Er:YAG laser. De laserbehandeling vond plaats bij 10 kinderen, in de eerste levensweken. De Er:YAG laser ablatie werd door alle kinderen goed verdragen en de directe resultaten waren goed. De epidermis en sterk gepigmenteerde nacvuscellen waren afwezig in de huidbiopsicn die direct na de laserbehandeling werden afgenomen. Postoperatieve huidbiopsien tijdens followup toonden afwezigheid van sterk gepigmenteerde cellen in het bovenste deel van de dermis. Seriele huidbiopsien konden de theorie over de migratie van de naevuscellen niet ondersteunen.

Concluderend is Er:YAG laser resurfacing een excellente methode om CMN te abladeren met een minimaal risico op littekens en complicaties.
In boofdsmk 4 worden de complicatics beschreven dic kunnen optreden na laser resurfacing. Wij presenteren een patient net cutane neurofibromatose dic postoperatief hypertrofische littekens ontwikkelde. Daarnaast rapporteren wij 3 patiënten met diffuse actinische keratosen op de atrofische kale schedel, bij wic dric verschillende behandelingen werden toegepast. De methoden waarmee het hele schedeloppervlak werd behandeld betroffen ecn medium dicpe chemische peeling, een cryopecling, en een ablatieve laser resurfacing. Ondanks het feit dat verschillende behandelmethoden zijn gebruikt, trad bij alle patiënten een sterk vertraagde wondgenezing op.

In boofdstuk 5 worden de resultaten van de beschreven onderzoeken gepresenteerd en bediscussicerd, tevens worden aanbevelingen gegeven.

$\mathrm{CO}_{2}$ en Er:YAG laserbehandelingen zijn bewezen effectieve methoden om een resurfacing van de huid te bewerkstelligen. Naast het doel een cosmetische verjonging van de huid te verkrijgen, is deze techniek ook zeer geschikt om benigne of premaligne huidafwijkingen te behandelen. Dit geldt met name als deze aandocningen een groot gebied beslaan, zoals het geval is bij diffuse aktinische keratosen en grote of reuze congenitale melanocytaire naevi. 


\section{Dankwoord}

Het schrijven van een dankwoord heeft meestal beperkingen. Ik kan niet alle mensen noemen die mij direct of indirect hebben bijgestaan tijdens de totstandkoming van mijn proefschrift. Ook diegenen die niet vermeld worden toch heel crg bedankt. Het is lastig om in cen paar zinnen de complete dankbaarheid te uiten, ik ga een poging doen.

Gertruud, los van alle inspiratie en wetenschappelijke spirit, heeft het zakclijke instinct destijds de grondslag gelegd voor dit boekje. Daarnaast hebben jouw "drive" en de continu positieve motivatie er mede voor gezorgd dat ik het proefschrift uiteindelijk heb afgemaakt. Op het gebied van research waren jouw praktische en heldere adviezen onontbeerlijk. Onze telkens afwisselende zwangerschappen, hebben onze beide energiecurven niet doen dalen, ook niet in de startfase van onze gezamenlijke maatschap in Eindhoven. Typerend zijn de laptop in de keuken en in het kraambed. Vergaderingen en telefoongesprekken verstoord door kindergekrijs konden jou niet afleiden. Jij bleef ongestoord een collegiale, professionele en fantastische ondersteuning bieden. Heel veel oprechte dank!

Professor Neumann: "simply the best". Ik prijs me gelukkig door jou te zijn opgeleid, dat heeft mede mijn succes, in de vorm van onder andere dit proefschrift, bepaald. De veelgestelde vragen van jou tijdens mijn opleidingstijd waren: "wat gaan we doen en waarop gaan we promoveren?" Met name in de periode waarin ik staflid werd en de keren dat we gezamenlijk fameuze horecagelegenheden bezochten, werd de stimulans alsmaar groter en wist ik na het nuttigen van passende druivendrankjes waarover mijn wetenschap dan uiteindelijk zou moeten gaan. Eindelijk durf ik jou dan ook Martino te noemen. De momenten dat ik samen met Paul en later ook met de kinderen bij jou en Julia hartelijk werd ontvangen, met voor ons exquise gerechten en dito flaconnetjes waren bijzonder. Ik hoop dat we nog vaak "te Banholt" mogen zijn!

Anja en Nicole, het feit dat ik destijds jullie paranimf mocht zijn heeft mij enorm gestimuleerd om ook uiteindelijk mijn eigen feestje te kunnen geven. Ik vond het een eer om het destijds te doen en dank jullie voor de collegialiteit, vriendschap en continue aansporing om het boekje af te maken.

Daniëlle, dank dat jij mijn paranimf wil zijn. Ik hoop de uitnodiging voor jouw promotiefeest nog dit jaar te mogen ontvangen.

Patricia, toen jij enkele jaren geleden tijdens het sollicitatiegesprek kenbaar maakte hard te kumnen werken wist ik meteen dat jij de geschikte kandidate was. Jc hebt het ook werkelijk waar gemaakt. Door jouw inzet heb je een substantiele bijdrage geleverd aan de totstandkoming van mijn proefschrift en is zelfs jouw eigen boekje (bijna) klaar. Iedereen weet dat ik zonder jou nooit zover was gekomen. Ook een eer dat jij mijn paranimf wilt zijn. Nu nog bubbels leren drinken! 
Beste Peter. Wij hadden samen een veende start, want jouw komst kwam tegelijkertijd met mijn (gedeeltelijke) vertrek naar Eindhoven. Wij moesten even aan elkaar wennen. Ik ben blij met de bijzonder goede samenwerking die wij op dit moment hebben. 1) view vanuit het Oxford-penthouse heeft mij zelfs cloen twijfelen om toch niet als staflid terug te komen. Jij en ook de overige stafleden: Charles, Jocp, Anja, Monique, Françoise, Jorge, Pamela, Adrienue, Nicole en Michel hebben mij de mogelijkheid geboden om mijn promotie verder af te ronden. Veel dank hiervoor!

Ton Vermeulen, dank voor de uurtjes die wij samen achter de microscoop hebben doorgebracht. Ondanks dat je het druk had makte je tijd voor mij vrij.

Patty Nelemans, dank voor jouw "fantastatistische" ondersteuning. Sorry dat ik stecds dezelfde vragen bleef stellen. Voor mij blijft epidemiologie een bijzonder vak.

Frederique en Miranda, jullie keuzestage is geëindigd in twee fraaic publicatics. Dank voor jullie grote inzet en betrokkenheid.

Beste Petra, Annelies, Ingrid, Nicole, Kim en Els. Julli ondersteuning van de laatste jaren was voor mij onontbeerlijk. Fijn dat ik met mijn tienduizenden vraagjes altijd bij jullie terechtkon. De lekkernijen tussendoor gaven altijd weer nicuwe energie.

Wil Lokkerbol, jouw altijd even goede humeur en jouw praktische kijk op dingen hebhen mij altijd vertrouwen gegeven in een goede afloop van zaken.

Lieve medewerkers polikliniek $A Z M$. Ik noem jullic niet allemaal bij naam, behalve Irene, het "opperhoofd". "Jullie hebben mij in al die jaren opgevoed van destijds de mecst arrogante assistente naar het "leukste" staflid, toch? Ik spreck nog steeds geen dialect, maar één ding blijft mij bij: "t waor hiel gezellig!" Dank jullie allemaal voor jullie gewcldige samenwerking en betrokkenheid.

Lieve medewerkers polikliniek CZE. Vanaf het moment dat ik in Eindhoven kwam werken waait er een storm over de afdeling, maar toch blijven jullie aardig tegen mij. Ik dank jullic voor de flexibiliteit en medewerking. Ik vrees echter dat de wind niet gaat liggen na mijn promotie, ....... houd moed!

Simone, mijn stut, stem en toeverlaat in de laatste fase van het proefschrift. Je behoort tot de toppers waar het gaat om professionaliteit, collegialiteit, en ijver. Kortom cen glansrijkc carrière ligt in de schoot van jouw toekomst. Het is heel fijn om met je samen te werken, dank voor je geweldige inzet. 
Zo, en nu cerst...........

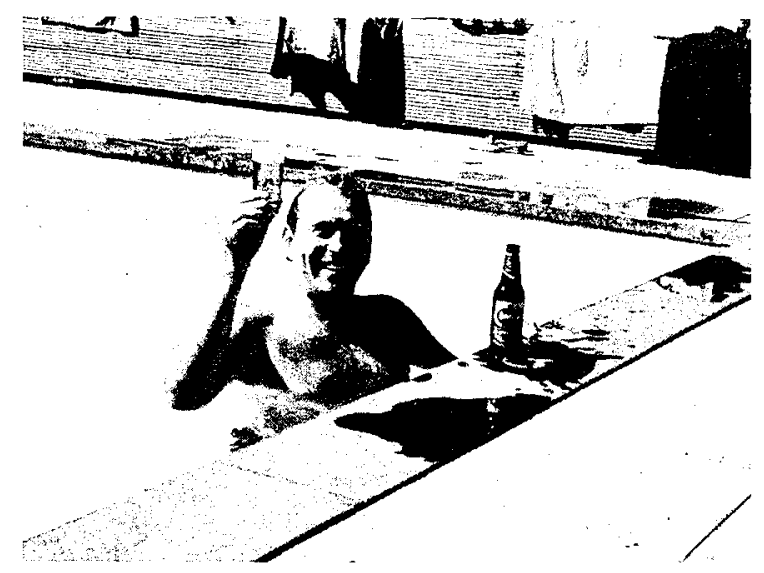

De beste die mijn levenspad gekruist heeft ben jij, lieve Paul.

Zonder jou was er helemaal niets van dit alles terecht gekomen. Jouw onuitputtelijke steun en motivatie zijn onmisbaar geweest en dankzij jou hebben we de drukte van de afgelopen jaren doorstaan.

Welke carric̀revrouw wenst zich niet deze werkelijk bestaande droomman, die naast een goede baan zorgt voor de kinderen, betrokken is in het huishouden, daarnaast nog aantrekkelijk, lief, attent en humoristisch is, sociale talenten heeft en cr alles aan doet om het de vrouw naar haar zin te maken? Dames, afblijven!

Paul, we gaan nu samen genieten! 


\section{Curriculum vitae}

Judith Ulla Ostertag werd geboren op 23 oktober 1966 te Konstanz "am Bodensec". Haar ouders verhuisden naar Limburg toen ze 4 jaar was, aldaar is zij geworteld.

Het VWO diploma behaalde zij in 1985 aan het St. Michiel te Gelecn. Vervolgens studeerde zij geneeskunde aan de Rijksuniversiteit Limburg te Maastricht en behaalde in 1992 haar artsexamen.

Nadat zij 2 jaar gewerkt had als AGNIO Dermatologic aan het Catharina ziekenhuis te Eindhoven en vervolgens 1 jaar chirurgische ervaring had opgedaan als AGNIO in de Heelkunde in het Elkerliek ziekenhuis te Helmond, begon zij in 1995 aan de opleiding tot Dermatoloog in het Academisch Ziekenhuis Maastricht.

Tijdens haar opleiding bij prof.dr. H.A.M. Neumann specialiseerde zij zich naast de algemene Dermatologie en Venereologie tevens in de Mohs Micrographische Chirurgie en Lasertherapie. De registratie als Dermato-Veneroloog volgde in 1999 waarna zij als staflid van de vakgroep Dermatologie in hetzelfde centrum werkzaam bleef. Naast taken als chef de polikliniek, was zij verantwoordelijk voor de Dermato-oncologie, Dermato-chirurgie, en Lasertherapie.

In 2004 zocht zij naast haar academische functie ecn nieuwe uitdaging in de periferie, bij haar vroegere opleiders en huidige maten in het Catharina ziekenhuis te Eindhoven. Samen met collega Krekels werd een Dermato-oncologisch centrum opgericht, waar inmiddels diverse dermato-chirurgische behandelingen, waaronder de Mohs Micrographische Chirugie, worden verricht. Tevens starte de praktijk met de perifcre opleiding tot Dermatologie en Venereologie in clusterverband met het Erasmus MC.

In haat privé-leven heeft ze na diverse omzwervingen in 1999 Paul de Baedts leren kennen. Samen hebben ze sedertdien 3 prachtige zonen (Valentin, Florian en Moritz) gekregen, zijn ze inmiddels ook getrouwd èn hebben ze naast een druk sociaal leven bovendien nog 2 huizen verbouwd. 


\section{List of publications}

Ostertag JU, Quaedvleig PJ, Ncumann IIA, Krekels GA. Recurrence rates and long-term follow-up after laser resurfacing as a treatment for widespread actinic keratoses on the face and scalp.

Dermatol Surg. 2006 Foh;:32(2):267-7.3.

Ostertag JU, Quacdvlieg PJ, Kerckhoffs li:, Vermeulen AH, Bertleff MJ, Venema AW, vd Geer S, Krekels GA. Congenital nevi treated with ErbiumYag laser (Derma-K) resurfacing in neonates; clinical results and review of literature. $\mathrm{Br} /$ Dermatol: 2006:154:889-895.

Smeets NW, Krekels (iA, Ostertag JU, Essers BA, Dirksen CD, Nieman FI, Neumann HA. Surgical excision vs Mohs' micrographic surgery for basal-cell carcinoma of the face: randomised controlled trial. I.ancet. 2004 Nov 13-19;364(9447):1766-72.

Smeets NW, Kuijpers DI, Nelemans P, Ostertag JU, Verhaegh ME, Krekels GA, Neumann HA. Mohs micrographic surgery for treatment of basal cell carcinoma of the face- results of a retrospective study and review of the literature. Br I Dermatol. $2004 J u l: 151(1): 141-7$.

Quaedvlieg P, Ostertag J, Krekels G. Het plaveiselcelcarcinoom: een potentieel levensbedreigende aandoening. Ned Tildsch Dem Venerol $2004: 14: 147-50$.

Venema A.W., Leeman F.W.J., Kardaun S.I I., Bertleff M.J.O.E., Krekels G., Ostertag J. Grote congenitale nacvus nacvocellularis: behandeling met erbium: YAG-laser. Ned Tijdschr Dermatol Venereol 14: 49-51. 2004.

Quaedvlieg PJ, Ostertag /U, Krekels (iA, Neumann HA. Delayed wound healing after three different trearments for widespread actinic keratosis on the atrophic bald scalp. Dematol Surg 200.3 $0 c t ; 29(10): 10.52-6$ lïeld I, Ostertag/, Krekels (i, Smeets N, Neumann H. Submental scar revision via cervicomental liposculpturing and submental sear resection. Dermatol Surg 2003 Jan;29(10): 114-5. 1.8

Quaedvlieg P.J.I., Thissen M.R.T.M., Ostertag J.U., Ideler A.H.L.B., Vermeulen A., Kremer B. Trichilemmaal carcinoon. Ned Tijdschr Dermatol Venereol 2003; 13:28.3-5.

Lapiere K, Ostertag JU, vd Kar T, Krekels CA. A neomate with a giant congenital naevus: new treatment option with the erbium:YAG laser. Br J Plast Surg 2002 Jul; $5.5(5): 440-2$.

Ficld L, Ostertag /, Krekels G, Smects N, Neumann H. Cervicomental "turkey gobbler": a new source for full-thickness grafts. Dermatol Surg 2002 Apr;28 (4):3.5.3-5.

Ostertag JU, Theunissen CC, Neuman HA. Iypertrophic scars after therapy with $\mathrm{CO}_{2}$ laser for treatment of multiple cutaneous neurofibromas. Dermatol surg 2002 Apr:28(4):296-8.

Godschalk RW, Ostertag JU, Zandsteeg AM, van Agen B, Neumann HA, van Straaten I, van Schooten FI. Impact of GSTMI on aromatic-IDNA adducts and p.5.3 accumulation in human skin and lymfocytes. Pharmacogenetics 2001 Aug: 1 16(6):5.37-4.3.

Rojas M, Godschalk R, Alexandrov K, Cascorbi I. Kriek F, Ostertag J, Van Schooten IF, Bartsch H. Myeloperoxidase-463A variant reduces benzo(a)pyrene diol DNA adducts in skin of coal tar treated patients. Carcinogenesis $2001 \mathrm{Jul}$;22(7): 1015-8.

Lapiere K, Krekels (i, Ostertag /. Nacvus naevocellularis congenitalis: behandeling met de Erbium-Yag laser. Ned Tïdsch Dermatol e'enereol 2001:11:297-9. 


\section{LIST OF PUBLICATIONS}

Berretty PJ, Ostertag $J U$, Neumann IIA. A new option for skin rejuvenation: $\mathrm{CO}_{2}$-laser resurfacing Ned Tijdschr Geneeskd. 2000 Fel 19;144(8):36.5-9.

Ostertag $/ U$, Berretty PJ. Fotothermische pecling. Leerboek Cosmetische Dermatochirurgie. Belvedere, Ouerveen $2000,65-75$

Van der Linden SG, Ostertag JU, Neumann HA Actinische keratosen: een overzicht van de therapeutische mogelijkheden. Ned Tijdschr Dematol Venereol 1999;9:289.97.

Godschalk RW, Ostertag $/ U$, Moonen EJ, Neumann HA, Kleinjans JC, van Schooten FJ. Aromatic DNA adducts in human white blood cells and skin after dermal application of coal tar. Cancer Epidemiol Biomarkers Prev 1998 Sep;7(9):767-73.

Ostertag JU. Recurrent postherpetic crythema multiforme presenting as a polymorphous light eruption and 'juvenile spring eruption Ned Tijdschr Dem Venereol 1998;8:164-6. Ned Tiidschr Geneeskd $1998(\mathrm{dec}) ; 142(49): 2711-2$. ()stertas /U. Actinic keratoses: treatment with ()$_{2}$ laser resurtacing. / Ent Acad Dermalel 1998, 1 1:541

Ostertag /U. Periorbitial oedeen of persisterend angio-oedecm. Ned Tijdschr Derm Venoreol $1998: 8: 167-8$.

Ostertag JU. Churg-Strauss-Syndroom. Ned Tijdschr Demi Venereol 1998,8:159-61.

Ostertag $J U$, van Neer IJ. Atypical juvenile pityriasis rubra pilaris. Treatment with acitretine. Posterpublicatie, 267e Wetenschappelijke Vergadering, Nederlandse Vereniging voor Dermatologie en Vencreologie. Ned Tijdschr Geneskd 1995;139(10):542. Br J Dermatol /995:132:302-3.

Ostertag JU, Berretty PJ, Janssen PJ. Contactallergic voor vitamine E bij lokaal gebruik. Een onverwachte reactic op gebruik van "natuurlijke vitaminen". Ned Tijdschr Derm Venereol 1995;5:101-2.

Ostertag JU, Hulsmans RF, Neumann HA. Bilateral linear temporoparietal scleroderma en coup de sabre. Hantarzt 1994 Jum;45(6):398-401. 